\title{
Antimicrobial Resistance
}

\section{and Sensitivity of \\ Phytophthora agathidicida. \\ by}

Kaitlyn Daley

A thesis submitted to the Victoria University of Wellington

in fulfilment of the requirements for the degree of Master of Science.

Victoria University of Wellington 


\section{Abstract}

Members of the oomycete genus Phytophthora are highly infectious plant pathogens. $P$. agathidicida affects the New Zealand native keystone species Agathis australis (kauri) and is the cause of kauri dieback. The complex oomycete lifecycle makes Phytophthora infections hard to manage. The current management of kauri dieback has been limited and antimicrobial resistance is a concern. Phosphite agrichemical preparations are commonly used in the control of Phytophthora diseases, including kauri dieback. However, phosphite is not the only option; the agrichemicals oxathiapiprolin, and the plant-derived natural products polygodial and falcarindiol, have also been shown to have activity against $P$. agathidicida. The overall goal of this thesis was to further explore aspects of sensitivity and resistance of $P$. agathidicida towards these four compounds.

In New Zealand, there are three commercially available phosphite preparations, Agri-Fos 600, Phosgard, and Foschek. All previous studies have used Agri-Fos 600, so the first aim was to determine whether the particular formulation altered antioomycete activity. No significant difference was found between the $50 \%$ inhibitory concentrations ( $\mathrm{EC}_{50}$ values) for the three formulations. Interestingly, however, formulating polygodial and falcarindiol with the surfactants and other non-phosphite ingredients of Foschek led to a significant increase in their inhibitory effects.

The second aim of this thesis was to implement a serial passaging protocol for $P$. agathidicida and attempt to isolate mutants with increased resistance to phosphite, polygodial or falcarindiol. Serial passaging was carried out on amended agar plated with increasing concentrations of each chemical. However, even after 7 passages, over 16-18 weeks of growth, no mutants with increased resistance were isolated. This could be due to the complicated modes of action of the polygodial, falcarindiol and phosphite, which makes it likely that several specific mutations are required to effect resistance. 
Oxathiapiprolin is a highly potent, new anti-oomycete agrichemical. It targets the Phytophthora oxysterol binding protein (OSBP) related protein (ORP1). Mutations in this protein are known to give oxathiapiprolin resistance in other species of Phytophthora; however, the $P$. agathidicida protein (PaORP1) has never been studied. In this work, the gene for PaORP1 was partially sequenced from five $P$. agathidicida isolates. None contained any of the known resistance mutations. A new protocol for expressing PaORP1 in E. coli and purifying it using immobilised metal affinity chromatography was also developed. After optimisation, this protocol yielded up to $30 \mathrm{mg}$ of purified protein per litre of $E$. coli culture and is the first successful example of heterologously expressing and purifying any $P$. agathidicida protein. In future, this will allow the biomolecular interaction between PaORP1 and oxathiapiprolin to be studied in more detail.

Overall, the work presented in this thesis assessed commercial formulations of phosphite, established a directed evolution protocol for studying resistance in $P$. agathidicida, and reported the first in vitro characterisation of a $P$. agathidicida protein. This research suggests that commercial formulation of plant-derived natural products may be a powerful new approach for combatting kauri dieback and, promisingly, also suggests that the risk of developing resistance to these compounds might be low. 


\section{Acknowledgements}

First and foremost, I would like to thank my supervisor, Wayne Patrick, words cannot express my gratitude for all the opportunity, support, guidance and patience you provided throughout this thesis. You always encouraged the best out of me, and for that, I am very grateful.

I would like to extend my appreciation to Monica Gerth. The passion you have expressed for the conservation of kauri has inspired the same passion in me. I am very grateful to be part of such an amazing project and would like to express my gratitude for the opportunity to work as part of the team.

A large thank you to for the MME laboratory group for the wonderful working environment. You have all made my post-graduate adventure memorable. Thank you for the support, the laughs, the parties and the lab adventures.

A special thanks to those on the Phytophthora team. In particular thank you to Mike, Randy and Monica S., for all the great chats, constant support, and laughs throughout this often weird but wonderful research.

To all my family, thank you for the support to get through the most academically challenging period. Thank you for all the never-ending support and constant belief in me. Thank you for all the reassuring phone calls.

Thank you to all my friends, Jaybee, Aimee, Patrika, and Russyl, who have given me unconditional encouragement throughout this period. Your support has always helped in times of stress. Thank you all for your unconditional friendship when I cancelled on our plans many times.

Thank you to all those who have experienced the postgraduate experience with me. Thank you to Jess, Janine and Sharna for all the support during those tough courses of ours Masters. Thank you, Tessa, for sharing the journey from undergraduate to 
postgraduate with me. It has been an adventure in tenacity, determination and personal evolution for all of us.

Lastly, I would like to thank Ben, who gave unconditional love and encouragement throughout this period and support for all the decisions I have made regarding my study. You have endured the lows and celebrated the highs with me, thank you. 


\section{Table Of Contents}

Chapter 1 Introduction ......................................................................................................... 1

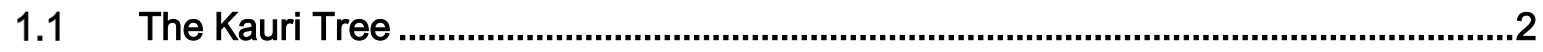

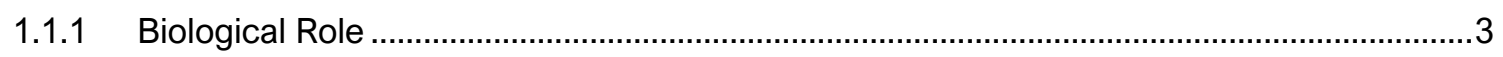

1.1.2 Economic Impact..................................................................................................................

$1.2 \quad$ Phytophthora Species..........................................................................................

1.2.1 Life Cycle of Phytophthora..............................................................................................

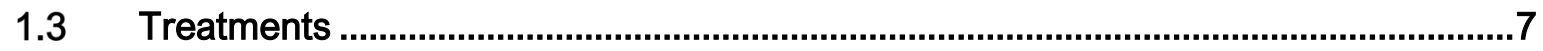

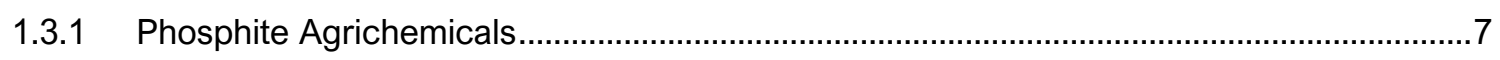

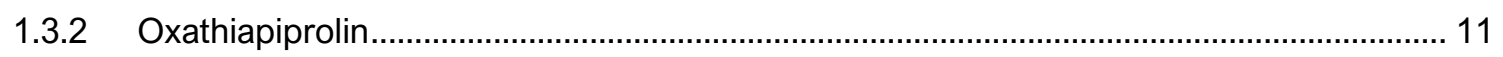

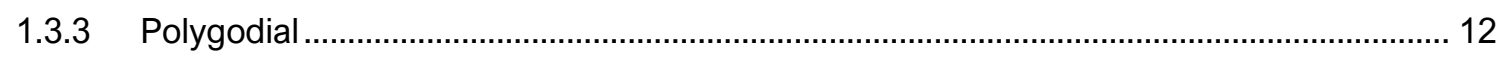

1.3.4 Falcarindiol ........................................................................................................... 14

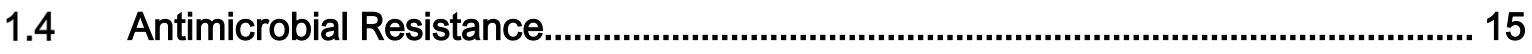

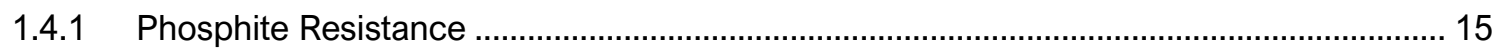

1.4.2 Oxathiapiprolin Resistance …………………………………………………………..... 16

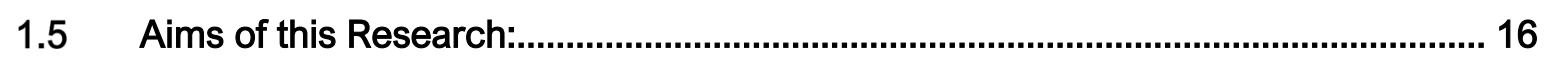

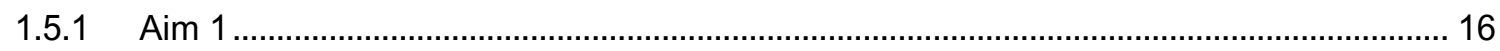

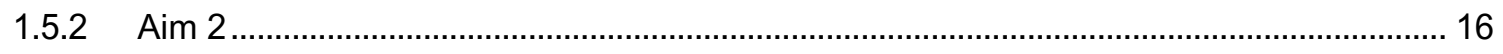

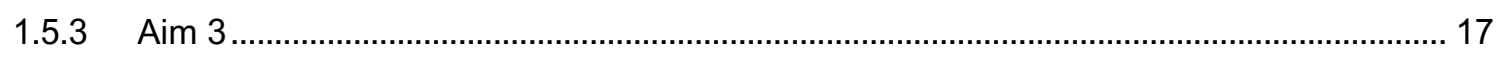

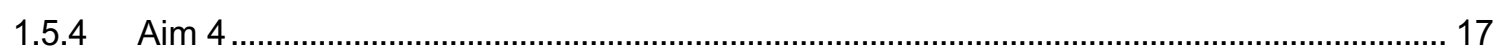

Chapter 2 Materials and Methods......................................................................... 18

$2.1 \quad$ Materials ............................................................................................... 19

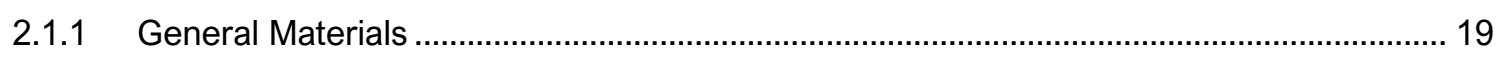

2.1.2 Phytophthora agathidicida Isolates .................................................................................. 19

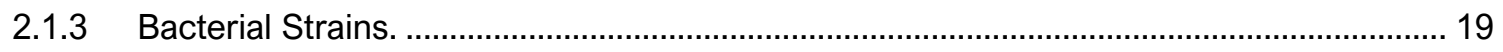

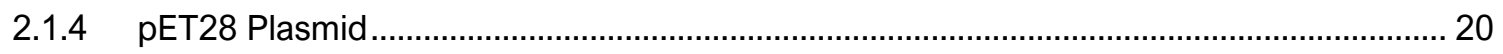

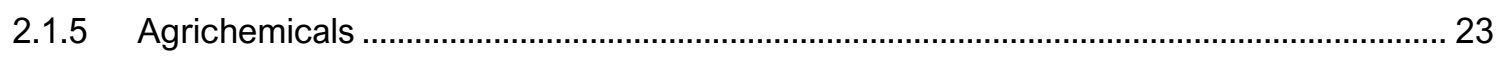

2.1.6 Antibiotics and Natural products.............................................................................. 23

2.1.7 PARP Agar …………………………………………………………………... 23

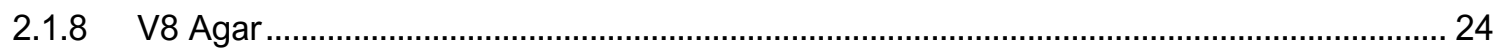

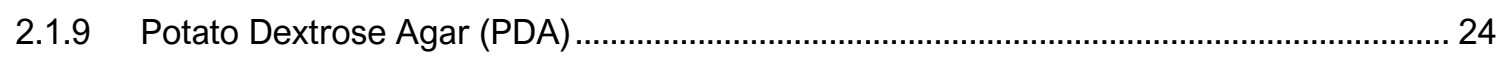

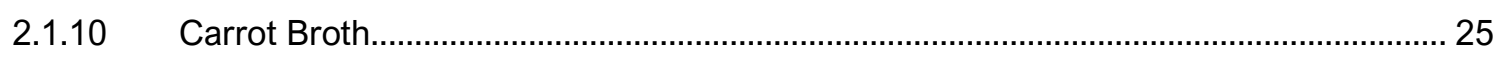

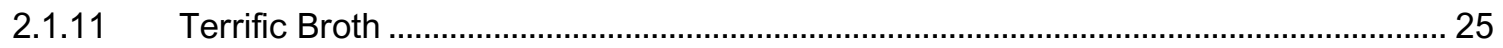

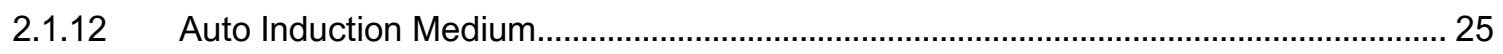

2.1.13 LB Broth ...................................................................................................................... 25 


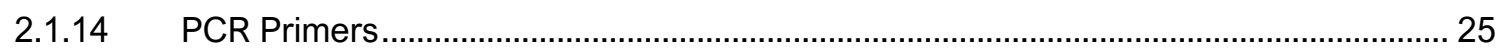

2.1.15 Protein Purification Buffers................................................................................. 26

2.1.16 Sodium Dodecyl Sulfate-Polyacrylamide Gel Electrophoresis (SDS-PAGE) ............... 27

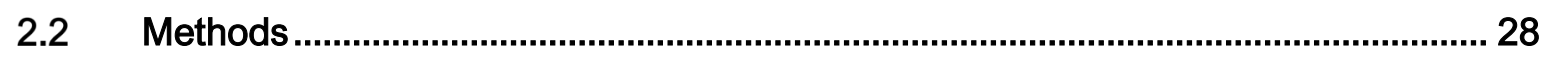

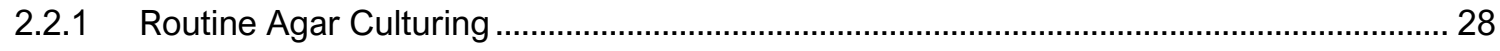

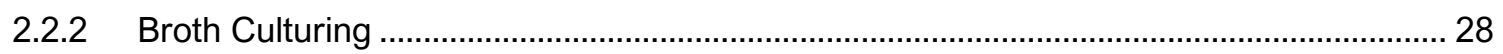

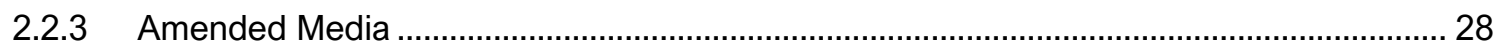

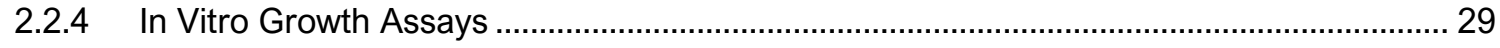

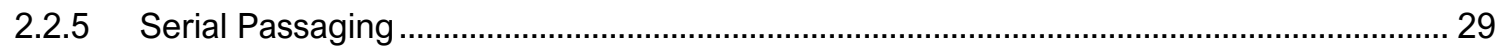

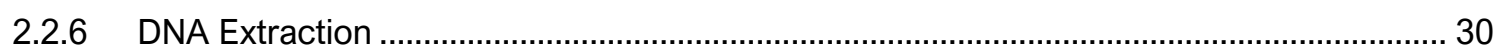

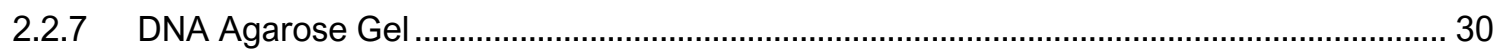

2.2.8 Polymerase Chain Reaction (PCR) ……................................................................ 30

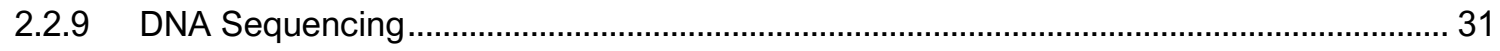

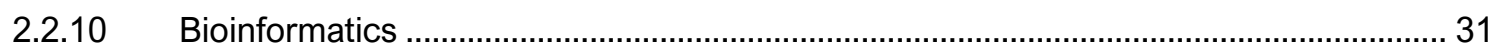

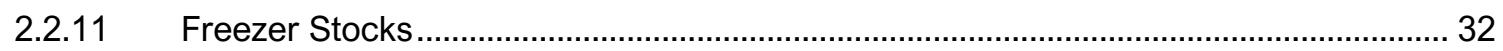

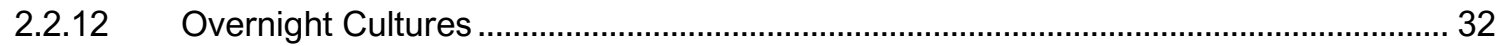

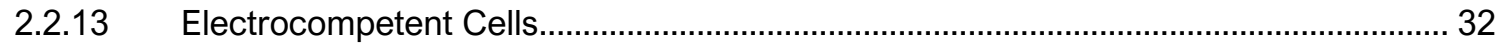

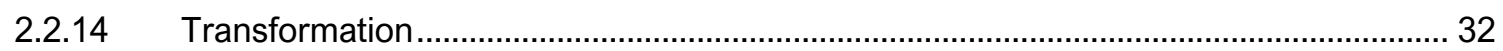

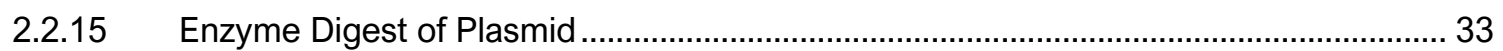

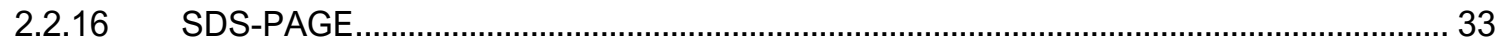

2.2.17 Protein Purification ................................................................................................ 34

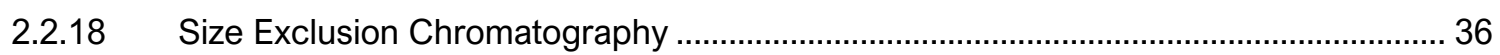

2.2.19 Fluorescence Thermal Shift Assay ............................................................................... 37

Chapter 3 Phosphite Formulations........................................................................... 39

3.1 Assessment of Agrichemical Formulation........................................................... 40

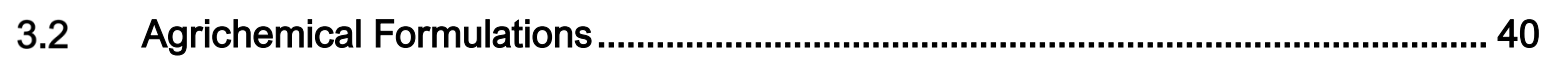

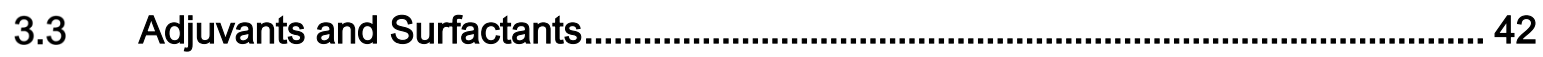

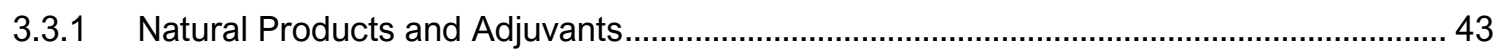

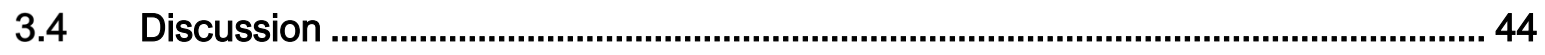

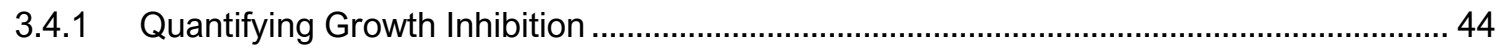

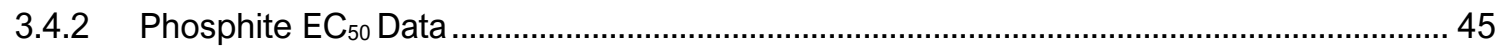

3.4.3 Using Adjuvants to Enhance the Bioactivity of Natural Products ..................................... 46

3.4.4 Treatments for Kauri Dieback ......................................................................................... 46

Chapter $4 \quad$ Investigating the Potential of Antimicrobial Resistance.............................. 47

$4.1 \quad$ Results ................................................................................................................ 48

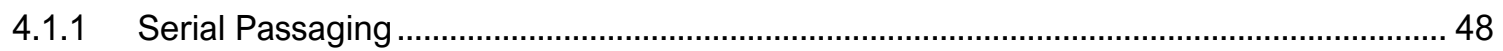


4.1.2 Serial Passaging in the Presence of Polygodial ................................................................ 49

4.1.3 Serial Passaging in the Presence of Falcarindiol ............................................................... 51

4.1.4 Serial Passaging in the Presence of Phosphite........................................................................ 53

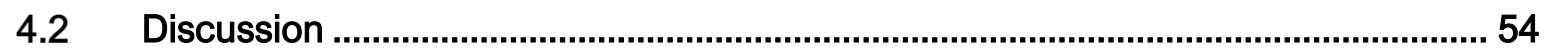

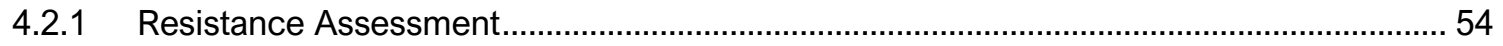

4.2.2 Solvent Used to Dissolve Natural Products ......................................................................... 55

4.2.3 Long Term Implications for Kauri Dieback............................................................................ 56

Chapter 5 Protein Characterisation ............................................................................. 57

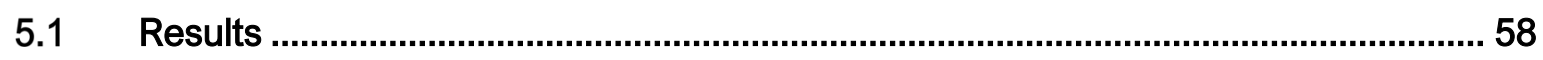

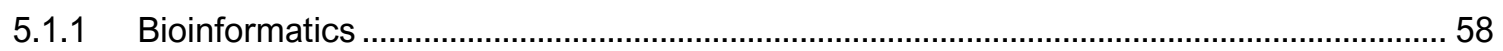

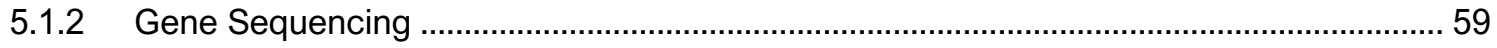

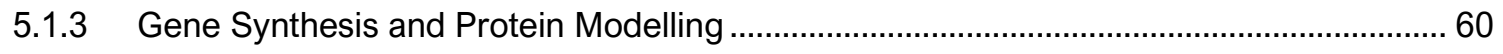

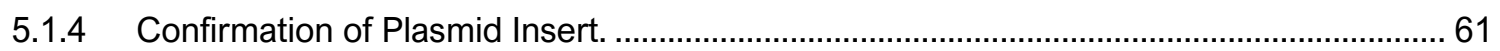

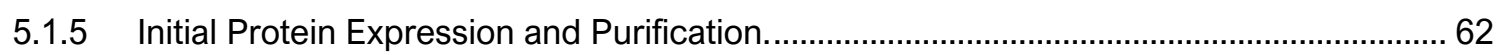

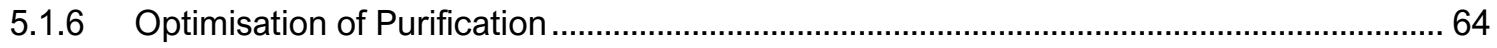

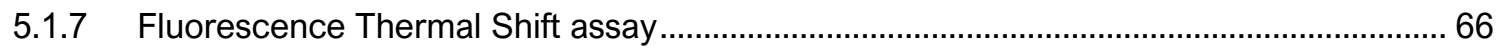

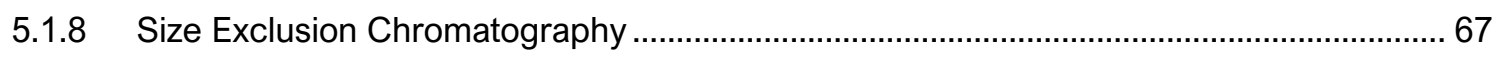

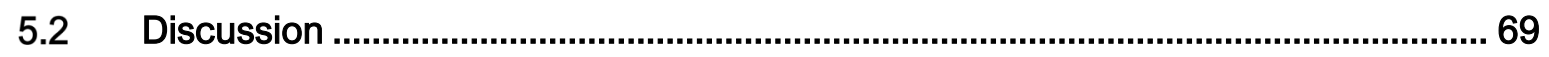

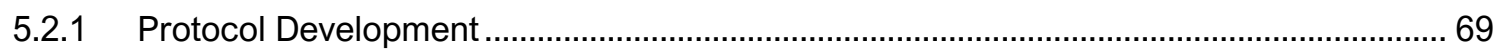

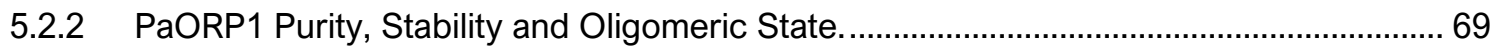

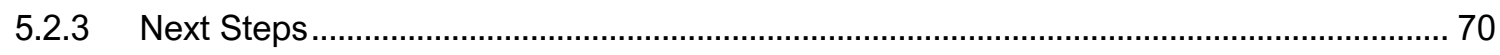

Chapter 6 Discussion ....................................................................................................... 72

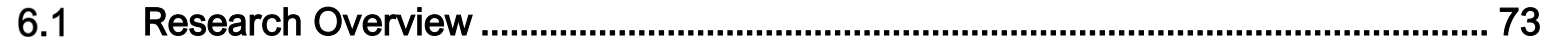

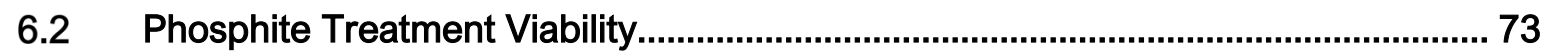

6.3 Natural Products and a Basis for Agrichemical Development.................................. 74

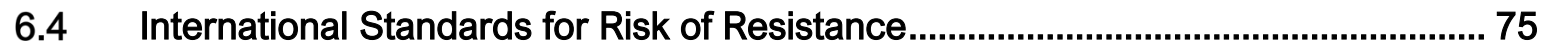

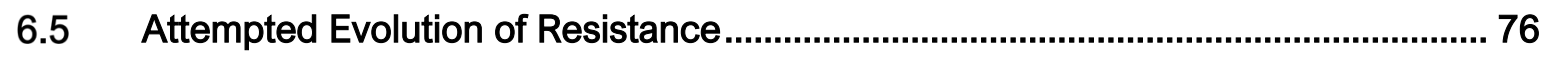

6.6 Expression and Purification of $P$. Agathidicida Proteins......................................... 77

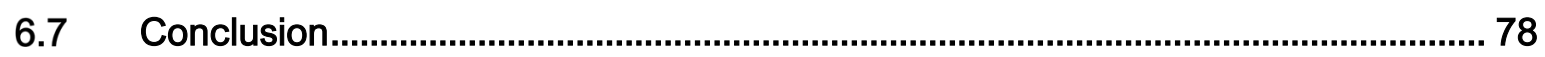

References 


\section{List Of Figures}

FIGURE 1.1 LIFE CYCLE OF PHYTOPHTHORA AGATHIDICIDA.

Figure 1.2 Chemical StRUCtURE OF PHOSPHATE AND PHOSPHITE OXYANION.

FIGURE 1.3 1-(4-\{4-[5-(2,6-DIFLUOROPHENYL)-4,5-DIHYDRO- 3-ISOXAZOLYL]-2-THIAZOLYL\}-1-PIPERIDINYL)-2-[5-METHYL-3-

(TRIFLUOROMETHYL)-1H-PYRAZOL-1-YL]ETHENONE (OXATHIAPIPROLIN), SOLD COMMERCIALLY AS ZORVIC OR SEGOVIS. .....11

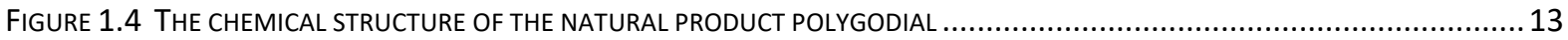

FIGURE 1.5 THE CHEMICAL STRUCTURE OF THE NATURAL PRODUCT FALCARINDIOL.................................................. 14

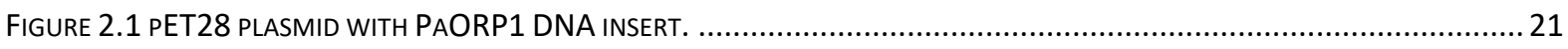

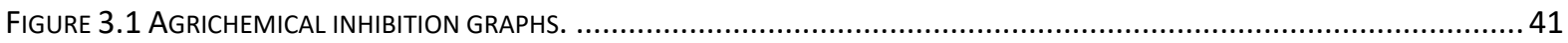

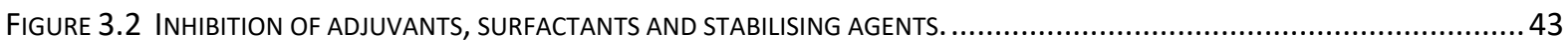

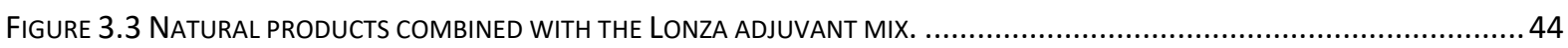

FIGURE 4.1 FLOW DIAGRAM FOR EVOLVING P. AGATHIDICIDA FOR RESISTANCE TOWARDS POLYGODIAL, FALCARINDIOL AND

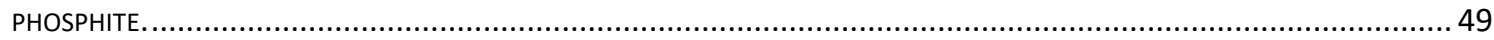

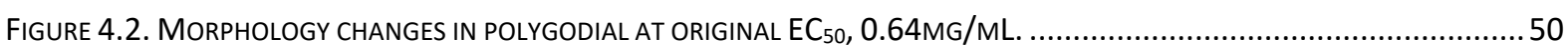

FiguRE 4.3 GROWTH RESPONSE CURVES FOR P. AGATHIDICIDA 3770, THE EVOLVED ISOLATE, AND THE P. AGATHIDICIDA ISOLATE 3813.

FIGURE 4.4. MORPHOLOGY CHANGES SEEN IN FALCARINDIOL.

FIGURE 4.5 EVOLUTION OF FALCARINDIOL, P. AGATHIDICIDA ISOLATES VS AN EVOLVED ISOLATE.

Figure 4.6 EVolution of Phosphite, P. AGATHIDICIDA ISOLATES VS AN EVOLVED ISOLATE. 54

FIGURE 5.1. PAORP1 GENE AND PROTEIN ANNOTATION.

FiguRE 5.2. StRUCTURES OF ORDS FOR PAORP1 AND KES1/OSH4. 61

Figure 5.3. ENZYME DIGEST OF PAORP1 PET28A PLASMID. 62

FIGURE 5.4. INITIAL EXPRESSION AND PURIFICATION TRIALS OF PAORP1 PROTEINS (WILD TYPE AND MUTANT)..... 63

Figure 5.5. ChANGES IN PROTEIN ABUNDANCE ASSOCIATED WITH THE OPTIMISATION OF THE PROTOCOL. 65

Figure 5.6. OPTIMIZED EXPRESSION AND PURIFICATION OF PAORP1 (WILD TYPE AND MUTANT). 66

Figure 5.7. Size Exclusion Chromatography of PAORP1 VARIANTS: WILD TYPe (LEFT) AND G771W MUtANt (RIGHT). .......68 


\section{List Of Abbreviations}

$\begin{array}{ll}\text { DMSO } & \text { Dimethyl Sulfoxide } \\ \text { EC }_{50} & 50 \% \text { Inhibition Of Growth } \\ \text { EDTA } & \text { Ethylenediaminetetraacetic Acid } \\ \text { FTS } & \text { Fluorescence Thermal Shift } \\ \text { IMAC } & \text { Immobilised Metal Affinity Chromatograph } \\ \text { IPTG } & \text { Isopropyl } \beta \text {-D-1-Thiogalactopyranoside } \\ \text { OD600 } & \text { Optical Density Reading At A Wavelength Of 600 Nm } \\ \text { ORD } & \text { Oxysterol-Binding Domain } \\ \text { ORPs } & \text { Oxysterol Binding Protein-Related Proteins } \\ \text { OSBP } & \text { Oxysterol Binding Proteins } \\ \text { Osh } & \text { Oxysterol Binding Proteins Homologue } \\ \text { SDS-PAGE } & \text { Sodium Dodecyl Sulfate-Polyacrylamide Gel Electrophoresis } \\ \text { SEC } & \text { Size Exclusion Chromatography } \\ \text { TB } & \text { Terrific Broth }\end{array}$




\section{Chapter 1 \\ Introduction}


Once, long ago, the sky father and earth mother had a love so strong, their embrace encased the world in darkness. Within their embrace, they had trapped their six children in the darkness and away from the light. Until one day, the sky father stirred and let a single beam of light in onto their children. The children yearned to free themselves and enter the world of light. Together they discussed separating the sky father and the earth mother.

All but one son agreed, and the other sons began to work on breaking the embrace of the earth mother and sky father. Their parents' love was too strong, and none succeeded, until Tāne Mahuta (god of the forest) lay on his back and with his legs Tāne pushed against his father.

Tāne pushed harder and harder until the bond between his parents began to tear. The light shone into the world. When Tāne fully extended his powerful legs, He forced the sky father into the heavens and flooded the world with light. The son who did not agree, Tawhiri-matea, was angered by the separation of his parents and went to the heavens with his father. Along with his children: Wind, Rain and Storms. From time to time they hurl themselves down in anger at the world ${ }^{1}$.

\subsection{The Kauri Tree}

The legendary kauri tree, Tāne Mahuta, still separates the earth mother and sky father today. He stands in Waipoua forest, with his shoulders pushed hard against his 'earth mother', and his feet stretched high towards the heavens. Tāne Mahuta is one of the oldest and largest trees in the world at $51 \mathrm{~m}$ high and with a girth of $13.8 \mathrm{~m}$. Alongside Tāne Mahuta, Te Matua Ngahere (the father of the forest) is the secondlargest kauri tree. He has considerably more girth than Tāne Mahuta, at $16.5 \mathrm{~m}$, but is shorter in height $(29.9 \mathrm{~m})$.

These two trees hold significant cultural importance for Māori, and indeed for all New Zealanders. Māori consider kauri to be taonga (a treasure) and a sign of general wellbeing of the ngahere (forest) and the people. Kauri are widespread in the native forests of northern New Zealand. 


\subsubsection{Biological Role}

Kauri are subtropical conifers ${ }^{2}$. The biomass produced by kauri change the forest environment and provide an enriched environment for an extensive range of other native flora that thrive under their canopy. Kauri trees provide nitrogen-rich soil from their leaf litter decomposition for the developing forest ${ }^{3}$ and a distinctive vegetation that surrounds them ${ }^{4}$. The forest contains different species of Podocarpus (native hardwoods), Cyperaceae (Grasses and Sedges), Alseuosmiaceae (urn-shaped or funnel-shaped flowering plants), and various myrtle species. These species associate with kauri, where they are usually found under the canopy and within the dripline.

Now, the giant kauri are under threat from an oomycete named Phytophthora agathidicida. P. agathidicida is a newly described, highly pathogenic microorganism ${ }^{5}$, ${ }^{6}$ that is beginning to have a profound impact on the New Zealand native Kauri forests. For example, the proportion of kauri trees showing signs of infection in the Waitākare Ranges area rose from 8\% (2008) to 18.95\% in 2011 and further to $22.65 \%$ by $2016^{7}$.

\subsubsection{Economic Impact}

Kauri forests are essential for tourism in Northland. It has been estimated that the spread of kauri dieback disease in Northland could reduce the tourism industry by $\$ 50$ million per annum as of $2017^{8}$.

\subsection{Phytophthora Species}

There are more than 500 known species of oomycetes, commonly known as water moulds, white rusts, or downy mildew ${ }^{9}$. The Phytophthora genus are notorious plant pathogens and make up six of the top ten plant pathogens as voted by plant pathologists ${ }^{10}$.

Phytophthora species have a complex lifecycle that superficially resembles that of fungi. However, modern molecular genetics suggest that the oomycetes are related 
to brown algae and diatoms ${ }^{11,12}$ with Phytophthora species lacking the chitin-based cell wall ${ }^{13-15}$ and ergosterol biosynthesis pathways ${ }^{16}$ of true fungi. Instead, Phytophthora cell walls are made up of cellulose, glycoproteins and other polysaccharides ${ }^{17}$.

\subsubsection{Life Cycle of Phytophthora}

Phytophthora species have an elaborate life cycle (Figure 1.1). They can spread through asexual production of motile zoospores, and produce two different types of survival spores; asexually produce chlamydospores and sexually produced oospores. Each stage of the life cycle is a potential target for anti-Phytophthora compounds. Unfortunately, while a compound may be effective against one life cycle stage, it may be ineffective against another aspect of the life cycle.

The motile zoospores are produced from the terminal hyphae extensions forming specialised branches called sporangia. Usually, six or more zoospores are held within the sporangia. When the apical point of the sporangia opens, the zoospores are released by turgor pressure into the environment ${ }^{12}$. The release of zoospores usually occurs under cool, humid conditions ${ }^{9}$. 


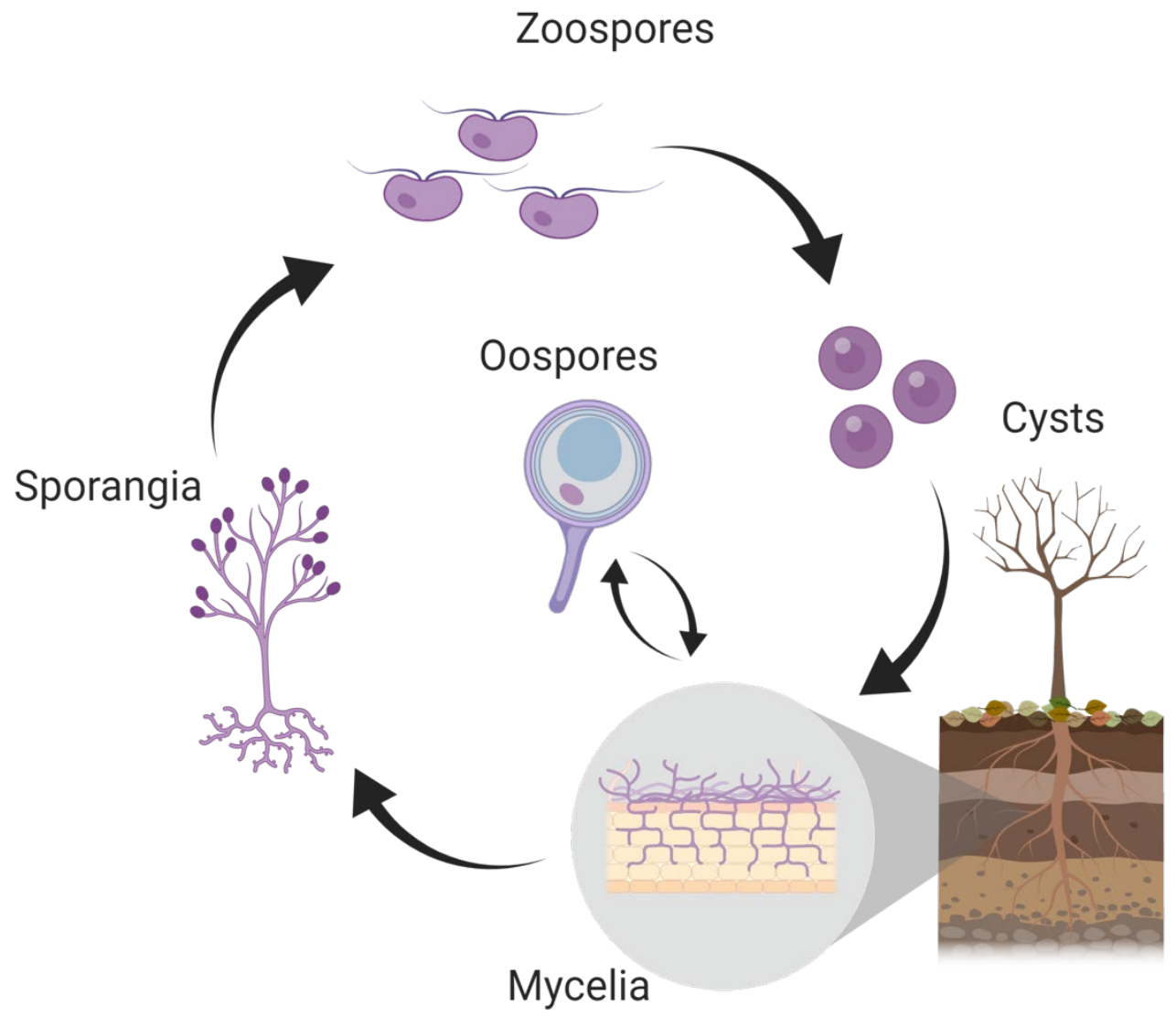

Figure 1.1 Life cycle of Phytophthora agathidicida.

The life cycle of Phytophthora begins and ends in the mycelium infection within a tree. When nutrients are low, the mycelium produce a specialised hyphae-call the sporangia. The sporangia contain motile zoospores. These motile spores swim through water logged soil towards a new host and encyst to start a new infection. The established infection forms a network of mycelium throughout the root system of the host.

Zoospores are well characterised. They are mono-nucleated ${ }^{12}$ and lack a cell wall. The outer surface is a phospholipid membrane ${ }^{18}$ with two flagella, posterior and anterior ${ }^{18}$. The posterior flagellum acts to turn the zoospore, and direct is as it swims. The anterior flagellum propels the zoospore backwards ${ }^{18}$. The zoospores are attracted to the roots of the host plants through a process called chemotaxis ${ }^{12}$. The chemo-attractive agents are different for each host species. They include sugars, amino acids, alcohols and vital metabolites produced by the host plant ${ }^{9,12,18}$. $P$. agathidicida is highly attracted to exudates of kauri root ${ }^{19}$ and currently only known to infect Kauri trees. 
Infection occurs once the zoospore reaches the root surface ${ }^{9,12,18}$. The process of spore adhesion and encystment is different from true fungi; no extra stimuli are required other than the root surface ${ }^{12}$. Encystment occurs rapidly as the zoospores align themselves along the ventral surface of the root, and the flagella extend towards the root ${ }^{20}$. Several vacuoles are expelled rapidly from the zoospore within 2 minutes of alignment, including an adhesive 'glue' while a germ tube is formed ${ }^{12,18}$. Along with the adhesive glue, degrading enzymes are released from the zoospore to aid in the mechanical penetration of the outer root surface by the germ tube ${ }^{12}$.

While zoospore encystment takes a short time ( $<10$ minutes), full germination takes up to half an hour. The alignment of the zoospore allows for the germ tube to penetrate between the epidermal cells below the spore ${ }^{18}$. Once the infection has been initiated, hyphae from the encysted spore are able to divaricate throughout the root tissue ${ }^{12}$, and form a variety of terminal hyphae that allow for nutrient uptake. These include intercellular and trans- or intracellular haustoria-like hyphae ${ }^{18}$. An established mycelial infection is the primary cause of plant death. Most Phytophthora infect at the roots. An established infections causes symptoms like root rot and/or collar rot. These symptom are caused by a lack of nutrients and water being transported throughout the plant. Eventually the infected plants withers and dies ${ }^{21}$. P. agathidicida is an aggressive pathogen, capable of infecting all kauri of all ages, including seedlings, rickers, and the larger mature trees.

Lastly, oospores are the thick-walled, durable, dormant, sexual survival spore of many Phytophthora 12, 13, 15, 17. Phytophthora species can form these sexual structures of two classes, either by self-fertilisation if they are homothallic, or by the interaction of opposite mating types, as in heterothallic species ${ }^{9,12,18,20}$. P. agathidicida falls into the homothallic category. This is unlike Phytophthora infestans - the causal agent of potato blight - which is heterothallic, and requires both $A 1$ and $A 2$ types to reproduce sexually.

Historically, the mating type $\mathrm{A} 1$ spores were geographically separated (Finland/Norway) by the Atlantic ocean from the A2 mating type (Mexico) ${ }^{22}$. Now, populations of $A 1$ and $A 2 P$. infestans are being reported in the same geographical 
space, allowing the production of the hardy survival oospores making control of potato late blight even more difficult. These two mating types have spread due to human influence and migration ${ }^{22}$. Oospores can persist in the environment for long periods until conditions are favourable for germination, leading to new mycelial growth, the development of sporangia and the eventual release of zoospores ${ }^{9}$. This allows Phytophthora species to infect crops in successive seasons or colonise replanted trees years later.

\subsection{Treatments}

The international standard for treatment is a phosphite based agrichemical, or a traditional fungicide. Recently there has been a scientific push to generate new treatment options. DuPont developed a compound called oxathiapiprolin, that specifically targets oomycete oxysterol binding proteins ${ }^{23}$.

Mātauranga Māori is the idea to take the knowledge, education, perspective, and creativity of the Māori culture and incorporate this idea into an area of research ${ }^{24}$. Our kaupapa (action plan) uses mātauranga Māori herbal medicine and customs to find natural product and plant-based metabolites from sources in the local forest environment ${ }^{24,25}$.

Our Māori collaborators shared a variety of plants that are used in traditional medicine.

Using these plants, previous members of our laboratory made root and leaf extracts and tested these complex mixtures against all the life cycle stages of $P$. agathidicida. Two of the most promising compounds for mycelium inhibition were isolated from extracts of tawhero and patē.

\subsubsection{Phosphite Agrichemicals}

Phosphite is a well-known agrichemical, that first arrived on the market in the late 1970 s and has been used widely ever since ${ }^{26}$. It is a dual-action agrichemical; 
playing a role in the upregulation of plant defence systems and directly inhibiting Phytophthora ${ }^{27-33}$. Recent reports suggest Phytophthora species, P. cinnamomi, $P$. citrophthora, $P$. syringae, and $P$. parasiticia, are developing tolerance to phosphite treatments and phosphite agrichemicals ${ }^{28,34}$.

\subsubsection{Plant Defence Systems}

Unlike the mammalian immune system, plants do not have mobile immune cells. Instead, they rely on localised response and cell to cell communication at the site of infection. However, like the mammalian immune system, plant cells do recognise pathogen-associated molecular patterns (PAMPS).

PAMPS are recognised by the Pattern Recognition Receptor proteins (PRR) in the intracellular space ${ }^{35}$. Once the pathogen is recognised, internal cellular ' $R$ ' genes are activated by Nucleotide Binding Site - Leucine-rich repeat proteins (NBS-LRR) ${ }^{36}$. Rgenes are disease resistance genes ${ }^{35}, 36$. The NBS-LRR proteins are considered to be the adaptive plant response to pathogen attack and interact with R-genes for regulation ${ }^{35}$.

The immune system acts in four phases ${ }^{36}$. The first of these is PAMP-triggered immunity. After a PAMP is recognised and the PRR is activated, a signalling cascade causing the second messenger molecules and NBS-LRR to begin to regulate the plant response to the immune system ${ }^{29,35,36}$. As the infection progresses, there is a plant versus pathogen struggle. Phytophthora species and other plant pathogens (Bulmeria grammis, Puccinia triticina, and Fusarium oxysrporum ${ }^{37}$ ) have developed ways to suppress the plants' immune system ${ }^{36-38}$. For example, Phytophthora can silence genes of Arabidopsis through the use of small interfering RNA. At the same time, Arabidopsis is also able to affect Phytophthora transcription using the same mechanism ${ }^{38}$.

Phosphite affects the plant immune system by priming it for the host-pathogen interaction. Phosphite-based agrichemicals are sprayed onto the leaf surface or injected directly into the trunk. Phosphite is transported through the phloem to the roots, which are the site of action. Phosphite primes the immune system by 
upregulating second messengers and reactive oxygen species. Upregulated pathways include jasmonic acid, salicylic acid, and abscisic acid production ${ }^{29}$.

An invading Phytophthora infection causes plant cytoskeleton and cell wall changes. These cytoskeletal changes enable cells to release a more substantial amount of reactive oxygen species and second messengers. The changes also allow for the production of pathogen-related (PR) proteins ${ }^{29}$ and anti-pathogen microRNA ${ }^{38}$.

\subsubsection{Phytophthora Inhibition by Phosphite}

The mode of action for phosphite inhibition in Phytophthora species is complex and several studies have explored this ${ }^{30,39-45}$. Phosphite and phosphate have a similar chemical structure (Figure 1.2). Phosphite is a competitive inhibitor for phosphate transport systems and hijacks these systems to get into cells ${ }^{40}$. The inhibitory effect is even more pronounced when Phytophthora is in a phosphate starved environment ${ }^{30,41}$. Transport across the membrane is $\mathrm{pH}$-dependent ${ }^{40}$. There are two phosphate transporters in Phytophthora; a constitutive active low-affinity transporter and a highaffinity transporter that is induced only when phosphate is limited. Phosphite is believed to be a competitive antagonist for the phosphate transport itself ${ }^{42}$.
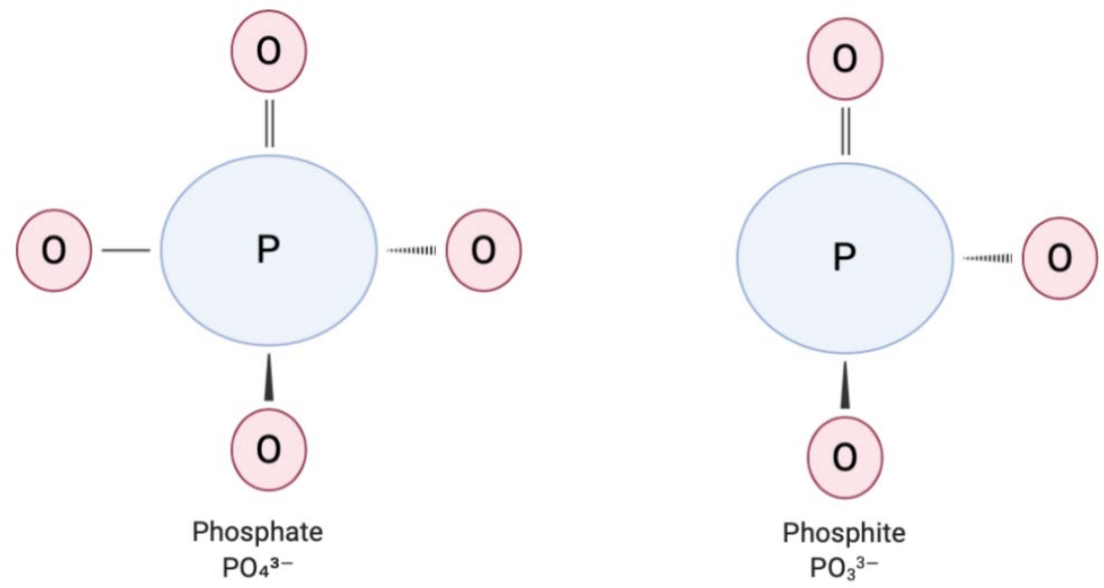

Figure 1.2 Chemical structure of phosphate and phosphite oxyanion.

The chemical structure of both phosphate and phosphite are similar. In their anionic state above they have the same chemical charge. However they do not contain the same of oxygen atoms. 
Once the phosphite is taken into the cell, it affects lipids, free fatty acids, diacylglycerol, phospholipase and tri-glycerols/wax esters. There is an increase in the phosphite abundance in lipids in a chloroform extraction. This abundance increase could be attributed to the cell wall structures. This change was also attributed to an increase in the membrane fluidity and permeability ${ }^{39}$.

Polyphosphate and pyrophosphate synthesis have been explored as another possible mode of action ${ }^{43-45}$. Phosphate depletion and phosphite transportation could not account for the level of growth inhibition alone ${ }^{45}$. However, a reduction in glycolysis and change in adenosine triphosphate (ATP) abundance when Phytophthora was treated with phosphite is partly accountable for this growth inhibition. There was no corresponding replenishment of ATP after phosphite treatment ${ }^{42}$. ATP depletion also causes an increase in polyphosphate and pyrophosphate synthesis. This increased ATP consumption, coupled with phosphite incorporation into the glycolysis pathway ${ }^{43}$, is attributed to the inhibition of Phytophthora species ${ }^{39}$.

While a definitive mode of action has yet to be confirmed, it has been made clear that phosphite does change gene expression in various Phytophthora species. When $P$. cinnamomi is grown in medium with $40 \mu \mathrm{g} / \mathrm{mL}$ phosphite, 16 essential genes are upregulated. These included 5 ADP-ribosylation factor genes and a glycosyltransferase 32, which can be attributed to an increase in ATP use. The 27 down-regulated genes included many cellulose synthases, phosphopyruvate dikinases, glucose transporters, and alternative oxidase ${ }^{32}$. These changes in gene expression and reduction in biosynthetic pathways (including the cellulose/cell wall pathway) can lead to lysis of the cell and to a change in hyphae morphology.

Phytophthora species have an increasingly devastating impact on agriculture annually. $P$. infestans, the cause of potato late blight, annually causes a $\$ 6.7$ billion USD loss in revenue alone ${ }^{46}$. P. infestans, $P$. sojae, and $P$. capsici, have developed resistance and cross-resistance to traditional fungicides currently used in agriculture ${ }^{47-53}$. In citrus orchards in California, USA, $P$. parasitica and $P$. citrophthora, have all begun to show signs of tolerance to phosphite ${ }^{34}$. Hunter $(2018)^{54}$ explored the 
relative sensitivity of Phytophthora isolates to phosphite. There is a co-existence of highly tolerant and sensitive cohorts within isolates of the same Phytophthora species ${ }^{55}$. With the emergence of resistance to traditional fungicides and phosphite tolerance there is a push to find new alternative treatment options.

\subsubsection{Oxathiapiprolin}

A new piperidinyl thiazole isoxazoline core-based compound, oxathiapiprolin, was developed to combat plant pathogens (Figure 1.3). This critical new chemical was optimised to target oomycetes specifically ${ }^{23}$. It has been shown to target most of stages of the life cycle stages of $P$. infestans, $P$. capsici, and $P$. sojae. For example, against $P$. capsici, $50 \%$ inhibition of growth $\left(\mathrm{EC}_{50}\right)$ by oxathiapiprolin was of $5.61 \times 10^{-4} \mu \mathrm{g} / \mathrm{ml}^{56,57}$. Armstrong ${ }^{19}$ confirmed that oxathiapiprolin was also highly active against $P$. agathidicida. This study reported an $\mathrm{EC}_{50}$ of $0.14 \times 10^{-4} \mu \mathrm{g} / \mathrm{ml}$ for inhibition of mycelial growth.

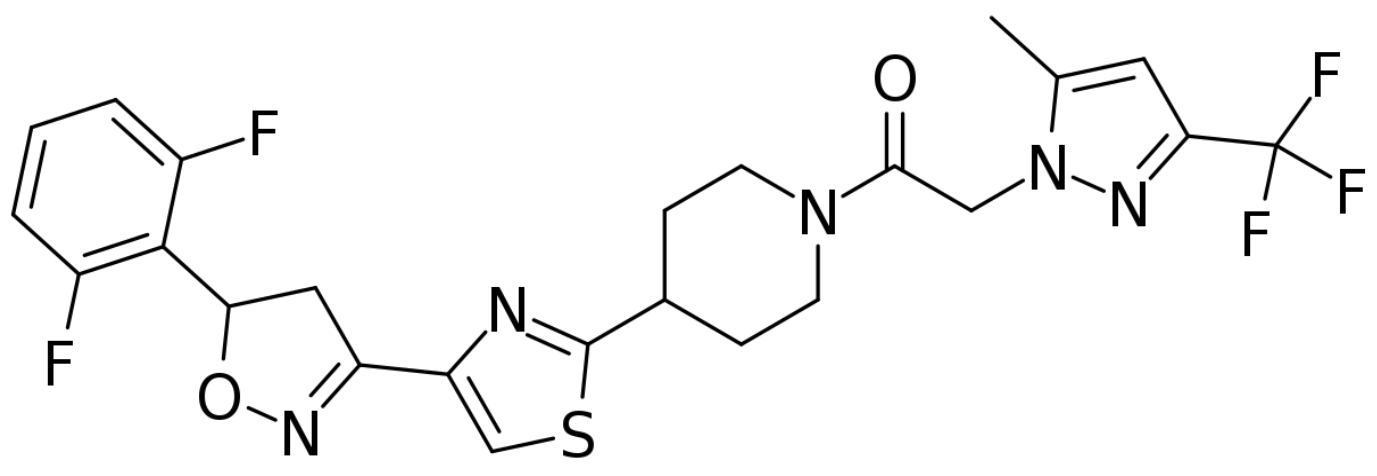

Figure 1.3 1-(4-\{4-[5-(2,6-difluorophenyl)-4,5-dihydro- 3-isoxazolyl]-2-thiazolyl\}-1piperidinyl)-2-[5-methyl-3-(trifluoromethyl)-1H-pyrazol-1-yl]ethenone (oxathiapiprolin), sold commercially as Zorvic or Segovis.

The oxysterol binding protein-related proteins (ORPs) were revealed as the target of oxathiapiprolin through the use of affinity chromatography and mass spectrometry methods ${ }^{23}$. In Phytophthora, ORPs are multi-domain proteins that contain a pleckstrin homology (PH) domain, the oxysterol-binding domain (ORD) and a StARrelated lipid-transfer (START) domain superfamily member. The functions of ORPs are still unknown in Phytophthora and are currently under exploration ${ }^{56-59}$. However, research has been conducted on the human and yeast oxysterol binding proteins 
(OSBP). These have been implicated in cell cycle regulation, lipid metabolism and transport ${ }^{60-62}$.

The Kes1/Osh4 ORP in yeast, Saccharomyces cerevisiae, is well-studied, with several known functions. Kes1/Osh4 is the most abundant ORP in S. cerevisiae ${ }^{63}$. Kes1/Osh4 has been implicated in cell cycle regulation via the Sec14 pathway. Kes1/Osh4 is regulated by $\mathrm{PI}(4) \mathrm{P}$ phosphoinositol signalling and is involved in transfer of oxysterols to the late golgi complex. Kes1/Osh4 is believed to function directly through ARF1 GTPase nucleotide binding and hydrolysis. Kes1/Osh4 activity is dependent on phosphatidylinositol 4-kinase 1 (Pik1). Kes1/Osh4 signalling leads to the inhibition of golgi secretions and is a cell cycle arrest point ${ }^{62,64}$.

A high resolution crystal structure of the Kes1/Osh4 protein has been solved. This is a relatively short protein, and contains only a oxysterol binding domain (ORD) ${ }^{65}$. However the ORD usually contains two multi-strand antiparallel $\beta$-sheets, forming a nearly complete $\beta$-barrel with a characteristic cap to the binding domain ${ }^{62,64,66}$.

\subsubsection{Polygodial}

Polygodial is a known, isolated natural product (Figure 1.4). Previously it was isolated from Warburgia stuhlmannii and $W$. ugandensis ${ }^{67}$. Our Mātauranga guided search isolated polygodial from Weinmannia silvicola (tawhero) (S. Lawrence, unpublished data). Polygodial has also been found in horopito (Pseudowintera axillaris) ${ }^{68}$.

Many of the sources of polygodial have been from traditional folk medicine. Māori traditionally use horopito for gastrointestinal distress as an antidiarrheal, for aches and pain ${ }^{69}$, and topically for yeast and ringworm infections ${ }^{70}$. Parts of tawhero are used traditionally for thoracic and abdominal pain and as a laxative ${ }^{71}$.

The mode of action of polygodial is not fully understood and complex. Polygodial primarily works through disrupting the electrochemical gradient across a phospholipid membrane. This leads to a change in permeability of the plasma membrane ${ }^{67}$. The electrochemical gradient of the plasma membrane is unable to be restored by the plasma membrane ATPases (PMA1) as it is affected by polygodial ${ }^{72}$. 
Addition to plasma membrane disruption, the mitochondrial electrochemical gradient is disrupted ${ }^{72}$, this change causes the uncoupling of the electron transport chain, and ATP synthesis ${ }^{73}$.

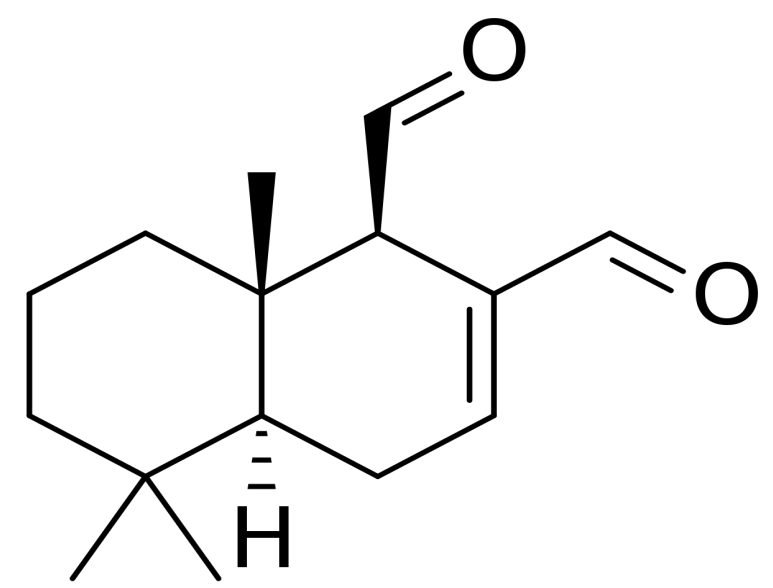

Figure 1.4 The chemical structure of the natural product polygodial

Polygodial is known to be synergistic with other antimicrobial compounds. The synergistic effect of polygodial was looked at using anethole and ethylenediaminetetraacetic acid (EDTA), respectively ${ }^{74,75}$. Anethole antimicrobial activity was not enhanced in yeast experiments. However, a combined solution of polygodial and EDTA solution decreases the minimum inhibitory concentration (MIC) of polygodial treatment of $S$. cerevisiae from $3.12 \mu \mathrm{g} / \mathrm{mL}$ to $0.78 \mu \mathrm{g} / \mathrm{mL}$.

Polygodial's antifungal properties have led to studies that include a general assortment of plant pathogens. This includes $P$. infestans ${ }^{68,76}$, and $P$. nicotiana ${ }^{77}$. Horopito ethanol extracts had in vitro activity against $P$. infestans ${ }^{68}$. This presents an innovative opportunity to explore the anti-Phytophthora activity of polygodial against P. agathidicida. 


\subsubsection{Falcarindiol}

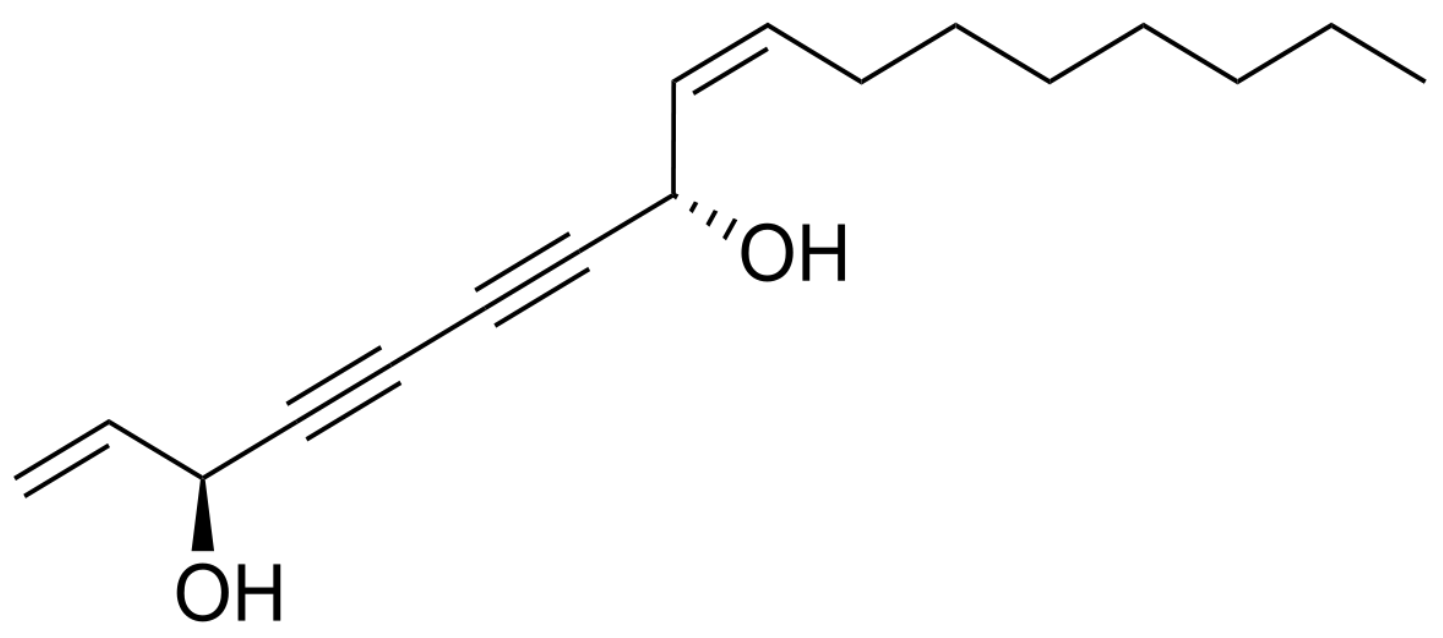

Figure 1.5 The chemical structure of the natural product falcarindiol

Falcarindiol can be found in many species of plants in the Apiaceae and Araliaceae families. Falcarindiol is constitutively active in many plants, including parsnips and carrots (Figure 1.5). This indicates that falcarindiol is one of the primary defence mechanisms to prevent infection in a range of vegetables ${ }^{78}$. Falcarindiol is the compound that gives the bitter taste to carrots.

Many of the Apiaceae and Araliaceae plant families are used in Russian, ${ }^{79}$ Dutch 80 and traditional Māori medicines. Falcarindiol was identified in an extract from Schefflera digitata, the patē tree (S. Lawrence, unpublished data), which is traditionally used by Māori as medicine. The sap of the patē tree is used to treat skin infections. Diethyl ether crude extracts from patē have been shown to be mildly antimicrobial ${ }^{70}$. The medicinal properties of falcarindiol are diverse. They include antifungal, antioxidant, anticancer, cytotoxic, and immunosuppressive properties, though the underlying mechanisms and cellular targets are still under exploration.

The anticancer and antiproliferative properties of falcarindiol help reduce colorectal tumour growth. Low concentrations of falcarindiol arrest the cell cycle in cancer cell lines at $S$ phase, while higher concentrations cause cellular arrest in the G2/M phase 81. A gastrointestinal mutagenic study shows that falcarindiol was protective against two food preservatives, that are known to be gastrointestinal carcinogens. 
Falcarindiol suppressed the SOS signal transduction pathway in the carcinogen study ${ }^{82}$.

Falcarindiol was also found to not have any allergenic activity compared to other polyacetylenes (PA) compounds. It has anti-inflammatory properties and inhibits platelet aggregation which act by inhibiting lipoxygenases and by COX-1 inhibition that modulates the prostaglandin pathway in inflammation ${ }^{83}$.

While falcarindiol is known to be an antimicrobial agent the current literature does not reflect any anti-Phytophthora activity. The addition of falcarindiol to antiPhytophthora agents has led to a promising new development in the fight against kauri dieback, and the Phytophthora genus.

\section{$1.4 \quad$ Antimicrobial Resistance}

There is a well characterised mechanism for antimicrobial resistance in microbial systems. Antibacterial compounds target critical cellular mechanisms. The use of traditional fungicides for the treatment of Phytophthora has led to resistance development. Mandipropamid treated $P$. infestans infections have already led to a resistance mutation in the PiCesA cellulose synthase ${ }^{84}$. More recently, a C239S mutation in the $\beta$-tubulin of $P$. sojae has conferred resistance to zoxamide ${ }^{47}$. Additionally metalaxyl and phenylamide treatments have led to cross-resistance for other traditional unrelated fungicides ${ }^{49,52,85}$.

\subsubsection{Phosphite Resistance}

Phosphite is the gold standard in the treatment of Phytophthora diseases; however, resistance or tolerance is an emerging risk. Adaskaveg (2017) ${ }^{34}$ and Hunter (2018) ${ }^{54}$ have looked at the increasing amount that is required to control Phytophthora infection in citrus fruit ${ }^{34,54}$. Hunter (2018) ${ }^{54}$ notes a high level of variability between geographical isolates of the same species. 


\subsubsection{Oxathiapiprolin Resistance}

As of 2012, the Chinese government requires resistance assessments of novel pesticides, to explore the potential of resistance. Therefore, a resistance assessment was performed on $P$. capsici isolates ${ }^{56,57}$. Serial plating was used to isolate $P$. capsici variants that showed higher growth rate after treatment with oxathiapiprolin ${ }^{23,57}$. All of the tolerant $P$. capsici variants showed mutations within the oxysterol-binding domain (ORD) of the ORP ${ }^{23}$. One such mutation was $\mathrm{G} 769 \mathrm{~W}$ in the P. capsici ORP1 protein ${ }^{56}$.

\subsection{Aims of this Research:}

The research in this thesis aimed to investigate the resistance and sensitivity of P. agathidicida towards existing and novel treatments. This may yield insights into disease management in New Zealand kauri forests, as current studies focus on pathogen control but do not address how long a treatment is likely to work.

\subsubsection{Aim 1}

The addition of another quantitative data set on the direct toxicity of phosphite towards $P$. agathidicida was explored in this research. A comparison of all three commercial preparations of phosphite (Agri-Fos 600, Foschek and Phosgard), and a pure sodium phosphite salt was performed to determine the $\mathrm{EC}_{50}$. The contribution of the adjuvants and surfactants, in the commercial preparations were also assessed as they may contribute to toxicity.

\subsubsection{Aim 2}

A risk assessment was undertaken to determine the likelihood of antimicrobial resistance to phosphite, polygodial and falcarindiol in $P$. agathidicida. An adapted protocol for evolving oxathiapiprolin resistance ${ }^{56}$ was used for sodium phosphite and the natural products. The final evolution rounds were compared to the parental isolate and a sensitive isolate of $P$. agathidicida isolates. 


\subsubsection{Aim 3}

The $P$. agathidicida ORP1 (PaORP1) gene was identified and compared to orthologues from other Phytopthora species. The PaORP1 gene was amplified for five isolates of $P$. agathidicida and assessed for genetic diversity.

\subsubsection{Aim 4}

A protocol was developed for expression and purification of PaORP1 ORD protein. This protocol was developed to express a wild type PaORP1 domain, and an equivalent resistance tryptophan mutant domain - PaORP1 G771W. These two ORP1 domains were cloned, expressed and purified in Escherichia coli. 
Chapter 2

Materials and Methods 


\section{$2.1 \quad$ Materials}

\subsubsection{General Materials}

General chemicals, such as calcium carbonate $\left(\mathrm{CaCO}_{3}\right)$, were purchased from Sigma Aldrich Inc, (St. Louis, MO, USA) and Thermo Fischer Scientific (Waltman, MA, USA), Unless stated otherwise. Restriction enzymes and their buffers were from New England Biolabs (water was deionized and filtered by Milli-Q Integral Water Purification System (EMD Millipore, Billerica, MA, USA). Solutions and media were sterilised by autoclaving (at $121^{\circ} \mathrm{C}, 100 \mathrm{kPa}$ for $15 \mathrm{~min}$ ) in a Systec-D series benchtop autoclave (Linden, Germany).

\subsubsection{Phytophthora agathidicida Isolates}

All $P$. agathidicida isolates used were provided by the Healthy Trees, Healthy Future Research Programme, Scion, Rotorua, New Zealand ${ }^{86}$ (Table 2.1). Unless stated otherwise, all work on $P$. agathidicida was conducted on isolate NZFS 3770.

Table 2.1. Phytophthora agathidicida isolate ID reference numbers, locations and year collected.

\begin{tabular}{|l|l|l|l|}
\hline Species & Isolate & Location & Year \\
\hline Phytophthora agathidicida & NZFS 3770 & Great Barrier, New Zealand & 2006 \\
\hline & NZFS 3772 & Coromandel, New Zealand & 2013 \\
\hline & NZFS 3813 & Coromandel, New Zealand & 2014 \\
\hline & NZFS 3814 & Coromandel, New Zealand & 2014 \\
\hline & NZFS 3815 & Coromandel, New Zealand & 2014 \\
\hline
\end{tabular}

The draft genome of $P$. agathidicida isolate 3772 was downloaded from GenBank (accession number LGTR00000000.1) ${ }^{86}$.

\subsubsection{Bacterial Strains.}

Protein expression and cloning experiments were conducted with the bacterial strains presented in Table 2.2. 
Table 2.2 Bacterial strains and their associated genotype.

\begin{tabular}{|l|l|l|}
\hline E. coli strain: & Genotype & Source \\
\hline BL21-(DE3)-gold & $\begin{array}{l}\text { ompT gal dcm lon hsdSB(rB- mB-) } \lambda(\text { DE3 [lacl lacUV5-T7 } \\
\text { gene 1 ind1 sam7 nin5]) }\end{array}$ & Agilent \\
\hline E. cloni 10G & $\begin{array}{l}\text { F- mcrA } \Delta(\text { mrr-hsdRMS-mcrBC) endA1 recA1 } \\
\text { \$80dlacZ } \Delta M 15 \Delta \text { lacX74 araD139 } \Delta \text { (ara,leu)7697 galU } \\
\text { galK rpsL nupG } \lambda \text { - tonA }\end{array}$ & Lucigen \\
\hline
\end{tabular}

\subsection{4 pET28 Plasmid}

The plasmids were designed using SnapGene software and the plasmid construct was produced by Twist Bioscience (San Francisco, CA, US). The plasmid map (Figure 2.1) shows the general construct. Two variants were produced by Twist. A wild type variant (PaORP1_wt) and a mutant variant (PaORP1_771W) (Table 2.3). These were shipped as dry pellets and resuspended in TE buffer (Tris, and Ethylenediaminetetraacetic acid at $\mathrm{pH} 7$ ) to a $50 \mathrm{ng} / \mu \mathrm{L}$ concentration. 


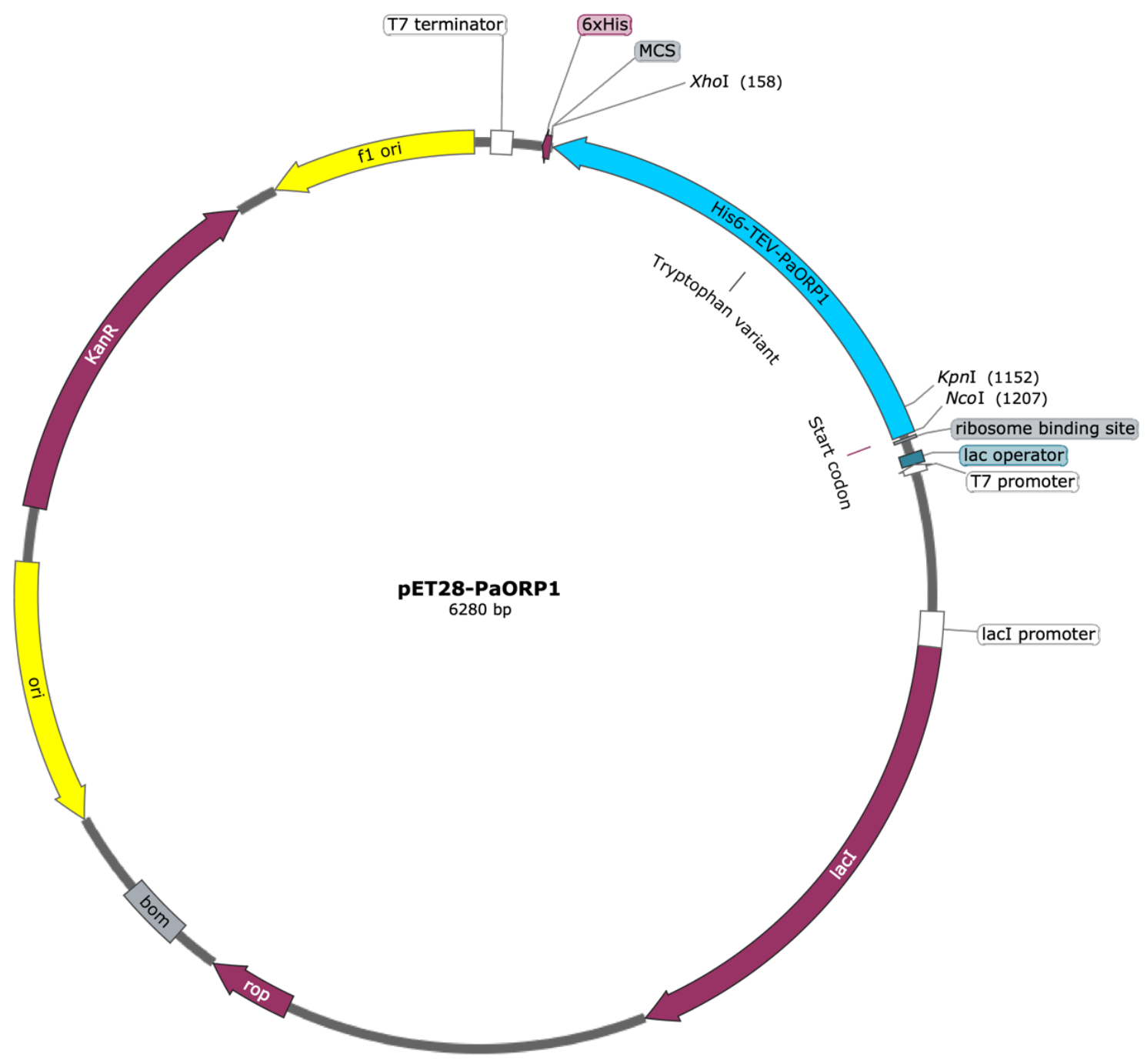

Figure 2.1 pET28 plasmid with PaORP1 DNA insert.

This DNA insert is Histidine tagged (6x his) and TEV cleavage site before the $P$.

agathidicida ORP1 sequence. Knp1 restriction site was introduced into the plasmid. 
Table 2.3 PaORP1 DNA insert of wild type and mutant variants

PaORP1 inserted DNA into pET28 plasmid

\begin{tabular}{|c|c|}
\hline PaORP1_wt & $\begin{array}{l}\text { GCCAAGAAGCAGGGTGGCGTGGTGAAGGATGTCATCAAATCGGCAG } \\
\text { GAGCAAAAATCCTGGAGGGCAAGTCGGCTGTGAGTCTATCGCTGCC } \\
\text { TGTGCGTATTTTCGAGCCTCGCACCAATCTGGAACGTGTGTGCGATT } \\
\text { AATGCTGTACGCGCCGACGTTCCTGAACGTTGCACACGCGCAGAAC } \\
\text { GATGCTTTAGAGCGATTCAAGTACGTCATGACATTTGCCGTGGCTGG } \\
\text { TCTGCACCACAGTATTGGACAGTTGAAGCCGTTAACCCCATCTTGG } \\
\text { GTGAGACGTTCCAGTCTACGCTGAACGATGGTACAGATGTAAGTTGC } \\
\text { GAACACACGAGCCATCACCCGCCTATCAGTAACTTCCAGTTCACCGG } \\
\text { AGAAAAGTACTCCATCGCTGGTTTTTGCTGTGGCATGCGAGCATGA } \\
\text { GCGTGAAGTCGAATGCAATGCTCAACACAAACAAGGGGCCTGTGCG } \\
\text { CGTGACGTTCCCCGACTCTGAAGGCCTTCCTGGAACGACCATCGAG } \\
\text { TACAACCTACCGTACTTGCAGATTGGTGGGTTGCTTTGGGGAGACCG } \\
\text { TACCGTTGACATCATGGGGAAATGGTGTTTGAAGACAAGAAGAACC } \\
\text { ATCTACAGTGCGAACTGCGCCTCAATCCGGATGCCAAGTCAGGAATG } \\
\text { GGCGGAATGTTTTCTAGCTCTAAAACCCCGACGGATTCGTTGCGTGG } \\
\text { TGTGATCTTGGACACTTCTGTGTCTCCACCGCGTGAGATTTGTGACGT } \\
\text { CTCGGGCTCCTGGCTGCATGACCTCGTGTTCGGCAACAAGACGTAC } \\
\text { TGGAGCATCAACAAACACCACAGCGGCTACATGGTACCGTACCCCG } \\
\text { AGAACAAGATTTTGGCGTCCGACTCTCGGTACCGCGAAGACCTGCA } \\
\text { CTATCTGGCAGCAGGCGACCTGGATGAATCGCAAGAGTGGAAGGTA } \\
\text { AAGCTGGAGGTTCTGCAGCGCGCTGATCGCAAGGCGCGTCTGGACG } \\
\text { GC }\end{array}$ \\
\hline PaORP1_G771W & $\begin{array}{l}\text { GCCAAGAAGCAGGGTGGCGTGGTGAAGGATGTCATCAAATCGGCAG } \\
\text { GAGCAAAAATCCTGGAGGGCAAGTCGGCTGTGAGTCTATCGCTGCC } \\
\text { TGTGCGTATTTTCGAGCCTCGCACCAATCTGGAACGTGTGTGCGATTT } \\
\text { AATGCTGTACGCGCCGACGTTCCTGAACGTTGCACACGCGCAGAAC } \\
\text { GATGCTTTAGAGCGATTCAAGTACGTCATGACATTTGCCGTGGCTGG } \\
\text { TCTGCACCACAGTATTGGACAGTTGAAGCCGTTTAACCCCATCTTGG } \\
\text { GTGAGACGTTCCAGTCTACGCTGAACGATGGTACAGATGTAAGTTGC } \\
\text { GAACACACGAGCCATCACCCGCCTATCAGTAACTTCCAGTTCACCGG } \\
\text { AGAAAATACTCCATCGCTGGTTTTGTGCTGTGGCATGCGAGCATGA } \\
\text { GCGTGAAGTCGAATGCAATGCTCAACACAAACAAGTGGCCTGTGCG } \\
\text { CGTGACGTTCCCCGACTCTGAAGGCCTTCCTGGAACGACCATCGAG } \\
\text { TACAACCTACCGTACTTGCAGATTGGTGGGTTGCTTTGGGGAGACCG } \\
\text { TACCGTTGACATCATGGGGAATATGGTGTTTGAAGACAAGAAGAACC } \\
\text { ATCTACAGTGCGAACTGCGCCTCAATCCGGATGCCAAGTCAGGAATG } \\
\text { GGCGGAATGTTTTCTAGCTCTAAAACCCCGACGGATTCGTTGCGTGG } \\
\text { TGTGATCTTGGACACTTCTGTGTCTCCACCGCGTGAGATTTGTGACGT } \\
\text { CTCGGGCTCCTGGCTGCATGACCTCGTGTTCGGCAACAAGACGTAC } \\
\text { TGGAGCATCAACAAACACCACAGCGGCTACATGGTACCGTACCCCG } \\
\text { AGAACAAGATTTTGGCGTCCGACTCTCGGTACCGCGAAGACCTGCA } \\
\text { CTATCTGGCAGCAGGCGACCTGGATGAATCGCAAGAGTGGAAGGTA } \\
\text { AAGCTGGAGGTTCTGCAGCGCGCTGATCGCAAGGCGCGTCTGGACG } \\
\text { GC }\end{array}$ \\
\hline
\end{tabular}




\subsubsection{Agrichemicals}

Four commercially available phosphite solutions were obtained. Agri-Fos 600 (Agrichem, Queensland, AUS) had previously been purchased by another member of the laboratory ${ }^{19}$. Foschek, a phosphite-less version of Foschek (Lonza, New Plymouth, NZ) and Phosgard (Grochem, Wellington, NZ), were donated by the manufacturers. The supplied stocks contained phosphite at $400 \mathrm{~g} / \mathrm{L}$ or $600 \mathrm{~g} / \mathrm{L}$, and were then diluted with water to working stocks of $1 \mathrm{mg} / \mathrm{mL}$ or $20 \mathrm{mg} / \mathrm{mL}$. Sodium phosphite (Sigma Aldrich Inc) was dissolved in deionised water, to the same working stock concentrations of $1 \mathrm{mg} / \mathrm{mL}$ or $20 \mathrm{mg} / \mathrm{mL}$. All commercial agrichemicals were sterilised by filtration through a $0.22 \mu \mathrm{m}$ membrane before use.

\subsubsection{Antibiotics and Natural products}

Kanamycin was supplied by Thermo Fisher Scientific. Kanamycin was prepared to a concentration of $30 \mathrm{mg} / \mathrm{mL}$ by dissolving in Milli-Q deionised water and then filter sterilised. All the antibiotics were syringe filtered through a $0.22 \mu \mathrm{m}$ filter (Jet BioFiltration Co. Ltd, GZ, China) were then stored at $-20^{\circ} \mathrm{C}$ and thawed for use.

Falcarindiol (purchased from Biosynth Carbosynth, Berkshire, UK) was dissolved in $100 \%$ dimethyl sulfoxide (DMSO) to a stock concentration of $1 \mathrm{mg} / \mathrm{mL}$ and $5 \mathrm{mg} / \mathrm{mL}$. Polygodial (purchased from Biosynth Carbosynth Berkshire, UK) was dissolved in DMSO to $1 \mathrm{mg} / \mathrm{mL}$ or $5 \mathrm{mg} / \mathrm{mL}$, then stored at $-20{ }^{\circ} \mathrm{C}$ and thawed for use.

\subsubsection{PARP Agar}

PARP agar plates were prepared by mixing $17 \mathrm{~g}$ of pre-formulated cornmeal agar $\left(\right.$ Difco $^{\mathrm{TM}}$ ) with 1 litre of water. Media were autoclaved and cooled to approximately 60 ${ }^{\circ} \mathrm{C}$ or until the container was warm to the touch and able to be held, before adding the antibiotics and fungicides (Table 2.4). Petri dishes were filled with approximately 20-25 mL of molten agar using aseptic techniques. Once solidified, the agar plates were wrapped in foil, and stored in the dark at $4{ }^{\circ} \mathrm{C}$. 
Table 2.4. Component volumes and concentrations of PARP agar ingredients

\begin{tabular}{|c|c|c|}
\hline Per litre: & Ingredients & Final Concentration \\
\hline $17 \mathrm{~g}$ & Cornmeal agar (DifcoTM) & \\
\hline $500 \mu \mathrm{L}$ & Amp (500 mg/mL stock) & $250 \mu \mathrm{g} / \mathrm{mL}$ \\
\hline $500 \mu \mathrm{L}$ & $\begin{array}{l}\text { Rifampicin }(20 \mathrm{mg} / \mathrm{mL} \text {, dissolved in DMSO or } \\
\left.\text { acetone - stock stored }-20^{\circ} \mathrm{C}\right)\end{array}$ & $10 \mu \mathrm{g} / \mathrm{mL}$ \\
\hline $400 \mu \mathrm{L}$ & $\begin{array}{l}\text { Pimaricin ( } 2.5 \% \text { solution, stored } 4^{\circ} \mathrm{C} \\
\text { - resuspend by pipetting before using). }\end{array}$ & $10 \mu \mathrm{g} / \mathrm{mL}$ \\
\hline $2.5 \mathrm{~mL}$ & $\begin{array}{l}\text { Pentachloronitrobenzene* (PCNB) } 40 \mathrm{mg} / \mathrm{mL} \text {, } \\
\text { dissolved in DMSO with vertexing - made fresh. }\end{array}$ & $100 \mu \mathrm{g} / \mathrm{mL}$ \\
\hline
\end{tabular}

\subsubsection{V8 Agar}

To prepare V8 broth, $100 \mathrm{~mL}$ of Original V8 Juice (Campbell Soup Company) was diluted with $150 \mathrm{~mL}$ of water. $1 \mathrm{~g} \mathrm{CaCO}_{3}$ was added to adjust the $\mathrm{pH}$ to approximately 7.0. Once the $\mathrm{pH}$ was adjusted the broth was made up to $1 \mathrm{~L}$. Then 15 $\mathrm{g}$ of agar (Formedium ${ }^{\mathrm{TM}}$ ) was added per litre of broth, before sterilisation by autoclaving. The agar was cooled until the container was warm to the touch and able to be held. Plates containing approximately 20-25 mL of agar were poured using standard aseptic techniques. Freshly poured plates were allowed to cool and dry under a Bunsen flame for at least $30 \mathrm{~min}$. Once solidified, agar plates were stored at $4{ }^{\circ} \mathrm{C}$ in the dark ${ }^{87}$.

\subsubsection{Potato Dextrose Agar (PDA)}

Premixed potato dextrose agar (Difco ${ }^{\mathrm{TM}}$ ) was used to make and pour PDA plates. 39 $\mathrm{g}$ of powdered premix was dissolved in $1 \mathrm{~L}$ of deionised water before sterilised by autoclave. The agar was cooled until the container was warm to the touch and able to be held. Plates containing approximately $20-25 \mathrm{~mL}$ of agar were poured using standard aseptic techniques. Freshly poured plates were allowed to cool and dry under a Bunsen flame for at least $30 \mathrm{~min}$. Once solidified agar plates were stored at 4 ${ }^{\circ} \mathrm{C}$. 


\subsubsection{Carrot Broth}

$50 \mathrm{~g}$ of carrot and $100 \mathrm{~mL}$ of deionised water were blended using a George Foreman Mix \& Go Classic blender (Spectrum Brands, WI, USA). $1 \mathrm{~g}$ of $\mathrm{CaCO}_{3}$ was added to adjust the $\mathrm{pH}$ to approximately 7.0. Once the $\mathrm{pH}$ was adjusted, the broth was made up to $1 \mathrm{~L}$ before being sterilised by autoclave.

\subsubsection{Terrific Broth}

Terrific broth was made up to $1 \mathrm{~L}$ in a $2.5 \mathrm{~L}$ Ultra Yield ${ }^{\mathrm{TM}}$ flask, (Thomson Instrument Company) using $47.6 \mathrm{~g}$ of premixed terrific broth powder (Formedium ${ }^{\mathrm{TM}}$ ) dissolved into $1 \mathrm{~L}$ Milli-Q deionised water. This solution was autoclaved to become sterilised before inoculating with a bacterial culture.

\subsubsection{Auto Induction Medium}

$55.85 \mathrm{~g}$ of premixed autoinduction medium powder (Formedium ${ }^{\mathrm{TM}}$ ) was dissolved in $1 \mathrm{~L}$ deionised water, in a $2.5 \mathrm{~L}$ Ultra Yield ${ }^{\mathrm{TM}}$ flask (Thomson Instrument Company). 8 $\mathrm{ml}$ of $50 \%$ glycerol was added to the autoinduction medium before the solution was sterilised by autoclaving. The appropriate antibiotic was added (1:1000 dilution) once the solution was cool to the touch or at room temperature.

\subsubsection{LB Broth}

$6.25 \mathrm{~g}$ of premixed, powdered LB broth Miller (Formedium ${ }^{\mathrm{TM}}$ ) was dissolved in 250 $\mathrm{mL}$ of deionised water before being sterilised by autoclave. This was then used for routine overnight culturing of Escherichia coli.

\subsubsection{PCR Primers}

Primers (Table 2.5) were designed for the $P$. agathidicida ORP gene sequence using SnapGene software. Primers were supplied by Macrogen (South Korea). The GK4 primers in Table 2.5 were for PCR controls and were designed previously ${ }^{19}$. All primers were resuspended in TE buffer (Tris, and EDTA at pH 7). 
Table 2.5 Polymerase chain reaction primers and melting temperatures

\begin{tabular}{|l|l|l|}
\hline Primer & \multicolumn{1}{|c|}{ Sequence $\left(5^{\prime} \rightarrow 3^{\prime}\right)$} & $T_{\mathrm{M}}$ \\
\hline PTA_OSBP_For_1 & CGGCTTATTTCTTGCCTGCCCGCTG & $66^{\circ} \mathrm{C}$ \\
\hline PTA_OSBP_For_2 & CCAATTCCAGCAGTTCTGCACCGTCGTC & $66^{\circ} \mathrm{C}$ \\
\hline PTA_OSBP_For_4 & TGGCGTGGTGAAGGATGTCATC & $69^{\circ} \mathrm{C}$ \\
\hline PTA_OSBP_Rev_1 & TACGCTTGCTTTCGCTGGTTATCGCAGAG & $61^{\circ} \mathrm{C}$ \\
\hline GPCR_GK4 Forward & $\begin{array}{l}\text { ATTGGATCCATGGCGGTGTGCGCGCCCGAGACG } \\
\text { GC }\end{array}$ & $76^{\circ} \mathrm{C}$ \\
\hline GPCR_GK4 Reverse & $\begin{array}{l}\text { CGCAAGCTTCTATATCTCCATTGAGAGGTTGGAGT } \\
\text { CCAATGAGACGTTCG }\end{array}$ & $71^{\circ} \mathrm{C}$ \\
\hline
\end{tabular}

\subsubsection{Protein Purification Buffers}

All buffers (Table 2.6) were prepared using Milli-Q deionised water. Each buffer was made to $500 \mathrm{~mL}$ or $1 \mathrm{~L}$ and stored at $4{ }^{\circ} \mathrm{C}$. Each buffer was $\mathrm{pH}$ adjusted before being made up to a final $500 \mathrm{~mL}$ or $1 \mathrm{~L}$ stock solutions. $5 \mathrm{mM} \beta$-mercaptoethanol was added to $100-150 \mathrm{~mL}$ aliquots of buffer, as needed for each purification. These solutions were vacuum filtered using a $0.22 \mu \mathrm{m}$ filter disc, degassed and then stored at $4{ }^{\circ} \mathrm{C}$.

Table 2.6. Protein purification buffer components.

\begin{tabular}{|l|l|l|}
\hline \multicolumn{1}{l}{ Lysis Buffer (pH 7.8) } & \multicolumn{1}{l|}{ Elution Buffer (pH 7.8) } & Size Exclusion Buffer (pH 5) \\
\hline $50 \mathrm{mM} \mathrm{HEPES,}$ & $50 \mathrm{mM}$ HEPES, & $50 \mathrm{mM}$ Sodium Acetate \\
\hline $300 \mathrm{mM} \mathrm{NaCl}$ & $300 \mathrm{mM} \mathrm{NaCl}$ & $150 \mathrm{mM} \mathrm{NaCl}$ \\
\hline $10 \mathrm{mM}$ Imidazole & $300 \mathrm{mM}$ Imidazole & Acetic Acid \\
\hline $\begin{array}{l}10 \% \text { Glycerol } \\
\text { mercaptoethanol } \beta \text { - }\end{array}$ & $10 \%$ Glycerol & $5 \mathrm{mM}$-mercaptoethanol \\
\hline $0.5 \%$ Tween-80 & & \\
\hline
\end{tabular}




\subsubsection{Sodium Dodecyl Sulfate-Polyacrylamide Gel Electrophoresis (SDS-PAGE)}

SDS-PAGE was used to visualize and separate the proteins based on size. The components to make SDS-PAGE gel are shown in Table 2.7. Glass plates were aligned and held together within a plastic multi caster system (Bio-Rad, Hercules, CA, USA). The resolving gel was poured between the plates until the solution was approximately $2 \mathrm{~cm}$ from the top, then $70 \%(\mathrm{v} / \mathrm{v})$ ethanol was overlaid to prevent dehydration and to level the top of the resolving gels. After approximately $1 \mathrm{~h}$, polymerisation of this resolving gel was complete and the ethanol was rinsed off with distilled water. The stacking gel was then poured on top and a 15 well, $1 \mathrm{~mm}$ comb was inserted into the liquid gel. Once polymerisation had taken place, the gel was wrapped in damp paper towels and placed into a plastic bag. The gel was stored at 4 ${ }^{\circ} \mathrm{C}$ to prevent dehydration from occurring.

Table 2.7. Components for pouring 10 SDS-PAGE gels.

\begin{tabular}{|c|c|c|}
\hline Components of SDS Gel & Resolving & Stacking \\
\hline 1.5 M Tris-HCl pH 8.8 & $16.5 \mathrm{~mL}$ & \\
\hline 0.5 M Tris- $\mathrm{HCl} \mathrm{pH} 6.8$ & & $6 \mathrm{~mL}$ \\
\hline Milli-Q water & $28.7 \mathrm{~mL}$ & $15.2 \mathrm{~mL}$ \\
\hline SDS $(10 \%(w / v))$ & $660 \mu \mathrm{L}$ & $240 \mu \mathrm{L}$ \\
\hline $\begin{array}{l}40 \% \text { solution, } 29: 1 \text { acrylamide : bis- } \\
\text { acrylamide }\end{array}$ & $19.8 \mathrm{~mL}$ & $2.4 \mathrm{~mL}$ \\
\hline Ammonium persulfate $(10 \%(\mathrm{w} / \mathrm{v}))$ & $330 \mu \mathrm{L}$ & $120 \mu \mathrm{L}$ \\
\hline Tetramethylethylenediamide & $66 \mu \mathrm{L}$ & $24 \mu \mathrm{L}$ \\
\hline
\end{tabular}




\section{$2.2 \quad$ Methods}

\subsubsection{Routine Agar Culturing}

$P$. agathidicida was routinely cultured on V8 agar. A plug of agar ( $\sim \mathrm{mm})$

containing $P$. agathidicida mycelia was placed centrally on a V8 agar plate (standard petri dish $90 \mathrm{~mm}$ diameter). After $5-7$ days incubating at $22^{\circ} \mathrm{C}$ in darkness, a plug of agar was removed from the leading edge of the mycelial mat and placed on a new V8 agar plate.

After culturing on agar 6-8 times, it is standard practice for Phytophthora cultures to passage through plant tissue to preserve the pathogenicity ${ }^{87}$. For $P$. agathidicida, a plug of agar from the leading edge of the mycelial growth was passaged through a pear according to standard protocols ${ }^{87}$. Briefly, the plug of mycelium was placed in a pear and incubated for approximately 7 days at $24^{\circ} \mathrm{C}$. A small section $(5 \mathrm{~mm}$ diameter) from the pear was then cut from the advancing section of rot and placed on selective PARP agar to re-isolate $P$. agathidicida ${ }^{88}$. The plates were incubated at $22{ }^{\circ} \mathrm{C}$ for 5-7 days. Once $P$. agathidicida mycelia had grown on PARP, the incubation on V8 agar restarted and the culturing cycle continued.

\subsubsection{Broth Culturing}

A plug of V8 agar $(\sim 5 \mathrm{~mm})$ containing $P$. agathidicida mycelia was placed in a tube containing, $30 \mathrm{~mL}$ of carrot broth or potato dextrose broth. The mycelial mat was used after 5 days of growth.

\subsubsection{Amended Media}

An agrichemical was added to molten potato dextrose agar at about $60{ }^{\circ} \mathrm{C}$. Plates $(60$ $\mathrm{mm}$ diameter) containing approximately $10 \mathrm{~mL}$ of agar were poured using standard aseptic techniques. Freshly poured plates were allowed to cool and dry under a Bunsen flame for at least $30 \mathrm{~min}$. Once solidified, agar plates were stored at $4{ }^{\circ} \mathrm{C}$ in 
the dark until inoculated with a $2.5 \mathrm{~mm} P$. agathidicida plug. Once inoculated, the plates were grown for 5 days at $22^{\circ} \mathrm{C}$.

\subsubsection{In Vitro Growth Assays}

After 5 days of growing at $22^{\circ} \mathrm{C}$, the sizes of mycelial mats were measured using Image J software ${ }^{89}$. A positive control plate (potato dextrose agar only) was also inoculated with a $2.5 \mathrm{~mm} P$. agathidicida plug, to set a baseline for $100 \%$ growth. Agrichemical concentrations in the amended plates ranged from $0.1 \mu \mathrm{g} / \mathrm{mL}$ to $200 \mu \mathrm{g} / \mathrm{mL}$. The overall diameter of the mycelial mat was measured, the centre was found, then 6 measurements of radial growth were obtained. The average radial growth at each agrichemical concentration was squared to give a relative area of mycelial growth. $\mathrm{EC}_{50}$ values were calculated using linear regression in Prism GraphPad version 8.0.

\subsubsection{Serial Passaging}

For serial passaging, molten agar was amended with a chemical, as previously described in methods 2.2.3. The agar plate was inoculated with a $2.5 \mathrm{~mm}$ $P$. agathidicida plug before growing for 5 days at $22^{\circ} \mathrm{C}$. After 5 days, the inoculated media had another amended agar layer added over the top of the current agar plate. This double-layer inoculated agar was grown for another 5 days at $22{ }^{\circ} \mathrm{C}$ to allow mycelia to grow up through the overlaid agar containing an inhibitory chemical.

After day 10, a plug was taken from the double layer agar and used to inoculate a new plate amended with a higher concentration of the chemical. This was repeated until there was no growth on the new amended agar.

For long-term storage, 10-15 plug samples (2.5 mm diameter) were taken along the leading edge of the mycelial growth and placed into a $5 \mathrm{~mL}$ amber glass vials. The vials were then filled with $3-5 \mathrm{~mL}$ of sterile water until the plugs were covered and capped. These vials were stored at room temperature in the dark until further use. 


\subsubsection{DNA Extraction}

A $5 \mathrm{~mm}$ plug of $P$. agathidicida was grown in $20 \%$ carrot broth for 10 days. The resulting mycelial mat was washed several times with sterile deionised water to remove any carrot broth contamination. Mycelial mats were left to dry in a $37^{\circ} \mathrm{C}$ incubator for 30 minutes. DNA was extracted using the Promega Wizard DNA extraction kit and plant extraction protocol, as described previously by Armstrong $(2018)^{19}$.

\subsubsection{DNA Agarose Gel}

DNA obtained from PCR was separated according to size by gel electrophoresis. A $1 \%$ agarose gel was made with 1 x TAE buffer (400 mM tris-acetate $\mathrm{pH} 8.4,1 \mathrm{mM}$ EDTA, $20 \mathrm{mM}$ acetic acid). DNA was mixed with a loading dye (KAPA Biosystems). A DNA size marker, $1 \mathrm{~kb}+$ Universal Ladder (KAPA Biosystems), was loaded on the gel along with the samples. Gels were electrophoresed in $1 \times$ TAE for 25 minutes at 110 V. Gels were stained using ethidium bromide for 30 minutes after electrophoresis, then rinsed with deionised water. Gels were visualised under a UV light in a UV Tec Geldoc system (Uvitec Ltd, Cambridge, UK).

\subsubsection{Polymerase Chain Reaction (PCR)}

PCRs made use of KAPA Taq Ready Mix with dye (KAPA Biosystems). Reactions were carried out in a total volume of $20 \mu \mathrm{L}$ : $10 \mu \mathrm{L}$ Ready Mix, $0.8 \mu \mathrm{L}$ Reverse Primer and $0.8 \mu \mathrm{L}$ forward primer (each primer stock at $10 \mu \mathrm{M}$ ), $1 \mu$ l of template DNA (concentration 8 to $120 \mathrm{ng} / \mu \mathrm{L}$ ) and $7.4 \mu \mathrm{L}$ of sterile deionised water. Thermal cycling was carried out in a MultiGene ${ }^{\mathrm{TM}}$ Gradient Thermal Cycler (Labnet International Inc, US), as shown in Table 2.8. 
Table 2.8. Pre-programmed thermocycling temperatures.

\begin{tabular}{|l|l|l|}
\hline Start & 94 & Temperature $\left({ }^{\circ} \mathrm{C}\right)$ \\
\hline Cycles (30) & 94 & $20 \mathrm{sec}$ \\
\hline & 57 & $20 \mathrm{sec}$ \\
\hline & 72 & $20 \mathrm{sec}$ \\
\hline Extension & 72 & $3 \mathrm{~min}$ \\
\hline Hold & 10 & $3 \mathrm{~min}$ \\
\hline
\end{tabular}

\subsubsection{DNA Sequencing}

Sanger DNA sequencing was carried out by Macrogen (Seoul, South Korea).

\subsubsection{Bioinformatics}

The draft genome of $P$. agathidicida isolate 3772 was downloaded from GenBank (accession number LGTR00000000.1). The file contained 3000+ contigs. The contig tags were removed using a custom Python script and one continuous sequence was generated. The one continuous sequence was analysed using SnapGene software.

An open reading frame of $3330 \mathrm{bp}$ was found to have the closest sequence identity to the other Phytophthora species. A 16 bp motif (GCTCATTYBNNNWTTY) ${ }^{11}$ surrounds the transcriptional start site of many genes and was located via a find and search method in Snap gene. Exon-Intron junction information was found using this same method and sequence $55^{\prime}$-GTRNGT. . .YAG- $3^{\prime}{ }^{11}$. The intronic sequences were confirmed with a CTAAC motif present between the exon-intron junctions.

Once the PaORP gene was located, SnapGene was used to translate it into a protein sequence. This was checked against the ORP sequences from other Phytopthora species reported in Andreassi, Gutteridge, Pember, Sweigard and Rehberg ${ }^{90}$. SWISS-MODEL was used for protein structure prediction ${ }^{91}$. 


\subsubsection{Freezer Stocks}

All bacterial strains were permanently stored at $-80{ }^{\circ} \mathrm{C}$. Stocks were generated from overnight cultures mixed $1: 1$ with sterile $50 \%$ glycerol.

\subsubsection{Overnight Cultures}

Overnight cultures were $5 \mathrm{~mL}$ of appropriate media with the required antibiotics.

Each was grown overnight (16hrs) at $37^{\circ} \mathrm{C}$ and aerated by shaking at $180 \mathrm{rpm}$ in an Innova 44 Shaking incubator (New Brunswick Scientific, NJ, US). The media was inoculated using either freezer stock or from a single colony on an agar plate using sterile techniques.

\subsubsection{Electrocompetent Cells}

A $6 \mathrm{~mL}$ overnight culture was divided into $1.5 \mathrm{~mL}$ aliquots and harvested by centrifugation at $15,000 \mathrm{xg}$ for 1 minute at room temperature. Each bacterial pellet was washed three times with $1 \mathrm{~mL}$ of $300 \mathrm{mM}$ sucrose at room temperature. The pellets were pooled into 2 aliquots of $50 \mu \mathrm{L}$. These aliquots could be then used to transform E. coli strains with a plasmid (Methods 2.2.14)

\subsubsection{Transformation}

The pET28 plasmid was added to an aliquot of electrocompetent cells using sterile techniques in a $2 \mathrm{~mm}$ MicroPulser electroporation cuvette (Bio-Rad, Hercules, CA, USA). The cells were electroporated with a $2.5 \mathrm{kV}$ electric pulse in the MicroPulser (Bio-Rad, Hercules, CA, USA), after which $500 \mu \mathrm{L}$ SOC (super optimal broth with catabolite repression) medium (Ready to use, purchased from Thermo Fisher) was added immediately. The cells were recovered for approximately 1 hour at $37{ }^{\circ} \mathrm{C}$ and then aliquots were spread on selective agar plates which were incubated overnight at $37^{\circ} \mathrm{C}$. 
Colonies that grew on the selective agar plates were used to inoculate $5 \mathrm{~mL} L B$ including the appropriate antibiotic and incubated at $37^{\circ} \mathrm{C}$ with shaking at $180 \mathrm{rpm}$ overnight. Each culture was made into a freezer stock by mixing an aliquot 1:1 with sterile $50 \%$ glycerol and permanently storing at $-80^{\circ} \mathrm{C}$.

\subsubsection{Enzyme Digest of Plasmid}

Diagnostic restriction digests made use of the enzyme combinations Ncol-HF/Xhol and $\mathrm{Kpnl} / \mathrm{Xhol}$, incubated at $37^{\circ} \mathrm{C}$ for $1 \mathrm{~h}$. Each reaction mixture contained $300 \mathrm{ng}$ of plasmid DNA, $2 \mu \mathrm{L}$ of Cut-Smart buffer and $0.5 \mu \mathrm{L}$ of each restriction enzyme, made up to a $20 \mu \mathrm{L}$ volume with sterile deionised water. The products were separated by electrophoresis on a $1 \%$ agarose gel and then visualised under UV light in a UV Tec Geldoc system (Uvitec Ltd, Cambridge, UK).

\subsubsection{SDS-PAGE}

Samples collected from protein expression, purification or size exclusion chromatography (SEC) were mixed at a 1:1 ratio with $2 \times$ SDS-PAGE loading dye (100 mM Tris-Cl at pH 6.8, 4\% SDS, 20\% glycerol, 0.2\% bromophenol blue, $200 \mathrm{mM}$ $\beta$-mercaptoethanol). The protein samples were then denatured by heating at $95{ }^{\circ} \mathrm{C}$ for $10 \mathrm{~min}$ in a MultiGene ${ }^{\mathrm{TM}}$ Gradient Thermal Cycler (Labnet International Inc, US). The SDS-PAGE gel was loaded with $5 \mu \mathrm{L}$ of a molecular weight marker (Bio-Rad, Hercules, CA, USA) and $5 \mu \mathrm{L}$ of total and soluble protein fractions from the various time points. Electrophoresis was conducted in a Mini-Protean tetra cell system (BioRad, Hercules, CA, USA) at $200 \mathrm{~V}$ for 50 minutes in SDS-PAGE running buffer (25 $\mathrm{mM}$ Tris at $\mathrm{pH} 8.3,250 \mathrm{mM}$ glycine, $0.1 \%$ SDS). The separated proteins were visualised with Coomassie blue staining (1.5 M Coomassie R250, 50\% methanol, $10 \%$ acetic acid) for approximately 30 minutes while gently rocking on a Platform Rocker (Labnet International Inc, US). The stain was then removed, and the gel was transferred into destain ( $30 \%$ methanol, $10 \%$ acetic acid) until the gel was sufficiently de-stained and protein bands were visible. 
The gel was then visualised under white light in a UV Tec Geldoc system (Uvitec Ltd, Cambridge, UK).

\subsubsection{Protein Purification}

\subsubsection{Initial Protocol}

An overnight (16 to $18 \mathrm{hrs}$ ) culture was used to inoculate TB growth medium (Materials 2.1.11) with $30 \mu \mathrm{g} / \mathrm{mL}$ kanamycin. The culture was placed into an Innova 44 shaking incubator (New Brunswick Scientific, NJ, US) at $37^{\circ} \mathrm{C}$ and $180 \mathrm{rpm}$ until an $\mathrm{OD}_{600}$ reading of 0.6-0.8 was reached (usually 3.5-4 h). Once the appropriate $\mathrm{OD}_{600}$ was reached, Isopropyl $\beta$-d-1-thiogalactopyranoside (IPTG) was added to a final concentration of $0.5 \mathrm{mM}$ to induce expression of PaORP1. The induced culture was grown overnight in an Innova 44 shaking incubator at $18{ }^{\circ} \mathrm{C}$.

The following day the cells were harvested by centrifugation at $1500 \mathrm{xg}$ for 20 minutes. The pelleted cells were transferred into a $50 \mathrm{~mL}$ tube, weighed and used in the following method, or snap-frozen by liquid nitrogen and stored at $-20{ }^{\circ} \mathrm{C}$ for later use. The newly transferred cells were resuspended in the first three components of the lysis buffer (Table 2.6) along with the following components in Table 2.9. The cells and solution were vortexed to help resuspend cells and then left to incubate on ice for 30 minutes.

\section{Table 2.9. Resuspending solution components}

\begin{tabular}{|c|c|c|}
\hline Component & & Concentration \\
\hline Lysis Buffer (pH 7.8) & & $5 \mathrm{~mL} / \mathrm{g}$ of pellet \\
\hline Lysozyme & $20 \mathrm{mg} / \mathrm{mL}$ stock & $0.5 \mathrm{mg} / \mathrm{mL}$ \\
\hline Benzonase & & $0.1 \mu \mathrm{L} / \mathrm{g}$ of pellet \\
\hline Protease inhibitor cocktail (PIC) & & $20 \mu \mathrm{L} / \mathrm{g}$ of pellet \\
\hline
\end{tabular}

After incubation, the cells were lysed by sonication (10 s on, $30 \mathrm{~s}$ off, 10 cycles, at a power setting no higher than $40 \%$ ) on ice. The lysate was transferred to a $40 \mathrm{~mL}$ centrifuge tube. The lysate, with balance, was centrifuged in a Sorvall LYNX 4000 Superspeed Centrifuge (Thermo Fisher Scientific, USA) to pellet cell debris at 
$15,000 \mathrm{xg}$ for 60 minutes at $4{ }^{\circ} \mathrm{C}$. Once centrifuged, the lysate was transferred to a clean $50 \mathrm{ml}$ tube, and clarified through $0.45 \mu \mathrm{m}$ syringe-driven filter, then a $0.22 \mu \mathrm{m}$ filter (Jet Bio-Filtration Co. Ltd, GZ, China).

Immobilised metal affinity chromatography (IMAC) was done using a nickel His-trap column ( $1 \mathrm{~mL}$ or $5 \mathrm{~mL}$; GE Healthcare Bio-Sciences, PA, USA) on an ÄKTA Start protein purification system (GE Healthcare). The column was washed with degassed and filter sterilised Milli-Q water, and then lysis buffer (Table 2.6). The sample was loaded onto the His-trap column, before contaminants and PaORP1 were eluted over a gradient from 0 to $100 \%$ elution buffer (Table 2.6). The gradient was over a total volume of $30 \mathrm{~mL}$. Elution fractions were collected and analysed by SDS-PAGE (Methods 2.2.16 above).

\subsubsection{Optimised Protein Purification}

An overnight (16 hrs) culture was used to inoculate $1000 \mathrm{~mL}$ of pre-sterilised autoinduction medium (AIM) (Materials 2.1.12) supplemented with $30 \mu \mathrm{g} / \mathrm{mL}$ kanamycin. The culture was incubated at $37^{\circ} \mathrm{C}$ with shaking at $180 \mathrm{rpm}$ in an Innova 44 shaking incubator, until an $\mathrm{OD}_{600}$ reading of $0.6-0.8$ was reached (usually $3.5-4 \mathrm{~h}$ ). Once the appropriate $\mathrm{OD}_{600}$ was reached, the culture was transferred to a shaking incubator at $18{ }^{\circ} \mathrm{C}$ and $180 \mathrm{rpm}$, and allowed to grow overnight (16 to $18 \mathrm{hrs}$ ).

The following day, cells were harvested by centrifugation at $1500 \mathrm{xg}$ for 20 minutes. The pelleted cells were transferred into a $50 \mathrm{~mL}$ tube, weighed and used immediately, or snap-frozen in liquid nitrogen and stored at $-20^{\circ} \mathrm{C}$ for later use. The cell pellet was resuspended in $30 \mathrm{~mL}$ of lysis buffer (Table 2.6), along with the following components in Table 2.9. The cells were resuspended by vortexing and then left to incubate on ice for 30 minutes.

After incubation, the cells were lysed by the French press method on ice. The lysate was transferred to a $40 \mathrm{~mL}$ centrifuge tube. The lysate, with balance, was centrifuged (Sorvall LYNX 4000 Superspeed Centrifuge) to pellet cell debris at $15,000 \mathrm{xg}$ for 60 minutes at $4{ }^{\circ} \mathrm{C}$. Once centrifuged, the lysate was transferred to a clean $50 \mathrm{~mL}$ tube, and filtered through both $0.45 \mu \mathrm{m}$ and $0.22 \mu \mathrm{m}$ filters (Jet Bio-Filtration Co.). 
IMAC was done as described above (Methods 2.2.17.1) except an isocratic elution method was used instead of a gradient. Four stepwise increments, with increasing imidazole concentrations, were used to elute the protein (Table 2.10). Elution fractions were collected and analysed by SDS-PAGE (Methods 2.2.16 above).

Table 2.10 Isocratic elution steps for His-trap purification on the ÄKTA Start protein purification system.

\begin{tabular}{|l|l|l|l|}
\hline \multicolumn{2}{|l|}{ Step } & Lysis buffer & \multicolumn{2}{l|}{ Elution buffer } & \multicolumn{1}{l|}{ Column volumes } \\
\hline 1 & $65 \%$ & $35 \%$ & 10 \\
\hline 2 & $50 \%$ & $50 \%$ & 5 \\
\hline 3 & $20 \%$ & $80 \%$ & 5 \\
\hline 4 & $0 \%$ & $100 \%$ & 30 \\
\hline & & Total & 10 \\
\hline
\end{tabular}

\subsubsection{Protein Concentration}

Elution fractions containing the PaORP1 protein were concentrated using an Ultra-15 Centrifugal Filter Unit with 10 kDa molecular weight cut-off membrane (Sigma Aldrich Inc). The unit was centrifuged in a Sorvall LYNX 4000 Superspeed Centrifuge (Thermo Fisher Scientific, USA) 15,000g for 10 minute intervals until the volume was 1-2 $\mathrm{mL}$. The concentration was then measured using a Nanophotometer NP80 (Implen, München, Germany.)

\subsubsection{Size Exclusion Chromatography}

A Superdex 200 Increase 10/300 GL size exclusion column (GE Healthcare BioSciences, PA, USA) was connected to an ÄKTA Pure protein purification system. The column was equilibrated with degassed and filter sterilised milli-Q water before being washed with size exclusion buffer (Table 2.6). A $500 \mu \mathrm{L}$ sample of concentrated protein was loaded manually into the same valve, and run isocratically in size exclusion buffer at a flow rate of $0.75 \mathrm{~mL} / \mathrm{min}$. Fractions $(1.2 \mathrm{~mL})$ that showed a change in absorbance above the baseline at $280 \mathrm{~nm}$ were collected and analysed by SDS-PAGE (Methods 2.2.16 above). 


\subsubsection{Fluorescence Thermal Shift Assay}

A thermal shift assay was done using SYPRO Orange Protein Gel Stain (Sigma Aldrich Inc) in accordance with Lo, Aulabaugh, Jin, Cowling, Bard, Malamas and Ellestad ${ }^{92}$. The protein concentration was $<10 \mu \mathrm{M}$ and used a variety of buffers (Table 2.11) in a 48 well plate (Thermo Fischer Scientific). The final volume in each well was $20 \mu \mathrm{L}$, including $2 \mu \mathrm{L}$ of SYPRO Orange. Thermal melts were performed on a StepOnePlusTM Real-time PCR system (Applied Biosystems ${ }^{\mathrm{TM}}$, CA, USA). The 48 well plate was heated from 20 to $90^{\circ} \mathrm{C}$ with a heating rate of $0.5^{\circ} \mathrm{C} / \mathrm{mi}$. 
Table 2.11 Components of the buffer screen and 48-well plate set up.

\begin{tabular}{|c|c|c|c|c|c|c|c|c|}
\hline & 1 & 2 & 3 & 4 & 5 & 6 & 7 & 8 \\
\hline A & $\begin{array}{l}50 \mathrm{mM} \text { sodium } \\
\text { acetate-acetic acid } \\
50 \mathrm{mM} \mathrm{NaCl} \\
\mathrm{pH} 5.0\end{array}$ & $\begin{array}{l}50 \mathrm{mM} \text { sodium } \\
\text { MES } \\
50 \mathrm{mM} \mathrm{NaCl} \\
\mathrm{pH} 6.0\end{array}$ & $\begin{array}{l}50 \mathrm{mM} \text { bis-tris } \\
\text { chloride } \\
50 \mathrm{mM} \mathrm{NaCl} \\
\mathrm{pH} 6.5\end{array}$ & $\begin{array}{l}50 \mathrm{mM} \text { imidazole } \\
50 \mathrm{mM} \mathrm{NaCl} \\
\mathrm{pH} 7.0\end{array}$ & $\begin{array}{l}50 \mathrm{mM} \text { sodium } \\
\text { HEPES } \\
50 \mathrm{mM} \mathrm{NaCl} \\
\mathrm{pH} 7.0\end{array}$ & $\begin{array}{l}50 \mathrm{mM} \text { sodium } \\
\text { HEPES } \\
50 \mathrm{mM} \mathrm{NaCl} \\
\mathrm{pH} 7.5\end{array}$ & $\begin{array}{l}50 \mathrm{mM} \text { Tris } \\
\text { chloride } \\
50 \mathrm{mM} \mathrm{NaCl} \\
\mathrm{pH} 8.0\end{array}$ & $\begin{array}{l}50 \mathrm{mM} \text { glycl- } \\
\text { glycine } \\
50 \mathrm{mM} \mathrm{NaCl} \\
\mathrm{pH} 8.5\end{array}$ \\
\hline B & $\begin{array}{l}50 \mathrm{mM} \text { sodium } \\
\text { acetate-acetic acid } \\
50 \mathrm{mM} \mathrm{NaCl} \\
\mathrm{pH} 5.0\end{array}$ & $\begin{array}{l}50 \mathrm{mM} \text { sodium } \\
\text { MES } \\
200 \mathrm{mM} \mathrm{NaCl} \\
\mathrm{pH} 6.0\end{array}$ & $\begin{array}{l}50 \mathrm{mM} \text { bis-tris } \\
\text { chloride } \\
200 \mathrm{mM} \mathrm{NaCl} \\
\text { pH } 6.5\end{array}$ & $\begin{array}{l}50 \mathrm{mM} \text { imidazole } \\
200 \mathrm{mM} \mathrm{NaCl} \\
\mathrm{pH} 7.0\end{array}$ & $\begin{array}{l}50 \mathrm{mM} \text { sodium } \\
\text { HEPES } \\
200 \mathrm{mM} \mathrm{NaCl} \\
\mathrm{pH} 7.0\end{array}$ & $\begin{array}{l}50 \mathrm{mM} \text { sodium } \\
\text { HEPES } \\
200 \mathrm{mM} \mathrm{NaCl} \\
\mathrm{pH} 7.5\end{array}$ & $\begin{array}{l}50 \mathrm{mM} \text { Tris } \\
\text { chloride } \\
200 \mathrm{mM} \mathrm{NaCl} \\
\mathrm{pH} 8.0\end{array}$ & $\begin{array}{l}50 \mathrm{mM} \text { glycl- } \\
\text { glycine } \\
200 \mathrm{mM} \mathrm{NaCl} \\
\text { pH } 8.5\end{array}$ \\
\hline C & $\begin{array}{l}50 \mathrm{mM} \text { sodium } \\
\text { acetate-acetic acid } \\
200 \mathrm{mM} \mathrm{NaCl} \\
\mathrm{pH} 5\end{array}$ & $\begin{array}{l}50 \mathrm{mM} \text { citrate- } \\
\text { citric acid } \\
50 \mathrm{mM} \mathrm{NaCl} \\
\mathrm{pH} 6.0\end{array}$ & $\begin{array}{l}50 \mathrm{mM} \mathrm{ADA} \text { * } \\
50 \mathrm{mM} \mathrm{NaCl} \\
\mathrm{pH} 6.5\end{array}$ & $\begin{array}{l}50 \mathrm{mM} \text { sodium } \\
\text { MOPS } \\
50 \mathrm{mM} \mathrm{NaCl} \\
\mathrm{pH} 7.0\end{array}$ & $\begin{array}{l}50 \mathrm{mM} \\
\mathrm{Na} 2 \mathrm{H} / \mathrm{KH} 2 \text { phos } \\
50 \mathrm{mM} \mathrm{NaCl} \\
\mathrm{pH} 7.0\end{array}$ & $\begin{array}{l}50 \mathrm{mM} \\
\mathrm{Na} 2 \mathrm{H} / \mathrm{KH} 2 \text { phos } \\
50 \mathrm{mM} \mathrm{NaCl} \\
\mathrm{pH} 7.5\end{array}$ & $\begin{array}{l}50 \mathrm{mM} \\
\mathrm{Na} 2 \mathrm{H} / \mathrm{KH} 2 \text { phos } \\
50 \mathrm{mM} \mathrm{NaCl} \\
\mathrm{pH} 8.0\end{array}$ & $\begin{array}{l}50 \mathrm{mM} \text { CHES } \\
50 \mathrm{mM} \mathrm{NaCl} \\
\mathrm{pH} 9.0\end{array}$ \\
\hline D & $\begin{array}{l}50 \mathrm{mM} \text { sodium } \\
\text { acetate-acetic acid } \\
200 \mathrm{mM} \mathrm{NaCl} \\
\mathrm{pH} 5.5\end{array}$ & $\begin{array}{l}50 \mathrm{mM} \text { citrate- } \\
\text { citric acid } \\
200 \mathrm{mM} \mathrm{NaCl} \\
\mathrm{pH} 6.0\end{array}$ & $\begin{array}{l}50 \mathrm{mM} \text { ADA } \\
200 \mathrm{mM} \mathrm{NaCl} \\
\mathrm{pH} 6.5\end{array}$ & $\begin{array}{l}50 \mathrm{mM} \text { sodium } \\
\text { MOPS } \\
200 \mathrm{mM} \mathrm{NaCl} \\
\mathrm{pH} 7.0\end{array}$ & $\begin{array}{l}50 \mathrm{mM} \\
\mathrm{Na} 2 \mathrm{H} / \mathrm{KH} 2 \text { phos } \\
200 \mathrm{mM} \mathrm{NaCl} \\
\mathrm{pH} 7.0\end{array}$ & $\begin{array}{l}50 \mathrm{mM} \\
\mathrm{Na} 2 \mathrm{H} / \mathrm{KH} 2 \text { phos } \\
200 \mathrm{mM} \mathrm{NaCl} \\
\mathrm{pH} 7.5\end{array}$ & $\begin{array}{l}50 \mathrm{mM} \\
\mathrm{Na} 2 \mathrm{H} / \mathrm{KH} 2 \text { phos } \\
200 \mathrm{mM} \mathrm{NaCl} \\
\mathrm{pH} 7.5\end{array}$ & $\begin{array}{l}50 \mathrm{mM} \text { CHES } \\
200 \mathrm{mM} \mathrm{NaCl} \\
\mathrm{pH} 9.0\end{array}$ \\
\hline$E$ & $\begin{array}{l}300 \mathrm{mM} \mathrm{NaCl} \\
\mathrm{pH} 7.5\end{array}$ & $\begin{array}{l}500 \mathrm{mM} \mathrm{NaCl} \\
\mathrm{pH} 7.5\end{array}$ & $\begin{array}{l}50 \mathrm{mM} \mathrm{Na} 2 \mathrm{H} / \mathrm{KH} 2 \\
\text { phos } \\
50 \mathrm{mM} \mathrm{NaCl} \\
\mathrm{pH} 7.5+10 \% \\
\text { glycerol }\end{array}$ & $\begin{array}{l}50 \mathrm{mM} \mathrm{Na} 2 \mathrm{H} / \mathrm{KH} 2 \\
\text { phos } \\
200 \mathrm{mM} \mathrm{NaCl} \\
\mathrm{pH} 7.5+10 \% \\
\text { glycerol }\end{array}$ & $\begin{array}{l}50 \mathrm{mM} \mathrm{NaCl} \\
\mathrm{pH} 7.5+2 \mathrm{mM} \\
\text { DTT }\end{array}$ & $\begin{array}{l}200 \mathrm{mM} \mathrm{NaCl} \\
\mathrm{pH} 7.5+2 \mathrm{mM} \\
\text { DTT }\end{array}$ & Milli Q & H20 (Tap) \\
\hline
\end{tabular}

\footnotetext{
* $\mathrm{N}$-(2-acetamido)iminodiacetic Acid
} 
Chapter 3

Phosphite Formulations 


\subsection{Assessment of Agrichemical Formulation}

The results presented in this chapter were used to determine the $\mathrm{EC}_{50}$ values for varying phosphite agrichemical formulations against $P$. agathidicida isolate 3770 . The toxicity of all three commercial preparations of phosphite (Agri-Fos 600, Foschek and Phosgard), as well as the pure sodium phosphite salt, was assessed against the mycelial life stage of $P$. agathidicida. This adds to existing data on the direct toxicity of phosphite towards $P$. agathidicida ${ }^{19,93}$ but goes further, exploring the impact of other components of commercial phosphite formulations on $P$. agathidicida growth. The ability of a commercial adjuvant blend to increase the anti-oomycete effect of two plant-derived natural products was also assessed.

\subsection{Agrichemical Formulations}

The goal of the first experiment was to determine whether different commercial phosphite preparations had different inhibitory effects on $P$. agathidicida. While the concentration of phosphite could be standardised across agrichemicals, I aimed to discover whether the other components of each formulation affected activity.

$E_{50}$ values were estimated by inoculating $P$. agathidicida onto plates containing various concentrations of each agrichemical. Pure sodium phosphite was used as a control. The relative area of the mycelial mat on each plate was estimated by squaring the mean radius (Methods 2.2.4). The concentration values were logtransformed, as other studies have done ${ }^{19,93}$, and a normalised non-linear regression curve was generated for each data set (Figure 3.1). The $\mathrm{EC}_{50}$ values for each agrichemical, estimated from this analysis, are summarised in Table 3.1.

ANOVA detected no significant difference in $\mathrm{EC}_{50}$ between any of the agrichemicals (including pure phosphite). However, there was a clear visible difference in plate growth. $P$. agathidicida showed no growth when exposed to the commercial agrichemicals containing phosphite concentrations above $50 \mu \mathrm{g} / \mathrm{mL}$. Pure phosphite 
never completely inhibited growth. Some growth continued at $100 \mu \mathrm{g} / \mathrm{mL}$ and 200 $\mu \mathrm{g} / \mathrm{mL}$ of phosphite alone.

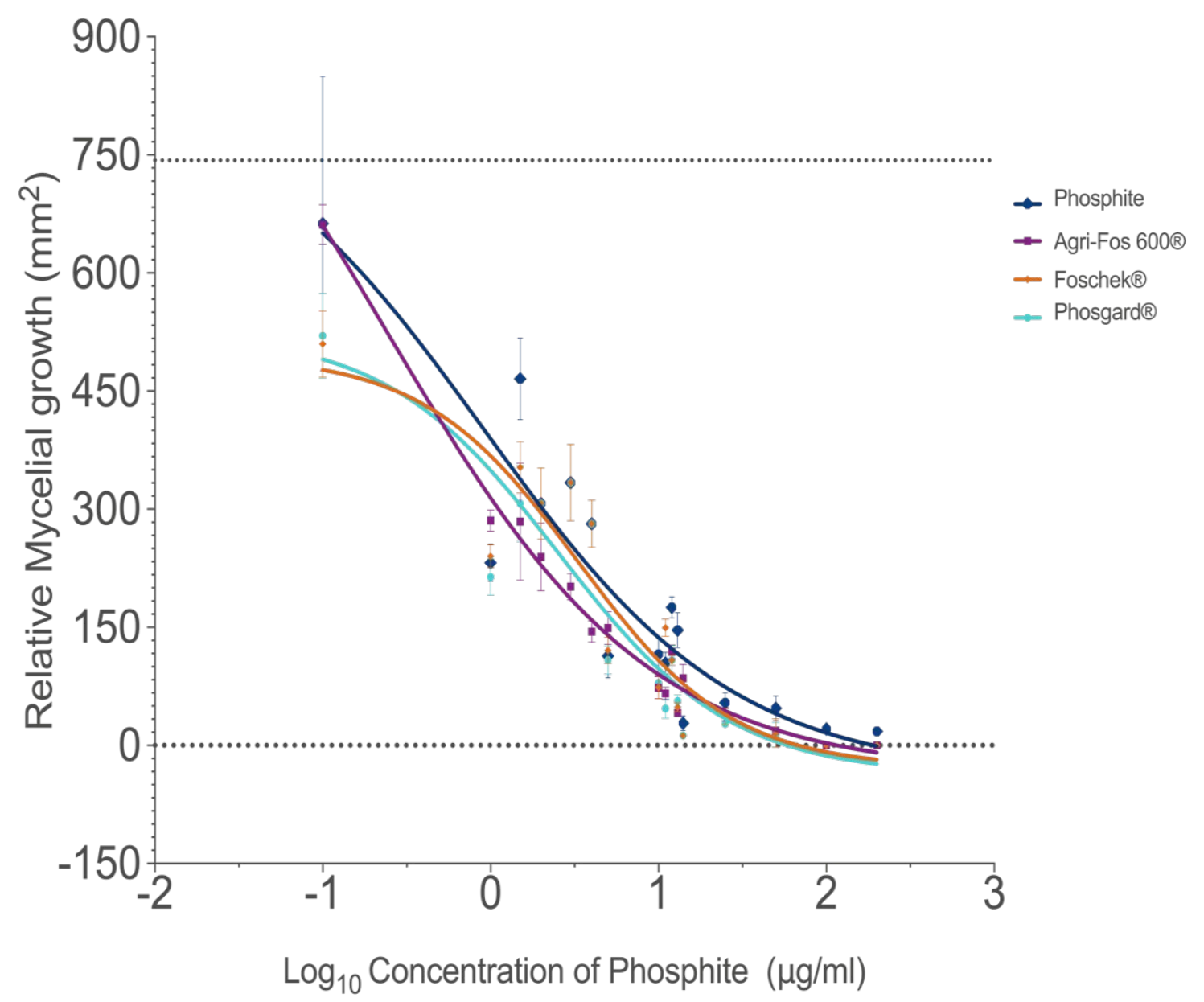

Figure 3.1 Agrichemical inhibition graphs.

Each data point on the graph is an average of mycelial growth ( $n=4$ independent biological replicates) in $\mathrm{mm}^{2}$, error bars are SD from the measurements. The dotted lines indicate zero growth, and uninhibited growth in the absence of agrichemical (normal growth). Original concentrations before log transformations were $\mu \mathrm{g} / \mathrm{mL}$ of phosphite. 
Table 3.1 EC50 values for inhibition of mycelial growth of $P$. agathidicida isolate 3770 with phosphite agrichemical formulations. Agri-Fos 600 , Foschek and Phosgard.

\begin{tabular}{|l|l|l|l|}
\hline \multicolumn{2}{|l|}{$E_{50}(\mu \mathrm{g} / \mathrm{mL})$} & $\mathrm{R}^{2}$ & $\begin{array}{l}85 \% \text { confidence intervals } \\
(\mu \mathrm{g} / \mathrm{mL})\end{array}$ \\
\hline Phosphite & 0.90 & 0.85 & \\
\hline Agri-Fos 600 & 0.24 & 0.98 & 0.0004 to 0.64 \\
\hline Foschek & 3.32 & 0.87 & 0.71 to 6.58 \\
\hline Phosgard & 2.54 & 0.86 & $8.01 \times 10^{-5}$ to 5.77 \\
\hline
\end{tabular}

I hypothesised that the three agrichemicals might cause complete inhibition because they were buffered to a different $\mathrm{pH}$ than pure sodium phosphite (which was unbuffered). However, when the $\mathrm{pH}$ was measured for each formulation, two (sodium phosphite and Agri-Fos 600) were basic $(\mathrm{pH}=8.0)$ and two (Foschek and Phosgard) were acidic $(\mathrm{pH}=5.9)$. Thus, it was unlikely the $\mathrm{pH}$ differences in the formulations were impacting the inhibition of $P$. agathidicida. There was so statistical difference between the $\mathrm{EC}_{50}$ measurements. It is likely the $\mathrm{pH}$ plays a role elsewhere and future experiments with a $\mathrm{pH}$ variation will need to be carried out if it does play a role elsewhere.

\subsection{Adjuvants and Surfactants}

Following the phosphite comparison, the adjuvants, surfactants and stabilising agents (which compromise over $60 \%$ of the formulation ${ }^{94}$ ) were assessed to determine their role in inhibition growth. Lonza provided their formulation for the adjuvants, surfactants and stabilising agents in Foschek under a confidentiality agreement. For simplicity, these other agents are referred to as adjuvants. The company also provided us with a pH-matched formulation of Foschek, minus the phosphite. This allowed a rigorous test of the contribution of adjuvants to growth inhibition. The non- 
linear regression curves were generated, and have $R^{2}$ values $>0.95$ for phosphite and the adjuvants (Figure 3.2). As expected, the adjuvants alone did not significantly inhibit growth of $P$. agathidicida isolate 3770 , although mild inhibition was observed with the undiluted adjuvant (far in excess of anything that could be applied in planta). On the other hand, mixing adjuvants with phosphite replicated the effect seen with Foschek; that is, complete growth inhibition could be observed at high concentrations (Figure 3.2 )

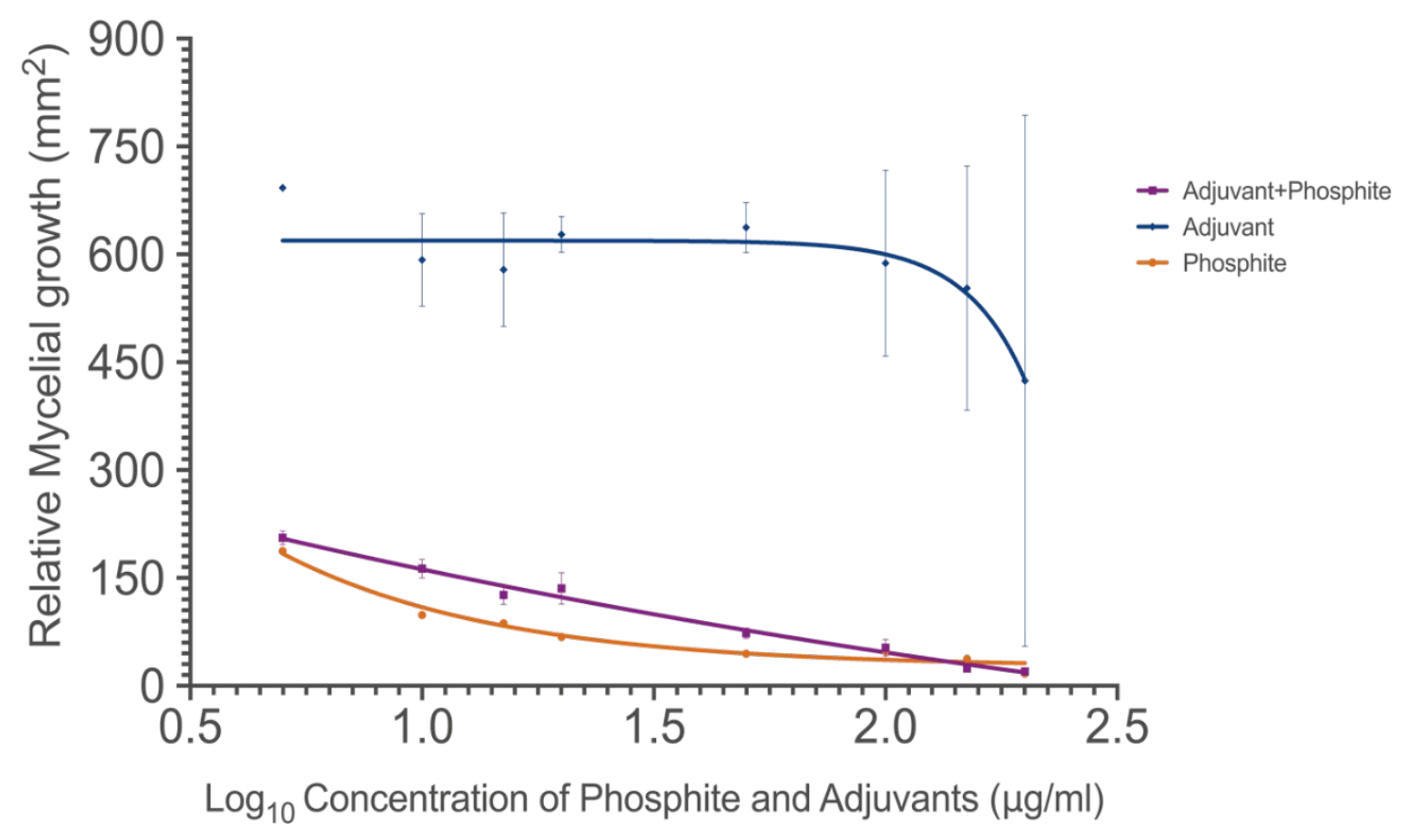

Figure 3.2 Inhibition of adjuvants, surfactants and stabilising agents.

The same concentrations were used as in figure 3.1 for all chemicals. The combination of phosphite salt and adjuvants were a 1:1 ratio.

\subsubsection{Natural Products and Adjuvants}

Next, I tested whether the Lonza adjuvant mixture was able to improve the inhibitory effects of the plant-derived natural products, polygodial and falcarindiol. The $\mathrm{EC}_{50}$ values for these pure compounds were previously determined to be $0.64 \mu \mathrm{g} / \mathrm{mL}$ and $2.9 \mu \mathrm{g} / \mathrm{mL}$, respectively (S. Lawrence, unpublished data). Mycelial growth inhibition was determined for concentrations above and below these $\mathrm{EC}_{50}$ values: $0.1-1 \mu \mathrm{g} / \mathrm{mL}$ for polygodial and $1-5 \mu \mathrm{g} / \mathrm{mL}$ for falcarindiol. The results were compared to the 
natural product used, without the commercial adjuvants. A stock of each natural product was mixed 1:1 (v/v) with the undiluted adjuvant formulation, and then this stock was diluted to the relevant working concentrations. The results of this experiment showed that the adjuvant mix had a dramatic effect on growth inhibition (Figure 3.3). Indeed, zero growth was observed at any tested concentration of either natural product, provided the adjuvants were present.
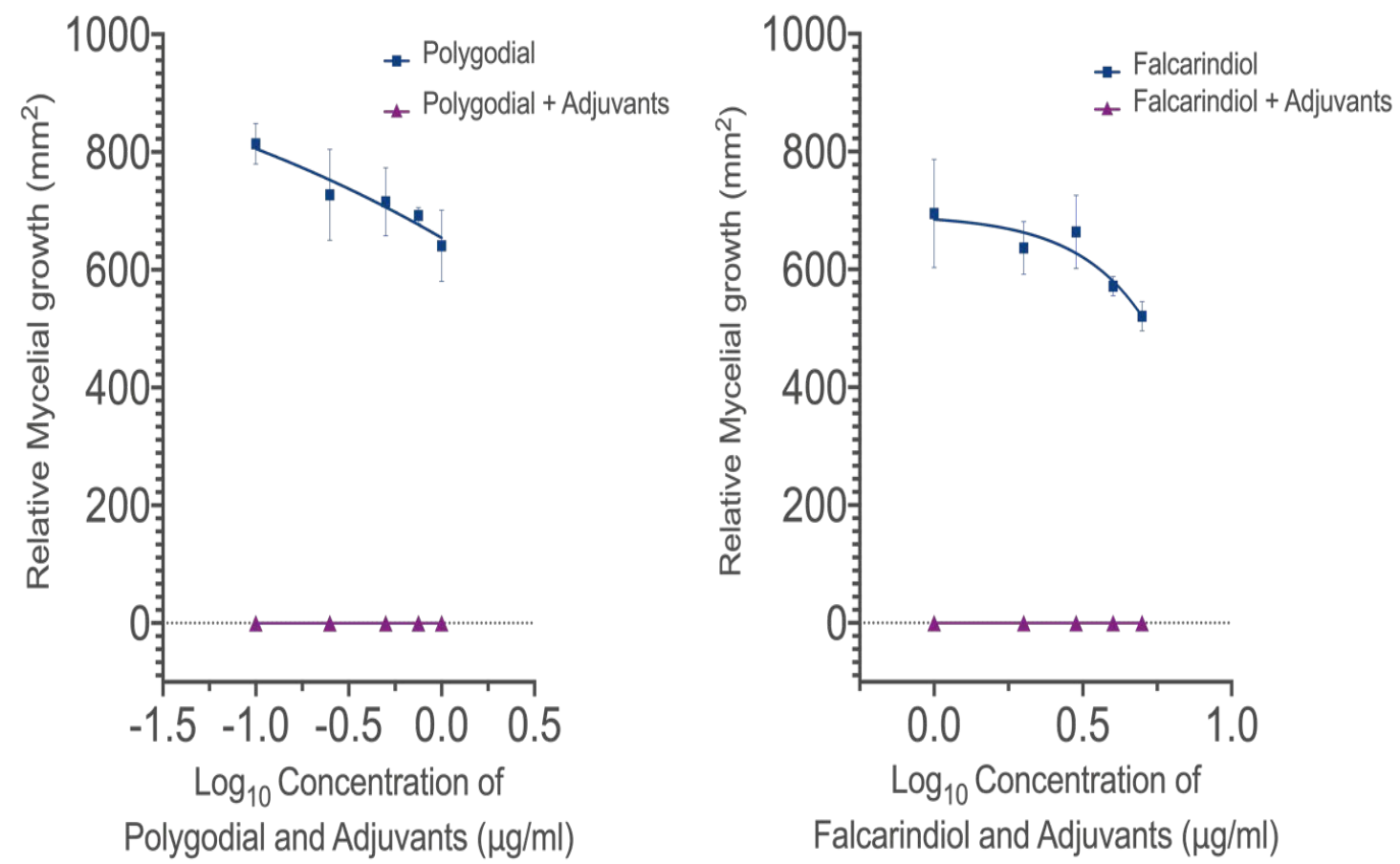

Figure 3.3 Natural products combined with the Lonza adjuvant mix.

Each point shows the mean and standard deviation for biological triplicates. No growth was observed in the case of the natural products with adjuvants, so the error bars are zero. The $x$-axis plots the $\log _{10}$ of natural product concentration in $\mu \mathrm{g} / \mathrm{mL}$.

\subsection{Discussion}

\subsubsection{Quantifying Growth Inhibition}

Currently, there is no standardised protocol for quantifying the growth and inhibition of Phytophthora mycelia. Previous research on $P$. agathidicida has used the distance grown outwards per day ${ }^{93}$ or the optical density of the mycelial mat in solution ${ }^{95}$, 
although I found the latter protocol to be extremely variable in preliminary experiments (data not reported). For studying the inhibitory effects of bioactive compounds, Armstrong used "the radius of the mat, as a percentage of the radius of a mat growing in the absence of bioactive" 19 .

In this work, I focused on a "relative area" measurement, rather than a "relative radius". Mycelial mats are not perfectly circular, so I measured the radius (from the agar plug to the edge of the mat) in six different locations of the mat. The average of these six measurements was then squared to yield a value that was proportional to the area of the entire mat. This method proved straightforward to implement, and accurately captured the relative mycelial growth that could easily be observed by eye.

\subsubsection{Phosphite $\mathrm{EC}_{50}$ Data}

Agri-Fos 600 is the only phosphite formulation that has previously been used in studies of $P$. agathidicida growth inhibition. The $\mathrm{EC}_{50}$ values reported in recent in vitro agar studies were $3.0 \mu \mathrm{g} / \mathrm{ml}$ and $4.0 \mu \mathrm{g} / \mathrm{ml}{ }^{19,93}$ and $0.0 \mu \mathrm{g} / \mathrm{ml}$ from the optical density based method ${ }^{54}$.

The data presented in this study contributes another layer to previous research, by testing whether specific formulations of phosphite alter $\mathrm{EC}_{50}$. While differences in $\mathrm{pH}$ were observed between the different formulations, overall there was no statistically significant differences in $\mathrm{EC}_{50}$ (Figure 3.1), and 95\% confidence intervals were unable to be calculated. However, $85 \%$ confidence intervals $(\mathrm{Cl})$ are in Table 3.1. On the other hand, it is noteworthy that some mycelial growth was observed even at the highest tested concentrations of pure sodium phosphite (above $50 \mu \mathrm{g} / \mathrm{mL}$ ), whereas the agrichemicals were able to prevent all growth at these elevated concentrations. 


\subsubsection{Using Adjuvants to Enhance the Bioactivity of Natural Products}

The results comparing pure phosphite with formulated agrichemicals led me to hypothesise that adjuvants and surfactants may increase the potency of antioomycete agents other than phosphite. As shown in Figure 3.3, this was found to be the case for polygodial and falcarindiol. When they were mixed with the adjuvant blend used in Foschek, they displayed significantly enhanced efficacy. Indeed, it was not possible to determine $\mathrm{EC}_{50}$ values for the mixtures, as complete growth inhibition was observed at the lowest concentrations tested. Future work will involve testing much lower concentrations of each active ingredient.

\subsubsection{Treatments for Kauri Dieback}

Phosphite agrichemical formulations could be used to treat kauri dieback. A welldeveloped agrichemical with adjuvants and surfactants could be put forward for field trials. 


\section{Chapter 4}

Investigating the Potential of Antimicrobial Resistance 
This chapter focussed on the potential evolution of resistance in $P$. agathidicida isolates. The protocol reported by Miao (2016) ${ }^{56}$ for evolving oxathiapiprolin resistance in $P$. capsici was adapted for use with polygodial, falcarindiol and pure sodium phosphite ${ }^{56}$. The $P$. agathidicida isolate 3770 was serially passaged on media amended with increasing concentrations of each compound. Once no further growth was observed, the evolved isolates were assessed for changes in $\mathrm{EC}_{50}$.

\subsection{Results}

\subsubsection{Serial Passaging}

The evolution experiment is outlined in Figure 4.1. Growth experiments were started on potato dextrose agar plates containing polygodial, falcarindiol or phosphite at a concentration equal to $0.25 \times \mathrm{EC}_{50}$. This was done to start the long-term passaging experiments under conditions that permitted growth but may favour beneficial mutations. At the time the experiment was started, our best estimates for $\mathrm{EC}_{50}$ values were $0.64 \mu \mathrm{g} / \mathrm{mL}$ for polygodial, $2.90 \mu \mathrm{g} / \mathrm{mL}$ for falcarindiol and $18.9 \mu \mathrm{g} / \mathrm{mL}$ for phosphite (although this was later shown to be an over-estimate; see Table 3.1). Therefore, the serial passages began with concentrations of $0.08,0.36$ and $2.3 \mu \mathrm{g} / \mathrm{ml}$ for the three compounds of interest.

The serial plating consisted of initially growing each inoculum in a set concentration and incubated for five days, or until the diameter of the mycelial mat reached $2 / 3$ that of the agar (whichever came first). A second layer of agar (at the same concentration) is then poured over the established growth, and incubated further as previously described (Methods 2.2.5). At that point, plugs were taken and used to start the next round of evolution on agar amended with chemical at twice the concentration of the previous plate. Additional plugs were stored in water for further analysis. Serial passaging continued until chemical concentrations were reached that resulted in no growth for 20 days. This was up to a total of 7 passages (Figure 4.1), comprising up to five months of constant chemical exposure. 


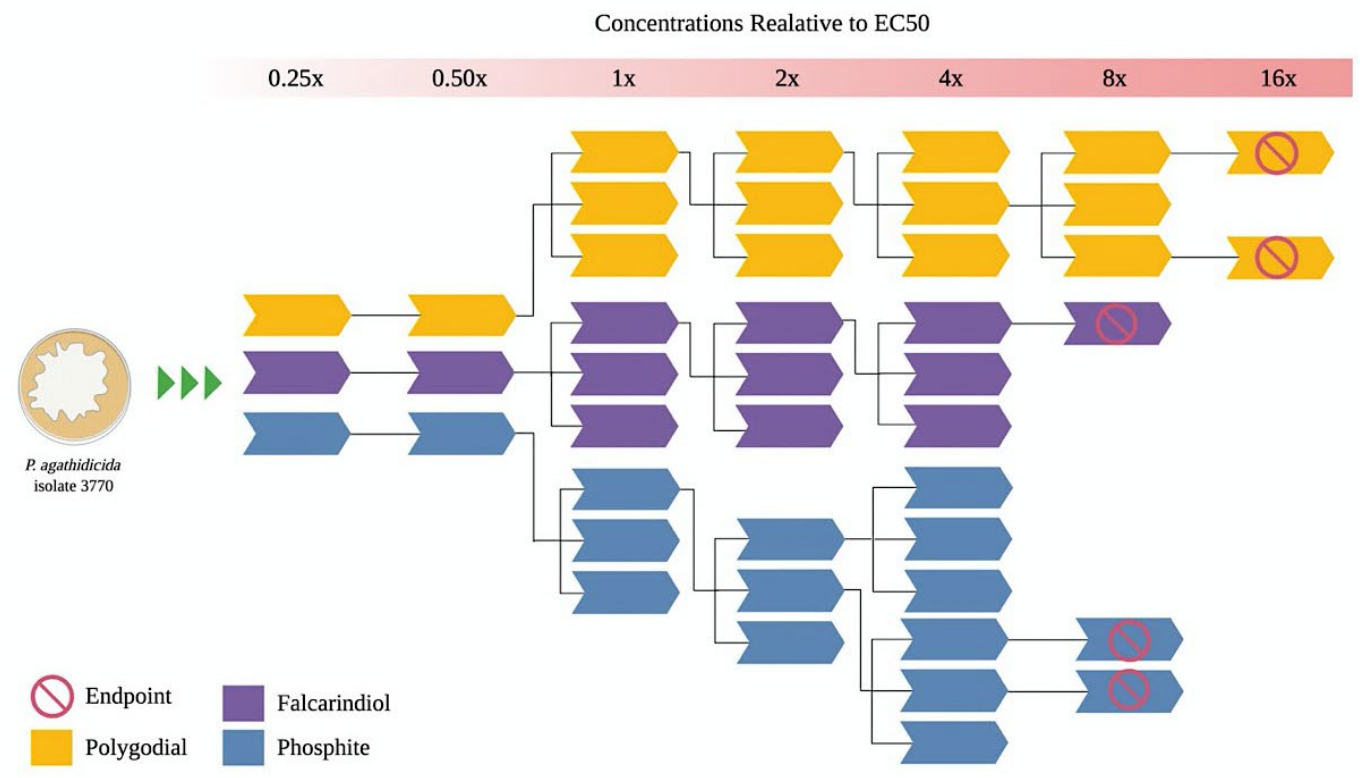

Figure 4.1 Flow diagram for evolving $P$. agathidicida for resistance towards polygodial, falcarindiol and phosphite.

Initial passages were performed on a single plate, until the $\mathrm{EC}_{50}$ was reached. For plating at the $\mathrm{EC}_{50}$ and beyond, three plugs were taken from each line and used to inoculate three independent plates. The fastest-growing clone(s) was used to inoculate three plates for the next round of evolution.

The extra $2 \mathrm{~mm}$ plugs were taken and stored in water were used later for assessing the parent isolate (3770) against its evolved strains.

\subsubsection{Serial Passaging in the Presence of Polygodial}

P. agathidicida grown in the presence of polygodial was the first to show a morphology change during the serial passaging process. This occurred at concentrations of $0.64 \mu \mathrm{g} / \mathrm{mL}$ (i.e. $1 \times \mathrm{EC}_{50}$ ) and beyond. The morphology changed from a regular, circular mat to random outcrops of mycelial growth. The appearance had irregular densities and a patchy texture (Figure 4.2), usually outside a period of regular mycelial growth. This change in morphology was seen frequently throughout the serial passages. The stored water plugs used to initiate further rounds of passaging were often taken from the mycelial area with this altered morphology. 


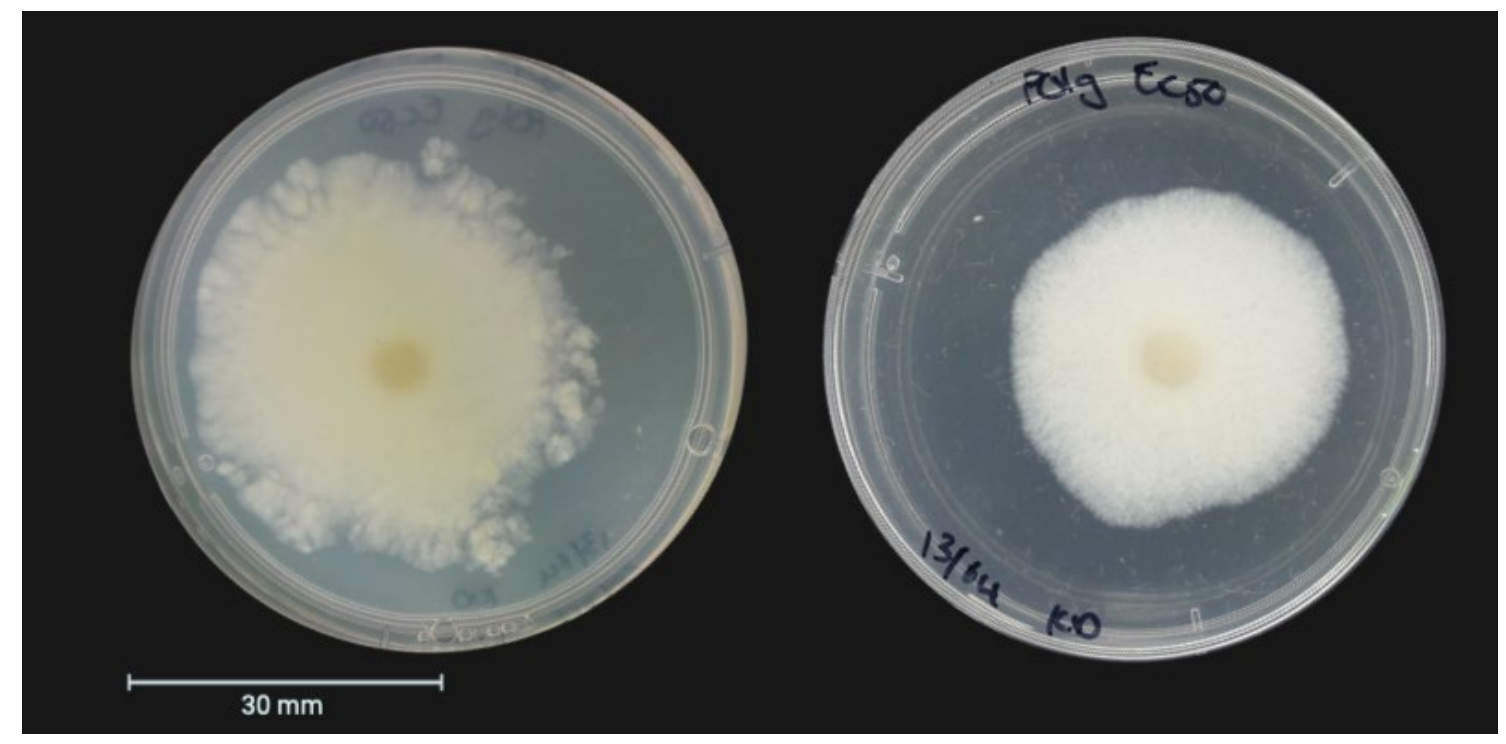

Figure 4.2. Morphology changes in polygodial at original $\mathrm{EC}_{50}, 0.64 \mu \mathrm{g} / \mathrm{mL}$.

This change in morphology was seen in a single round of evolution. Normal growth morphology is on the right, at $0.64 \mu \mathrm{g} / \mathrm{mL}$. The change was seen when the second layer of agar (at $0.64 \mu \mathrm{g} / \mathrm{mL}$ ) was poured over top and continued to grow (Left). These images were taken 5 days apart.

The growth rate was consistent during the early stages of the serial passage process. After plates with a new concentration of treatment were inoculated, there was often a period of normal growth. When the overlay was poured, there was a lag period of a few days before growth would resume at a steady rate. Higher concentrations of polygodial (above $2.5 \mu \mathrm{g} / \mathrm{mL}$ ) eventually decreased the overall growth rate.

While there were notable changes in morphology and growth rate (at all polygodial concentrations), these did not translate into statistically significant differences in $\mathrm{EC}_{50}$ (Figure 4.3). Under the conditions of this experiment, the parental strain $(P$. agathidicida isolate 3770$)$ showed $\mathrm{EC}_{50}=13.7 \mu \mathrm{g} / \mathrm{mL}(95 \% \mathrm{Cl} 10.82$ $22.68 \mu \mathrm{g} / \mathrm{mL}$ ). The evolved strain, isolated after 6 rounds of serial passaging, had an estimated $\mathrm{EC}_{50}=12.4 \mu \mathrm{g} / \mathrm{mL}$, another wild type isolate that had no previous exposure to the chemicals ( $P$. agathidicida isolate 3813$)$ was also tested and had an $\mathrm{EC}_{50}=13.49 \mu \mathrm{g} / \mathrm{mL}$. Overall, these data suggested that mutational processes had been occurring during the serial passaging, but they did not directly affect resistance 
to polygodial. The $95 \%$ confidence intervals $(95 \% \mathrm{Cl})$ were unable to be calculated for the evolved isolate and isolate 3813 due to the concentration range measured.

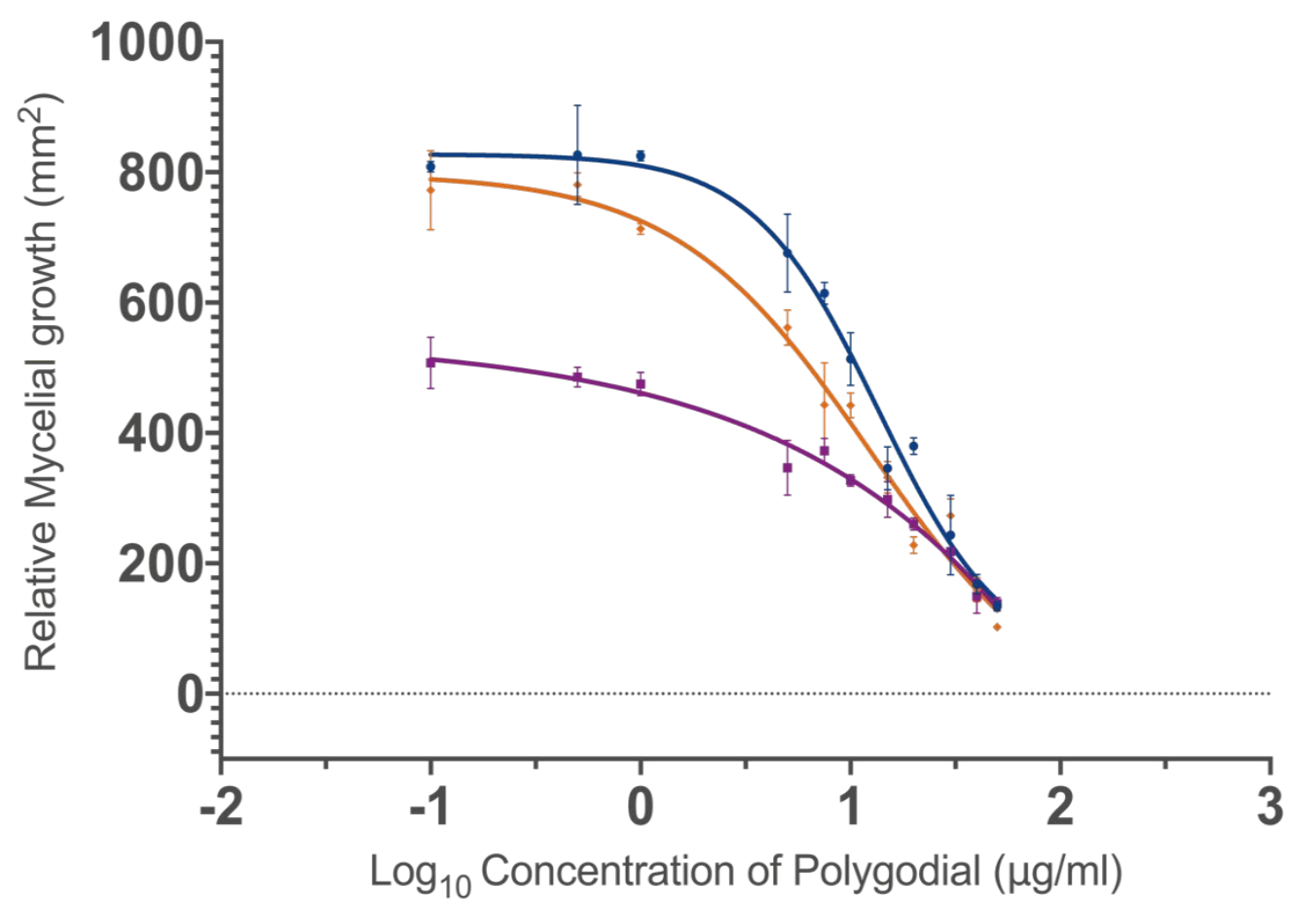

$\rightarrow$ Isolate 3770 - Evolved Polygodial _. Isolate 3813

Figure 4.3 Growth response curves for $P$. agathidicida 3770, the evolved isolate, and the $P$. agathidicida isolate 3813 .

All experimental data were fitted to the non-linear regression equation with $R^{2}>0.95$.

\subsubsection{Serial Passaging in the Presence of Falcarindiol}

P. agathidicida 3770 was also evolved by serial passaging in the presence of increasing falcarindiol concentrations. The growth in the presence of falcarindiol slowed significantly compared to the polygodial and phosphite evolutions during the serial passaging. The first inoculation layer at the start of each concentration increase was significantly reduced compared to the other evolutions (Phosphite and Polygodial). The growth normalised once the overlay of agar (Second layer) at the 
same concentration that was placed on top the established growth. This growth pattern continued until the end of the serial plating when plugs were used to inoculate a plate at $23.2 \mu \mathrm{g} / \mathrm{mL}\left(8 \times E_{50}\right)$ and then growth was not seen for $>20$ days.

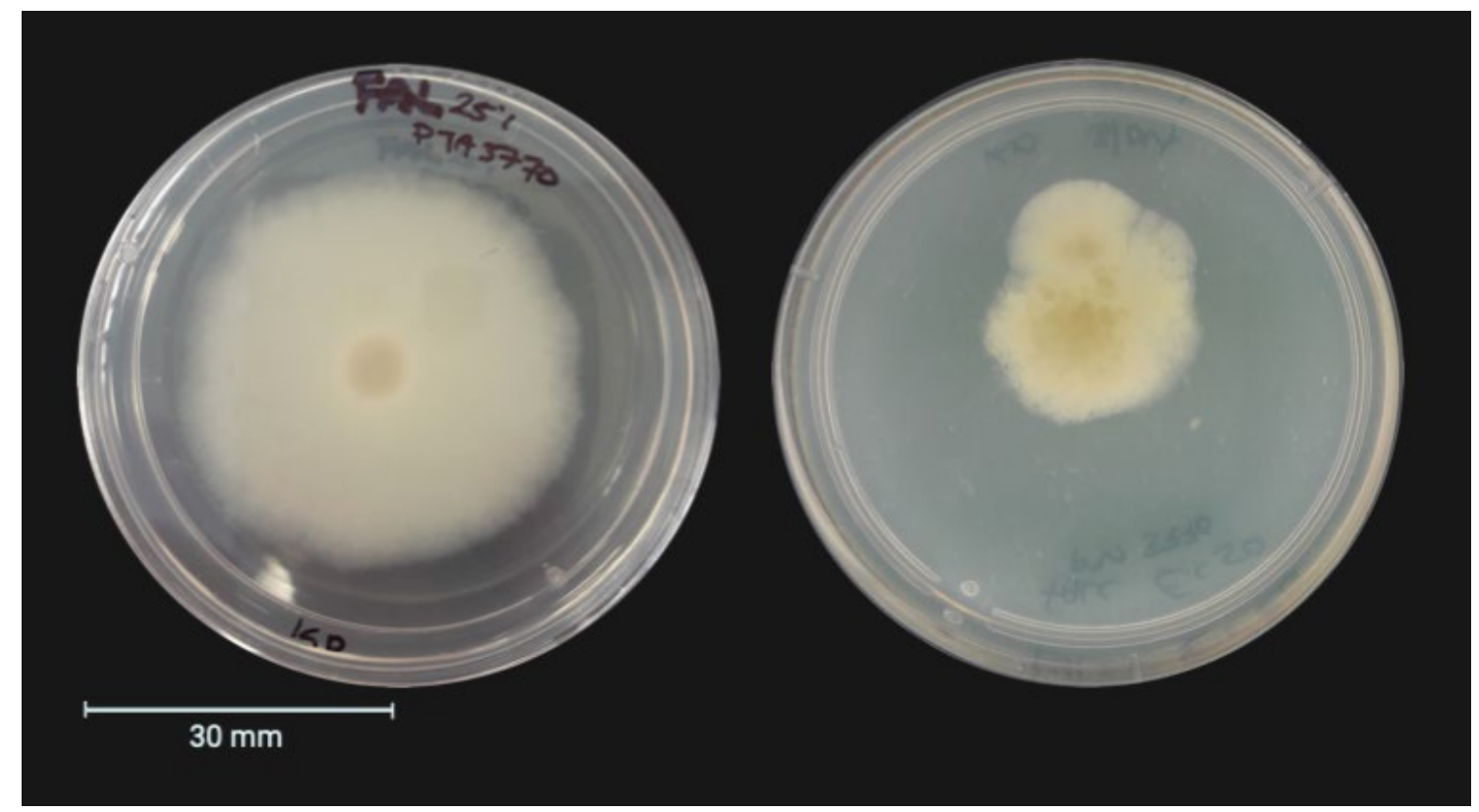

Figure 4.4. Morphology changes seen in Falcarindiol.

Normal growth of mycelial (Left) at $0.72 \mu \mathrm{g} / \mathrm{mL}(0.25 \times$ Ec50) and the change in morphology, an uneven mycelial surface at $2.9 \mu \mathrm{g} / \mathrm{mL}$ (Right). This change was seen after 15 days that included a the second layer of agar at $0.72 \mu \mathrm{g} / \mathrm{mL}$, a complete concentration increase $(1.44 \mu \mathrm{g} / \mathrm{mL})$ and inoculation at another higher concentration of $2.9 \mu \mathrm{g} / \mathrm{mL}\left(\mathrm{EC}_{50}\right)$.

$\mathrm{EC}_{50}$ values were determined for the isolate from the last round of evolution and the two wild type isolates 3770 and 3813. As shown in Figure 4.5, effects on mycelial growth rate and $\mathrm{EC}_{50}$ were both marginal. The previously reported $\mathrm{EC}_{50}$ for P. agathidicida 3770 was $2.9 \mu \mathrm{g} / \mathrm{mL}$ (S. Lawrence, unpublished data) and this study confirmed with this result, $\mathrm{EC}_{50} 3.0 \mu \mathrm{g} / \mathrm{mL}$, $(95 \% \mathrm{Cl} 2.5$ to $3.6 \mu \mathrm{g} / \mathrm{mL})$. Isolate 3813 was similar $\mathrm{EC}_{50} 3.3 \mu \mathrm{g} / \mathrm{mL}(95 \% \mathrm{Cl} 3.0$ to $3.8 \mu \mathrm{g} / \mathrm{mL})$. If anything, the evolved isolate was slightly more sensitive in this assay $\mathrm{EC}_{50} 2.3 \mu \mathrm{g} / \mathrm{mL}(95 \% \mathrm{Cl} 2.1$ to $2.5 \mu \mathrm{g} / \mathrm{mL})$ although none of the differences were significant when analysed in a one-way ANOVA using GraphPad prism 8. 


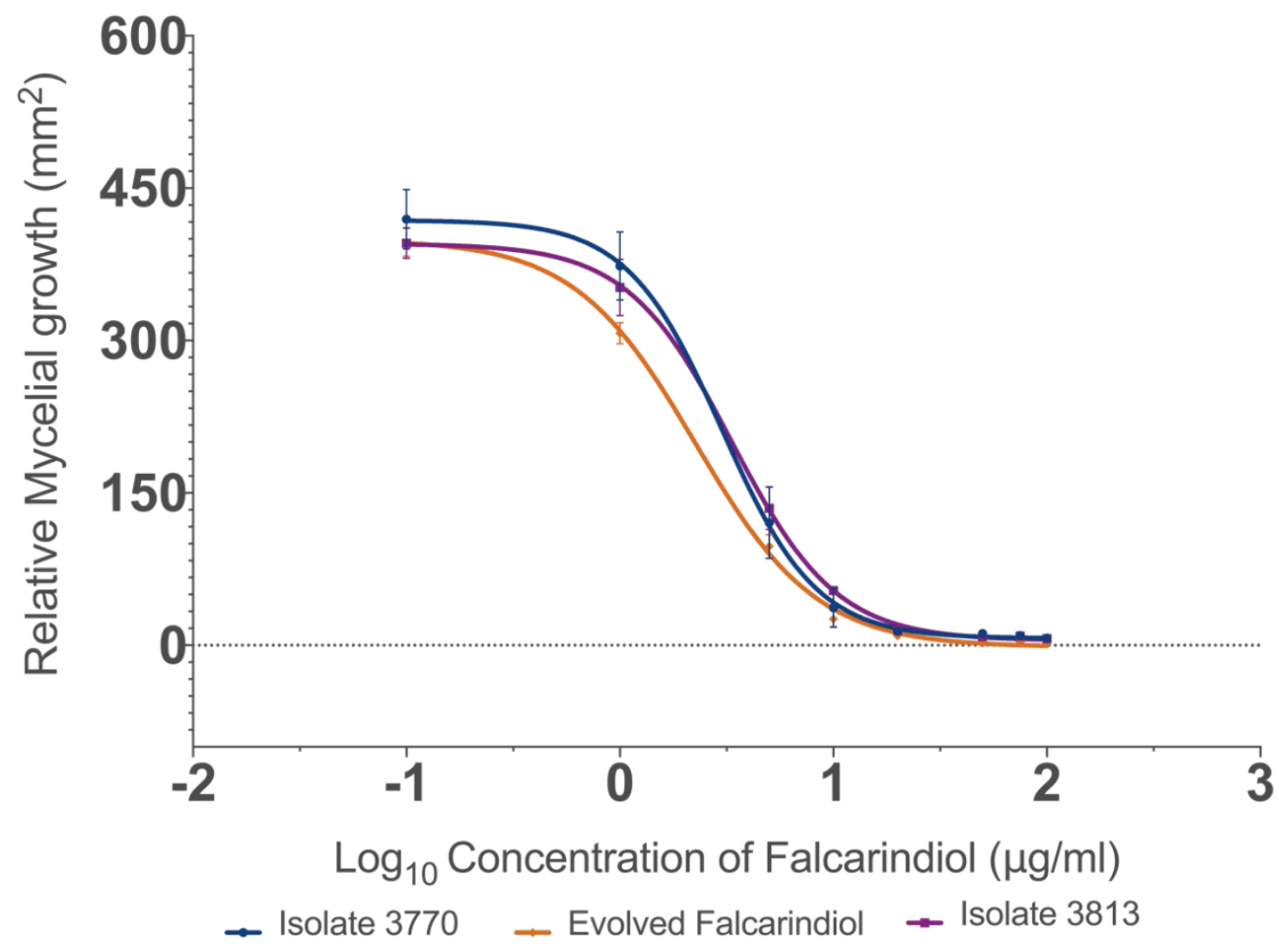

Figure 4.5 Evolution of falcarindiol, $P$. agathidicida isolates vs an evolved isolate. Growth response curved from the $P$. agathidicida isolate 3770 parent, the evolved isolate, and a $P$. agathidicida isolate 3813 . The $\mathrm{EC}_{50}$ are $3.00 \mu \mathrm{g} / \mathrm{mL}, 2.3 \mu \mathrm{g} / \mathrm{mL}$ and 3.4 $\mu \mathrm{g} / \mathrm{mL}$ respectively.

\subsubsection{Serial Passaging in the Presence of Phosphite}

Many factors led us to attempt the evolution of phosphite resistance. Some of these factors include recent studies showing that different isolates of the same Phytophthora species can be either sensitive or highly tolerant to phosphite ${ }^{55}$ and that ever-increasing concentrations of phosphite-based agrichemicals are being required to maintain control of Phytophthora species in California's citrus industry (implying the natural evolution of resistance) ${ }^{34}$.

In keeping with the results of the other two evolution experiments, serial passaging in the presence of increasing sodium phosphite did not yield an isolate with a significant difference in $\mathrm{EC}_{50}$. $P$. agathidicida isolate 3770 had a lower $\mathrm{EC}_{50}, 1.3 \mu \mathrm{g} / \mathrm{mL}$ 
(95\% Cl 1.0 to $1.6 \mu \mathrm{g} / \mathrm{mL}$ ) compared with isolate $3813, \mathrm{EC}_{50} 2.2 \mu \mathrm{g} / \mathrm{mL}$ (95\% $\mathrm{Cl} 1.8$ to 2.4 ). The evolved strain was similar to its ancestor with an $\mathrm{EC}_{50}$ of $1.4 \mu \mathrm{g} / \mathrm{mL}(95 \% \mathrm{Cl} 1.03$ to $1.8 \mu \mathrm{g} / \mathrm{mL})$

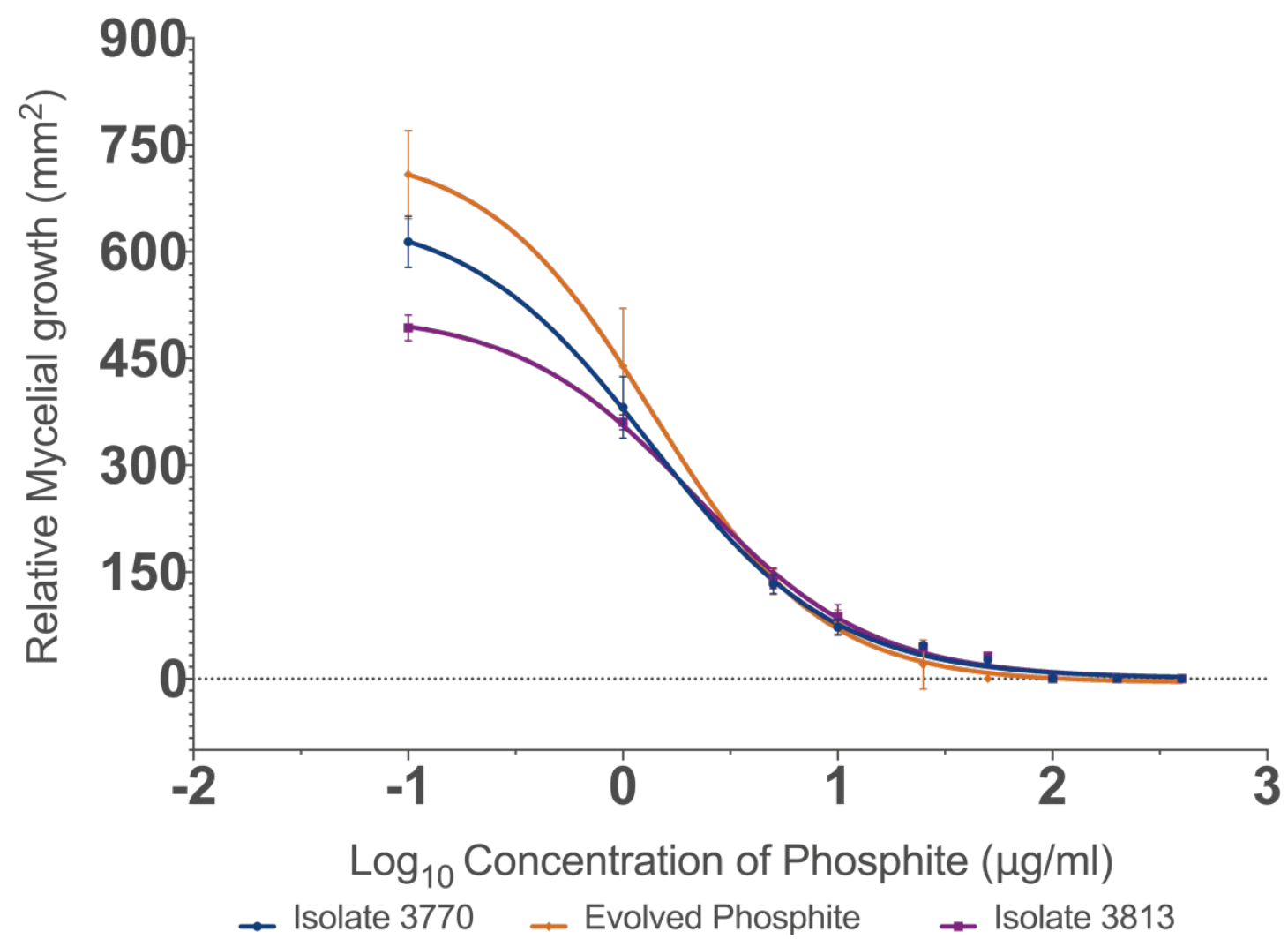

Figure 4.6 Evolution of Phosphite, P. agathidicida isolates vs an Evolved isolate. Growth response curved from the $P$. agathidicida isolate 3770 parent, the evolved isolate, and a $P$. agathidicida isolate 3813 . The $\mathrm{EC}_{50}$ measurements are $1.35 \mu \mathrm{g} / \mathrm{mL}, 1.4$ $\mu \mathrm{g} / \mathrm{mL}$ and $2.15 \mu \mathrm{g} / \mathrm{mL}$ respectively.

\subsection{Discussion}

\subsubsection{Resistance Assessment}

Other Phytophthora species have evolved resistance to traditional systemic fungicides in a relatively short period. Pyrimorph, zoxamide, and mandipropamid were all introduced during the early 2000's and already have well studied resistance mechanisms in P. capsici, $P$. sojae, $P$. infestans $22,47,49,50,52,96$. Here, we were unable 
to establish whether resistance to polygodial, falcarindiol or phosphite treatments evolved in P. agathidicida.

Unexpectedly, all three chemicals did not show an increase in $\mathrm{EC}_{50}$ from the ancestor (Isolate 3770) and the evolved strains. The inclusion of isolate 3813 was initially as a sensitive isolate compared to Isolate 3770 and the directed evolution isolates. However, isolate 3813 was more resistant than expected. Isolate 3813 continued to be included to address geographical isolate variability and sensitivity ${ }^{55}$, and an extra standard for comparison.

The protocols I adapted from Miao $(2016)^{56}$ was carried out for shorter periods of time than the original experiments. The original protocol slowly evolved $P$. capsici in 15-20 day cycles, and until the growth rates for the isolates were the same as normal growth on potato dextrose agar. Further adaptations of the protocol for $P$. agathidicida could include a longer period of exposure to the chemical and smaller incremental increases in concentration. The changes in phenotype seen in response to polygodial and falcarindiol indicate that some intracellular changes are occurring, even though these were not reflected in $\mathrm{EC}_{50}$. This could be due to cytotoxicty of the compounds or mutations. Sequencing the genomes of the parental and evolved isolates would be necessary to confirm any mutations due to these chemicals.

\subsubsection{Solvent Used to Dissolve Natural Products}

One unexpected finding from my experiments was the high $\mathrm{EC}_{50}$ values for polygodial (Figure 4.5). The serial passaging experiment was designed based on the $\mathrm{EC}_{50}$ value determined by our collaborator, Dr Scott Lawrence (University of Otago). He reported an $\mathrm{EC}_{50}$ of $0.68 \mu \mathrm{g} / \mathrm{mL}$ for $P$. agathidicida 3770 , while I obtained a value of $13.7 \mu \mathrm{g} / \mathrm{mL}$. A potential reason for this may be due to the solvents used in the experiments. S. Lawrence used an alcohol extract while I used DMSO dissolved solution. The highest concentration tested using the alcohol extracted polygodial was $10 \mu \mathrm{g} / \mathrm{mL}$, while our polygodial DMSO solution concentration went up to 50 $\mu \mathrm{g} / \mathrm{mL}$. The solvent in which polygodial is dissolved may impact the growth of $P$. agathidicida. 
The actual $\mathrm{EC}_{50}$ for our experiment is likely the $\mathrm{EC}_{50}$ of between 13.7 and 13.49 $\mu \mathrm{g} / \mathrm{mL}$, as determined by isolate 3770 , and isolate 3813 . Under these conditions there may not have been enough of a selection pressure. More experiments are required to determine the effect the solvent has on $P$. agathidicida and further concentration ranges measured.

\subsubsection{Long Term Implications for Kauri Dieback.}

The evolved $\mathrm{EC}_{50}$ measurements did not differ significantly to the geographical isolate 3813 in our forced evolution. This indicates that it is likely $P$. agathidicida does not evolve resistance quickly. While this was the first attempt at forced evolution, it should be an avenue that continues to be explored and assessed for all potential treatments of kauri dieback. This gives hope for a long term response for kauri dieback. 


\section{Chapter 5}

Protein Characterisation 
This section of research focuses on the $P$. agathidicida PaORP1 gene and the expression of the Oxysterol binding domain (ORD) of the PaORP1 protein. ORP1 was identified as the gene target for oxathiapiprolin. Oxathiapiprolin was developed as a specific anti-oomycete compound and has a known resistance mutation in $P$. capsici 56. A single point mutation resulting in a glycine to tryptophan substitution in the PcORP1 protein.

The PaORP1 gene produces oxysterol binding proteins that traffic sterols and oxysterols throughout the cell. The structure and function of OSBPs are limited to the general mechanism, i.e. golgi to endoplasmic reticulum transport. Furthermore, humans and yeast have been the only organisms extensively researched for structure and function of OSBP thus far.

The PaORP1 gene was identified, amplified, annotated, and assessed for genetic diversity. Wild type and mutant (glycine 771 to tryptophan, G771W) ORD domains from PaORP1 were commercially synthesised, then expressed in $E$. coli and purified.

\section{$5.1 \quad$ Results}

\subsubsection{Bioinformatics}

The $P$. capsici, $P$. infestans, and $P$. sojae ORP1 sequences were obtained from Andreassi, Gutteridge, Pember, Sweigard and Rehberg ${ }^{90}$. These were aligned to an unannotated draft genome of $P$. agathidicida isolate $3772{ }^{86}$. This analysis identified a $P$. agathidicida gene with high sequence identity to these known ORP1 genes. In particular, the candidate PaORP1 was $73 \%$ identical to the $P$. capsici gene sequence, $69 \%$ identical to the $P$. infestans gene sequence, and $67 \%$ identical to the $P$. sojae sequence. The PaORP1 gene is 3323 base pairs (bp).

Kamoun ${ }^{11}$ identified key molecular genetic features of oomycete genomes. The transcriptional start site for PaORP1 is predicted to be 216 bp upstream of the start codon. Kamoun ${ }^{11}$ identified consensus splice sites for introns (5' GTRNGT... YAG 3') and PaORP1 has one set of these sequences, suggesting that it possesses one 
intron. The upstream splice site (5' GTACT 3') is located 328 nucleotides from the transcriptional start site, while the $3^{\prime}$ splice site is 90 bp downstream. The position and relative size of the intron are shown in Figure 5.1.

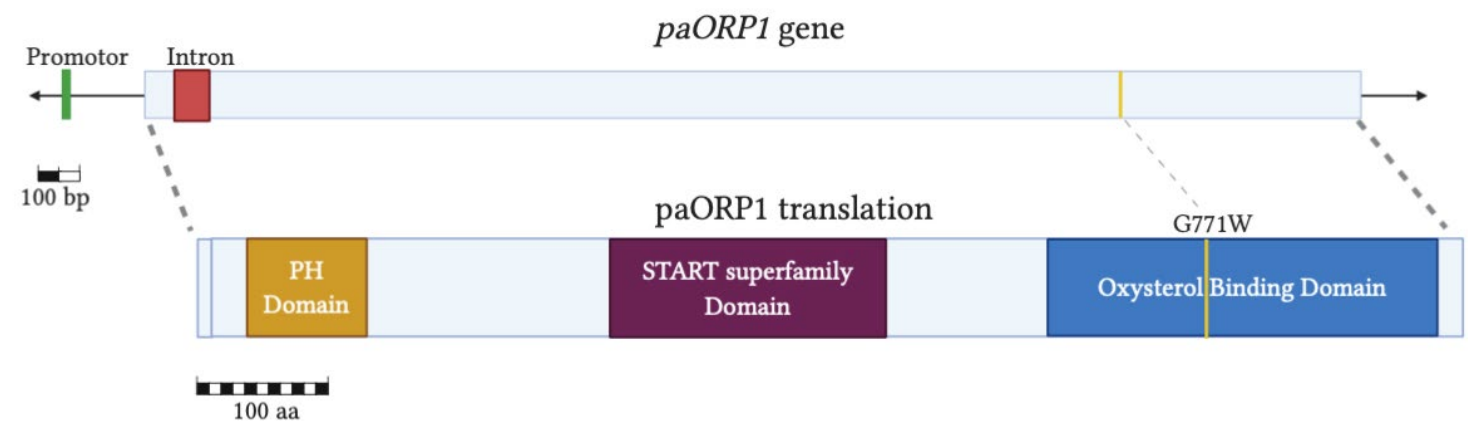

Figure 5.1. PaORP1 gene and protein annotation.

The gene was annotated based on the information provided Kamoun ${ }^{11}$. The translated polypeptide contains the typical domains found within the longer oxysterol binding proteins, as well as oxysterol binding protein-related proteins.

When the intron is spliced out, it removes two unfavourable stop codons in the predicted protein sequence. The protein produced from this gene contains 961 amino acids.

\subsubsection{Gene Sequencing}

To assess possible sequence diversity at the PaORP1 locus, genomic DNA was prepared from five geographically distinct isolates of $P$. agathidicida (Materials Table 2.1). In spite of a standardized protocol (Methods 2.2.6 - 2.2.9) total yields of genomic DNA were variable, ranging from $850 \mathrm{ng}$ to $20,800 \mathrm{ng}$ of DNA from $40 \mathrm{mg}$ of mycelial mat tissue.

The PaORP1 gene was amplified from the genomic DNA preparations. As the gene length was quite long (3379 bp), four different forward primers were designed for use in amplification and subsequent sequencing. Despite many attempts to optimise the 
reaction conditions, amplification of the full-length gene was not achieved using the primers OSBP_For1 and OSBP_Rev. On the other hand, primers OSBP_For2, OSBP_For3 and OSBP_For4 all worked with OSBP_Rev, albeit with variable yields of the product

There are several mutations in the P. capsici ORP1 gene (pcORP1) that are known to give resistance to oxathiapiprolin ${ }^{58}$. These mutations are all found in an area of 200 amino acids, from position 700 to 900 , which is located in the oxysterol binding domain (ORD) (Figure 5.1) Fortunately, the DNA encoding this region is contained within the PCR product resulting from amplification with OSBP_For4 and OSBP_Rev.

Sequencing with OSBP_For4 revealed that $P a O R P 1$ was almost identical to the pcORP1 gene in the resistance-causing positions. The only differences were that Thr768 in pcORP1 was a serine in PaORP1 and Phe877 was replaced by histidine.

The sequencing data also showed that all five $P$. agathidicida isolates had identical sequences in this region of the PaORP1 gene. None contained any of the known oxathiapiprolin resistance mutations. For example, the G769W mutation is known to confer resistance in $P$. capsici ${ }^{56}$. The equivalent residue in PaORP1 is G771, which was conserved as glycine in all five sequenced isolate (Materials Table 2.3).

\subsubsection{Gene Synthesis and Protein Modelling}

The online prediction tools SWISS-MODEL ${ }^{91}$ and CDART ${ }^{97}$ were used to predict the boundaries of the conserved protein domains and a protein structure. The structure of the ORD from the Saccharomyces cerevisiae OSBP homologue (Osh), Kes1/Osh4, had been determined previously by others ${ }^{66}$. This aided in the definition of the PaORP1 ORD, located from amino acids 620 to 940 . The homology model generated by SWISS-MODEL suggested that the $\mathrm{N}$-terminus begins almost immediately as an alpha helix, before becoming the characteristic almost beta-barrel and cap formation previously defined by Im, Raychaudhuri, Prinz and Hurley ${ }^{66}$ (Figure 5.2). 

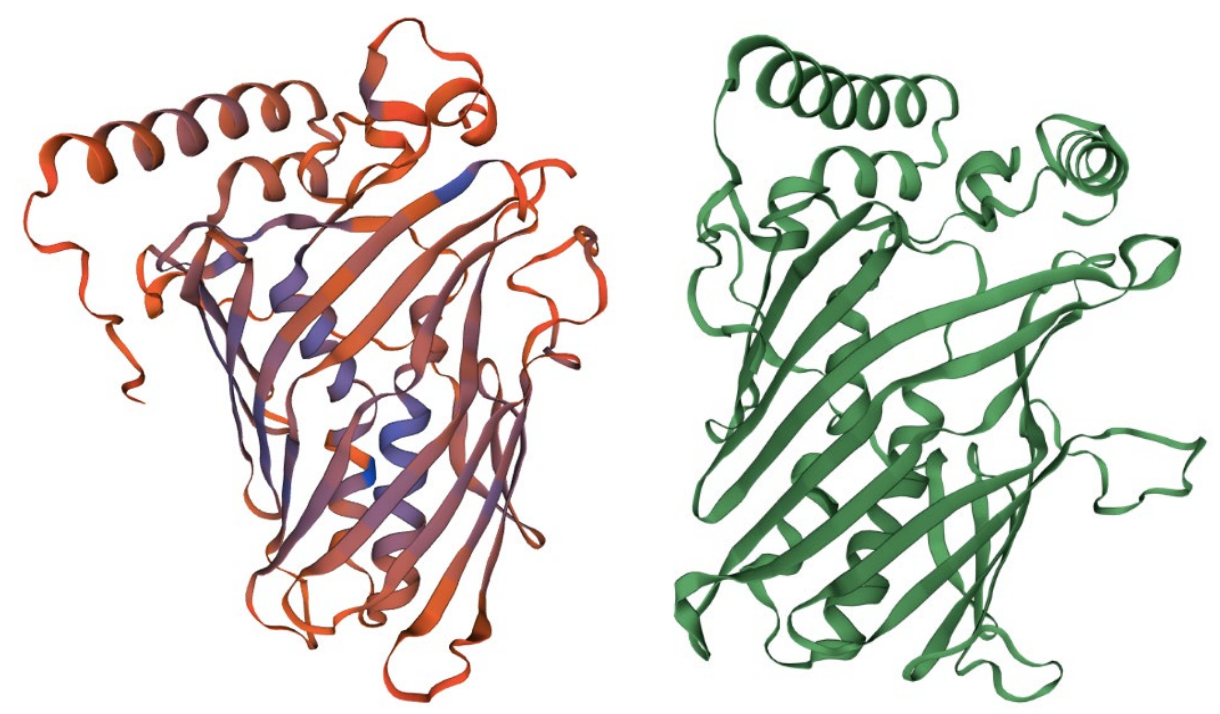

Figure 5.2. Structures of ORDs for PaORP1 and KES1/Osh4.

Predicted structure of PaORP1 (Red) from SWISS-MODEL ${ }^{91}$ next to the known structure of the KES1 ORD (Green).

The DNA sequence encoding the ORD was optimized for expression in E. coli, synthesized, and cloned into the expression vector pET28a by Twist Bioscience (San Francisco, CA, USA). The cloned insert also encoded an $\mathrm{N}$-terminal $\mathrm{His}_{6}$ tag, followed by a cleavage site for the tobacco etch virus (TEV) protease. A gene encoding the G771W mutation, predicted to impart oxathiapiprolin resistance, was also synthesized and cloned by Twist Bioscience.

\subsubsection{Confirmation of Plasmid Insert.}

A restriction enzyme digest was performed to confirm the size of the PaORP1 insert in the pet28a plasmid. Twist Bioscience had cloned the insert as an $\mathrm{Ncol} / \mathrm{Xhol}$ fragment, while a Kpnl site was located inside the PaORP1 gene. Digestions with combinations of these enzymes showed the expected banding patterns (Figure 5.3). For example, the Kpnl-Xhol digest shows a 944 bp fragment of the paORP1 insert, and the remaining $5286 \mathrm{bp}$ fragment of the pet28a vector. The Ncol-Xhol digest that also confirms the presence of the inserted sequence for both the wild type and mutant. 


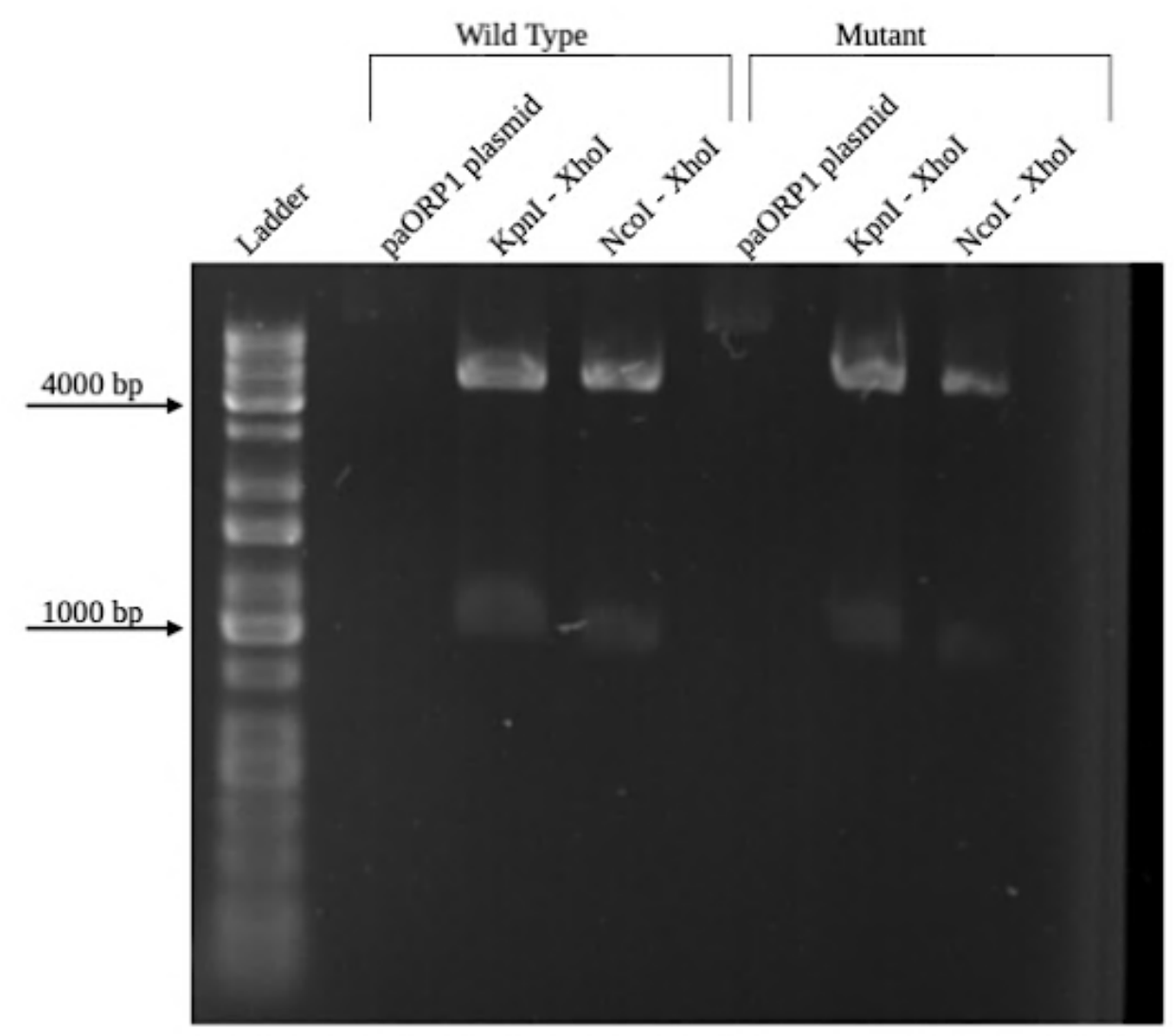

Figure 5.3. Enzyme Digest of PaORP1 pet28a plasmid.

Results of a Kpnl - Xhol, and Ncol- Xhol digest for both PaORP1 pet28a plasmids.

Columns 2-4 are Wild type plasmid, and 5-7 are the Mutant G771W plasmid.

\subsubsection{Initial Protein Expression and Purification.}

E. coli strain BL21 Gold was used for initial expression trials of PaORP1 wild type and PaORP1 mutant (G771W) (Materials 2.1.3 and 2.1.4). Interestingly, after overnight induction, the following morning yielded two very different cultures. The culture expressing PaORP1 mutant (G771W) was saturated, whereas the culture expressing PaORP1 wild type had not appeared to increase in optical density after protein expression was induced.

As expected, based on the culture observations, SDS-PAGE gel electrophoresis showed that PaORP1 wild type had not been expressed. However this was due to human error and was addressed in a follow up experiment. On the other hand, 
PaORP1 (G771W) was expressed initially and was able to be purified using metal affinity chromatography.

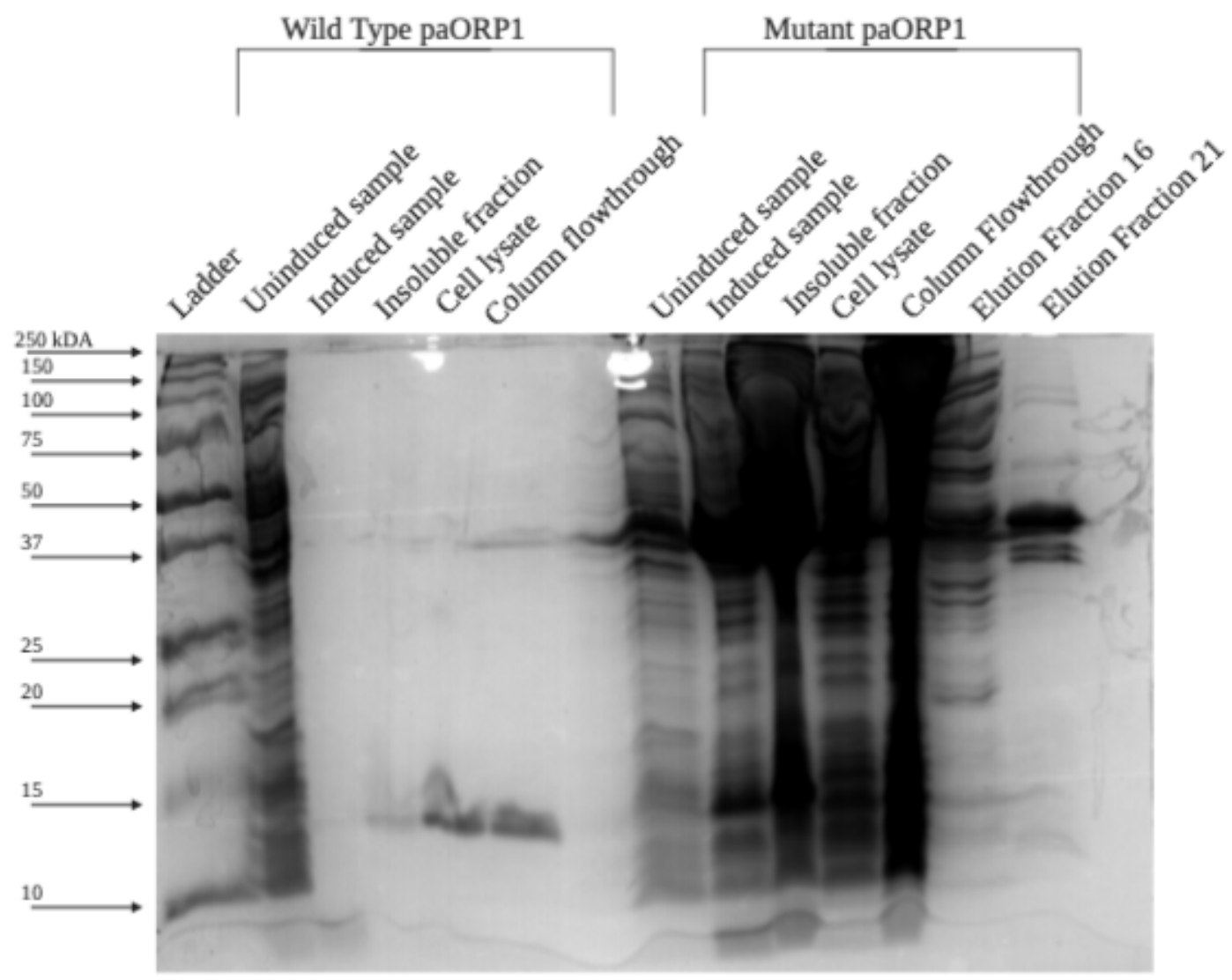

Figure 5.4. Initial expression and purification trials of PaORP1 proteins (Wild type and Mutant).

The uninduced sample was taken before IPTG was added to the broth. The induced sample was taken after the overnight incubation. The soluble cell lysate and insoluble samples were taken for comparison after the cells were lysed by sonication. A Column flow through sample was taken to the ensure that our PaORP1 sample bound to the column. For the mutant protein, the elution fraction showing the highest A280 absorbance peak was also analysed. Fraction 16 gives an indication of all the proteins that bind to the his-trap column, while elution fraction 21 contains PaORP1 ( 37kDA). 


\subsubsection{Optimisation of Purification}

After the initial expression and purification trials, an extensive series of optimisation experiments were undertaken. All changes made to the purification methodology are applicable to both the wild type and mutant PaORP1, and various experiments were conducted with each protein. Therefore, in this section of results, they will not be distinguished.

The first changes were the addition of $10 \%$ glycerol and $5 \mathrm{mM} \beta$-mercaptoethanol to all the purification buffers (i.e. lysis, wash and elution buffers). The lysis method was also changed from sonication to French-press. The additional components of the lysis buffer increased the soluble protein abundance from $<0.3 \mathrm{mg}$ to $0.68 \mathrm{mg}$ while French-press increased the yield of soluble protein to $1.56 \mathrm{mg}$ to $2.5 \mathrm{mg}$.

Terrific broth (TB) and IPTG were also switched to an autoinduction medium. In part, the switch was to help control bacterial pellet size. Overnight growth in TB produced up to $30 \mathrm{~g}$ of bacterial pellet per litre. Autoinduction medium cut this down significantly to $15-20 \mathrm{~g}$, which made it easier to resuspend in the $30 \mathrm{~mL}$ volume required to use the French-press.

Another change to the protein purification method was the addition of the detergent, Tween-80, to the lysis buffer only. This also increased the yield of soluble protein to $4.5 \mathrm{mg}$ to $6.5 \mathrm{mg}$. The effect of each change in the protocol is summarised in Figure 5.6. In addition, exchange from elution buffer (containing high concentrations of imidazole) to storage buffer was attempted using both centrifugal diafiltration and dialysis. The latter method was found to minimise aggregation and precipitation of the purified protein. 


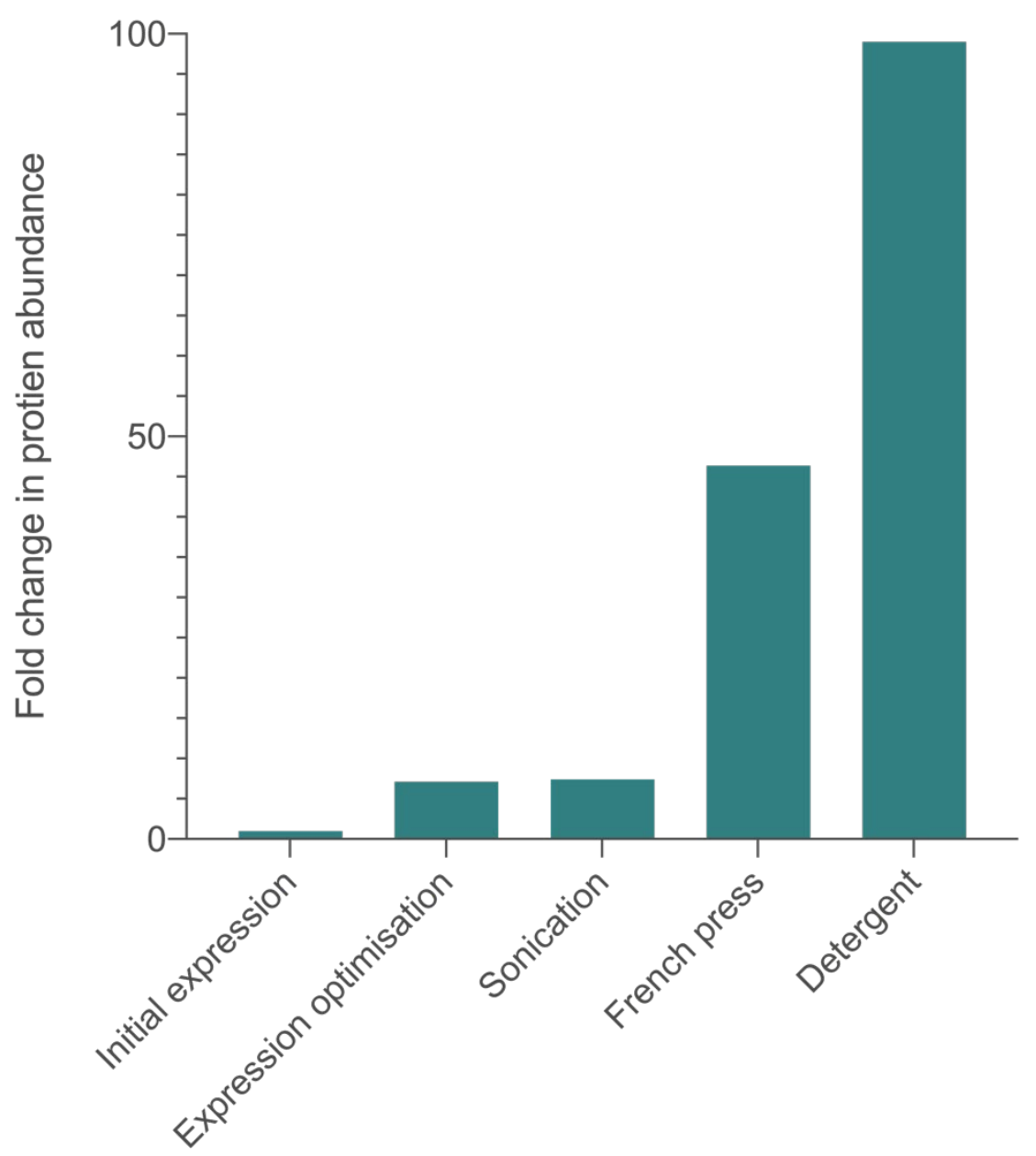

Adjustments to purifircation method

Figure 5.5. Changes in protein abundance associated with the optimisation of the protocol.

A comparison of protein abundance compared to the initial expression (set to a relative abundance of 1). Listed here are step in the purification where a significant increase in protein abundance was observed.

In the initial test (Results 5.1.5), most expressed PaORP1 protein was in the insoluble fraction. The incremental changes to the protocol shifted the ratio towards more soluble protein, although the majority remained in the insoluble fraction (Figure 5.6). 


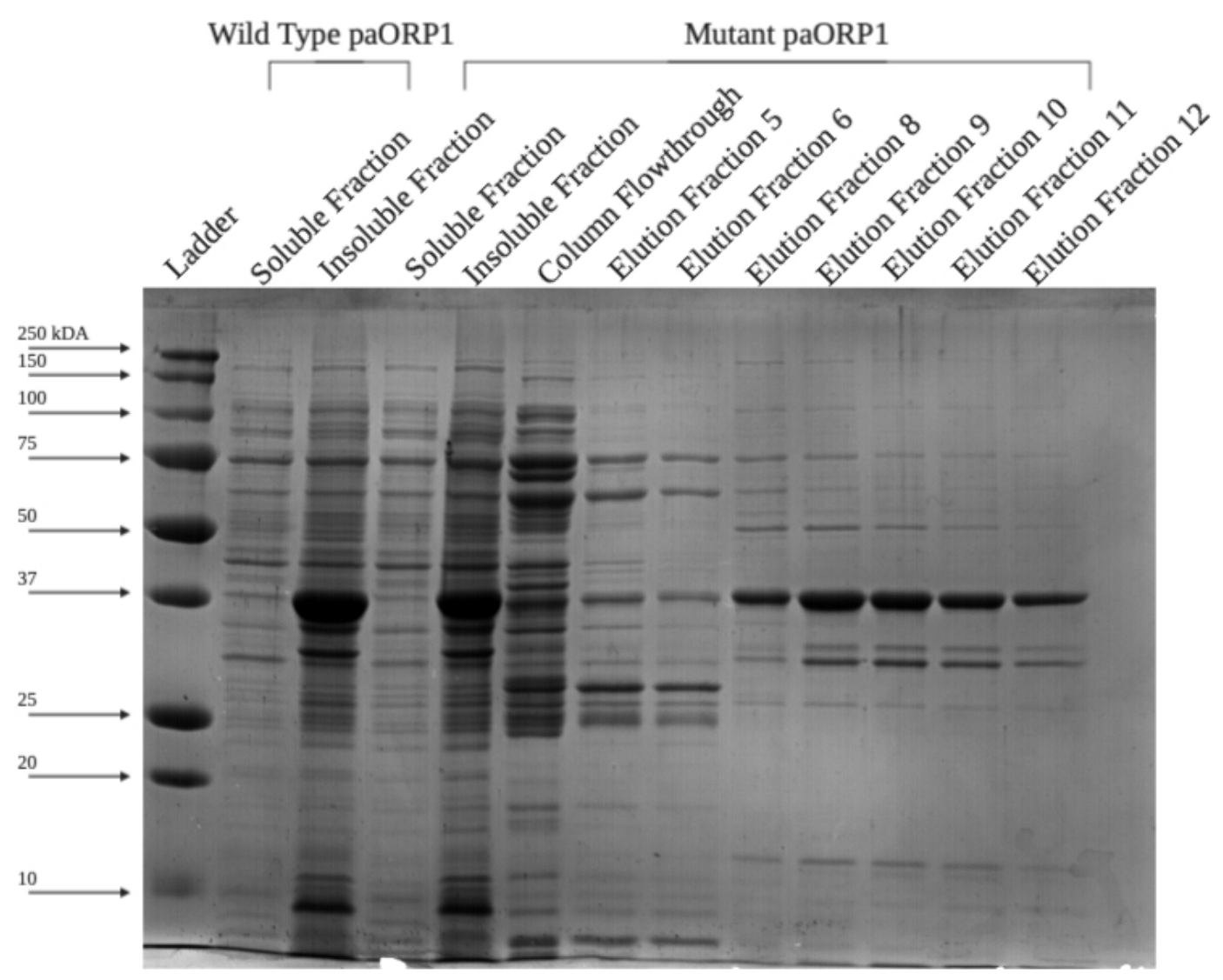

Figure 5.6. Optimized expression and purification of PaORP1 (Wild type and Mutant). This SDS-PAGE gel contains the re-expression of PaOR1 after some optimization with PaORP1 mutant. A high abundance of PaORP1 is present in the insoluble fraction. Purifying the mutant has increased abundance due to the changes listed in this section. Elution fractions 8 and 9 are the elution of protein that non-specific bind to the hi-trap column. While elution fractions 8 to 12 contain the mutant PaORP1.

\subsubsection{Fluorescence Thermal Shift assay}

Initial quantitative tests showed that PaORP1 was prone to aggregate on storage. A preliminary screen suggested that it was most stable in sodium acetate buffer at $\mathrm{pH}$ 5.0 (Methods 2.2.19). A fluorescence thermal shift (FTS) assay was used to validate this result and to determine the unfolding temperature of PaORP1 in a variety of different buffers (Table 5.1). 


\begin{tabular}{|c|c|c|c|c|c|c|c|c|}
\hline & 1 & 2 & 3 & 4 & 5 & 6 & 7 & 8 \\
\hline A & $37.8^{\circ} \mathrm{C}$ & $36.3^{\circ} \mathrm{C}$ & $36.8^{\circ} \mathrm{C}$ & $37.3^{\circ} \mathrm{C}$ & $34.8^{\circ} \mathrm{C}$ & $33.8^{\circ} \mathrm{C}$ & $33.3^{\circ} \mathrm{C}$ & $34.8^{\circ} \mathrm{C}$ \\
\hline B & $35.3^{\circ} \mathrm{C}$ & $33.3^{\circ} \mathrm{C}$ & $34.3^{\circ} \mathrm{C}$ & $36.3^{\circ} \mathrm{C}$ & $33.8^{\circ} \mathrm{C}$ & $32.8^{\circ} \mathrm{C}$ & $32.8^{\circ} \mathrm{C}$ & $29.8^{\circ} \mathrm{C}$ \\
\hline C & $34.3^{\circ} \mathrm{C}$ & $33.3^{\circ} \mathrm{C}$ & $29.3^{\circ} \mathrm{C}$ & $23.4^{\circ} \mathrm{C}$ & $32.3^{\circ} \mathrm{C}$ & $34.3^{\circ} \mathrm{C}$ & $30.3^{\circ} \mathrm{C}$ & $34.8^{\circ} \mathrm{C}$ \\
\hline D & $34.3^{\circ} \mathrm{C}$ & $32.3^{\circ} \mathrm{C}$ & $34.3^{\circ} \mathrm{C}$ & $30.8^{\circ} \mathrm{C}$ & $31.8^{\circ} \mathrm{C}$ & $31.8^{\circ} \mathrm{C}$ & $33.8^{\circ} \mathrm{C}$ & $33.3 \mathrm{v}$ \\
\hline E & & $35.8^{\circ} \mathrm{C}$ & $25.9^{\circ} \mathrm{C}$ & & & $32.8^{\circ} \mathrm{C}$ & $25.4^{\circ} \mathrm{C}$ & \\
\hline
\end{tabular}

Table 5.1 FTS assay to measure stability in different buffer solutions.

The results show the maximum temperature the PaORP1 protein is stable at. The higher the temperature, the more stable the PaORP1 protein in solution. Buffers can be found in Methods 2.2.19.

The results in Table 5.1 (above) confirmed that the most stable buffer is still sodium acetate pH 5.0 (well A1 in Table 5.1). A comparable condition was in A4, which was imidazole $\mathrm{pH} 7.0$ and $150 \mathrm{mM}$ sodium chloride. These are already components of the lysis and elution buffers.

\subsubsection{Size Exclusion Chromatography}

To determine the apparent oligomeric states of the two PaORP1 proteins fragments, they were passed down a Superdex 200 Increase 10/300 GL size exclusion column (Methods 2.2.18) . Three standards were also run: conalbumin, albumin and dextran blue, where their molecular weights are $75 \mathrm{kDa}, 40 \mathrm{kDa}, 2000 \mathrm{kDa}$ respectively. Albumin is about the same size as the PaORP1 monomer ( $37 \mathrm{kDa})$, while conalbumin is about the same size as a PaORP1 dimer (74 kDa). Dextran blue was used to determine the void volume of the column. The results are shown in Figure 5.7. 

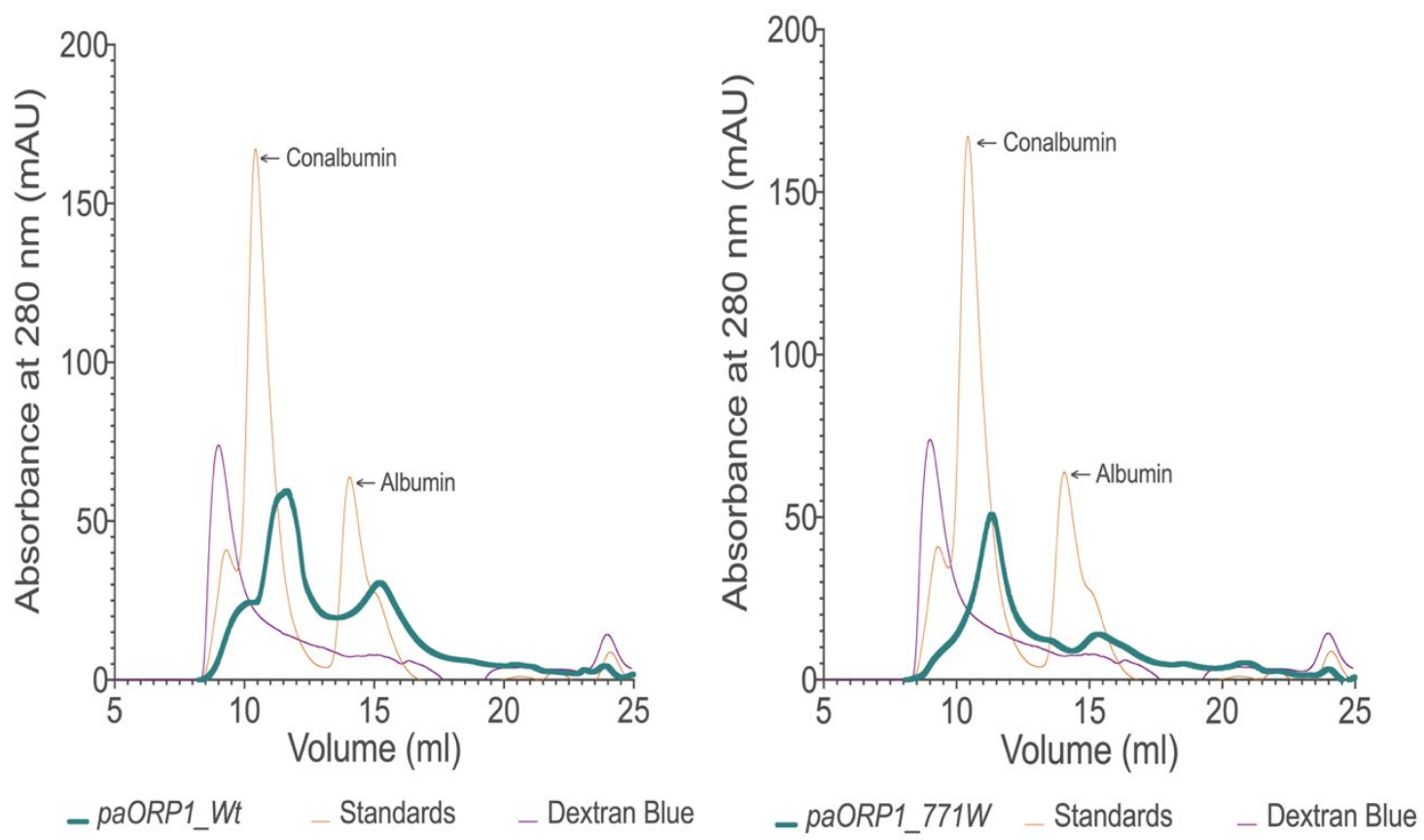

Figure 5.7. Size Exclusion Chromatography of PaORP1 variants: wild type (left) and G771W mutant (right).

The proteins used as standards are conalbumin $(75 \mathrm{kDa})$ and albumin (40 kDa), the two peaks seen in yellow. Along with a Dextran Blue standard, separate pink line.

If the expressed ORD of PaORP1 was a monomer, then it should appear around the $40 \mathrm{kDa}$ albumin standard, as the PaORP1 ORD is $37 \mathrm{kDa}$. If expressed ORD of the PaORP1 protein formed a dimer, then it would appear in a similar position to conalbumin around $75 \mathrm{kDa}$. Higher molecular weight forms would elute at lower volumes (nearer the dextran blue peak). The PaORP1_wt (wild type) appeared to elute as a mixture of dimer and monomer (elution volumes of $\sim 11.5 \mathrm{~mL}$ and $15.0 \mathrm{~mL}$ respectively in Figure 5.7), while the G771W mutant was mostly dimeric. In both cases, higher-order oligomers (elution volumes less than $11.5 \mathrm{~mL}$ ) were also apparent. 


\subsection{Discussion}

\subsubsection{Protocol Development}

The changes in expression and purification protocols were made over several months (Methods 2.2.17.2).

The initial expression protocol involved growth at $37^{\circ} \mathrm{C}$ for a few hours, then the addition of IPTG and continued incubation at $18{ }^{\circ} \mathrm{C}$ for 16 to $18 \mathrm{hrs}$ (overnight). The change to autoinduction medium allowed for a gentle transition into PaORP1 transcription. However, it greatly affected the bacterial pellet weight. Before this change, the bacterial pellet could weight more than $30 \mathrm{~g}$. It was difficult to resuspend, so it was usually divided into multiple aliquots to be purified separately. The change to auto-induction medium reduced the pellet size considerably and enabled easier resuspension. In turn, this also led to a decrease in the viscosity of the solution that underwent lysis using the French-press.

Ultimately, an isocratic method was used to purify PaORP1 (Methods 2.2.17.2). The best yields were obtained when the nickel affinity column was washed at a constant imidazole concentration of $150 \mathrm{mM}$, before stepping up to elute at $240 \mathrm{mM}$. After all of these changes and the development of the protocol, the expected yield of PaORP1 from a 5-10 g bacterial pellet after purification, dialysis, and concentrating would be $7.5 \mathrm{mg}$ to $10 \mathrm{mg}$.

\subsubsection{PaORP1 Purity, Stability and Oligomeric State.}

This was the first study to attempt biophysical characterisation of any $P$. agathidicida protein. The optimised protocol yielded PaORP1 protein that was at least $90 \%$ pure (Figure 5.5) and was sufficiently concentrated to assess stability and oligomeric state. The FTS assays showed that PaORP1 is not particularly thermostable in vitro, with unfolding temperatures from $25-38^{\circ} \mathrm{C}$ (depending on the storage buffer). At the same time, it is known that the optimum growth temperature of $P$. agathidicida is $21.5^{\circ} \mathrm{C}$ and the maximum temperature at which it can grow is $25^{\circ} \mathrm{C}^{5}$. Therefore, it is 
perhaps not surprising that proteins from this organism unfold at the temperatures we observed for PaORP1.

OSBPs are capable of dimerization but whether in hetero or homo dimer state remains unknown ${ }^{98}$. A monomer was observed in the crystal structure of the yeast KES1/Osh4 homologue. However, homodimers have been observed with native $\mathrm{OSBP}^{99}$. My size exclusion chromatography results (Figure 5.7) show that PaORP1 is able to dimerise as well, although it may exist in a concentration-dependent monomer-dimer equilibrium.

\subsubsection{Next Steps}

\subsubsection{Affinity of PaORP1 For Oxathiapiprolin}

Oxathiapiprolin is a highly potent anti-oomycete compound, but currently there is no published data on the strength of its interaction with its protein target, ORP1. This will be able to be assessed now that a protocol for obtaining PaORP1 has been optimised. Determining the binding affinity could be done through isothermal titration calorimetry (ITC). A potential limitation of using ITC to assess the binding affinity could be that very low concentrations of oxathiapiprolin are likely to be necessary ${ }^{19 .}$ 48,57 , which may make it difficult to detect the interaction. In contrast, I predict that the mechanism of resistance conferred by the G771W mutation is to weaken the interaction between the agrichemical and its target. Future experiments will now be able to test this hypothesis.

\subsubsection{Structure and Function}

Now that the protocol to obtain stable, usable protein has been established we may be able to obtain crystal structures.

No crystal structure has been recorded yet of any Phytophthora ORP1 protein. However, there are crystal structures of Kes1/Osh4 oxysterol binding domain 63, 64,66 from Saccharomyces cerevisiae. The studies on Kes1/Osh4 showed it is capable of binding both sterols and oxysterols. However, to obtain the empty binding site, the 29 
amino acid $\mathrm{N}$-terminal lid was removed. The lid structure is believed to stabilise binding within the active site and suggests it is a flexible component to the ORD ${ }^{63,64}$

The crystal structure of PaORP1 domain will most likely have a sterol or oxysterol within the active site. Im (2005) ${ }^{66}$ reported they were unable to obtain a crystal structure with an empty binding site with the full ORD domain, including the lid structure. Obtaining the crystal structure for PaORP1 variants produced from the protocol in this study could yield insight into the specific function of PaORP1 in Phytophthora. In particular, obtaining a structure with a bound ligand may give a clue to the physiological role.

Overall, the work described in this chapter represented the first attempt to characterise any $P$. agathidicida protein in vitro. While it demonstrated some of the challenges of working with proteins from this organism, it also set the groundwork for future studies. 


\section{Chapter 6}

\section{Discussion}




\subsection{Research Overview}

The overarching goal of this research was to investigate the sensitivity and resistance of $P$. agathidicida to various anti-oomycete compounds. Progress toward this goal was achieved. In particular, this thesis is the first to report on:

- A comparison of different phosphite agrichemical formulations for efficacy against $P$. agathidicida;

- Formulations that may enhance the efficacy of plant-derived natural products;

- The relative ease (or lack thereof) of $P$. agathidicida evolving resistance to bioactive compounds; and

- The expression and purification of a known drug target from $P$. agathidicida.

\subsection{Phosphite Treatment Viability}

Phosphite is considered as a short-term option for the treatment of kauri dieback. Phosphite formulations are not curative. Both spray and injection treatments require a rigorous surveillance programme and periodic retreatment ${ }^{100}$.

Thus far, the treatment of $P$. agathidicida has been limited to one phosphite formulation. The first phosphite study in $P$. agathidicida was published in $2013^{93}$ and forestry trials began in $2015^{100-103}$. This work used the Agri-Fos 600 phosphite formulation. These field trials used a girth measurement, and injection sites every 20 $\mathrm{cm}$ or $40 \mathrm{~cm}$. The injected kauri presented with leaf yellowing, a sign of phytotoxicity, and then required monitoring for three years post-injection. The levels of phosphite in the roots also were measured after 6 months, concluding that the concentration in the roots was less than $0.4 \mu \mathrm{g} / \mathrm{mL}^{101-103}$.

To date, the only other comparison of two phosphite formulations, Agri-Fos 600 and Foschek, was carried out to assess the effects of different wetting agents and adjuvants alone using cabbage leaf. This was a preliminary study before assessing the uptake and maintenance of phosphite levels in Pinus radiatus for an unspecified 
disease. However Foschek was recommended to proceed to field trials due to stability of the adjuvants and surfactants.

In Chapter 3, I rigorously compared three commercial phosphite preparations with the pure active ingredient. Overall all three of the commercial phosphite preparations inhibit the growth of $P$. agathidicida.

As described in Chapter 3.2, there was no significant difference between Agri-Fos 600 and the other commercial formulations, Foschek and Phosgard. Therefore, these should also be considered for the treatment of kauri dieback disease. One caveat is that my research was performed entirely in vitro. In planta trials are also required to optimise bioavailability and reduce phytotoxic side effects.

\subsection{Natural Products and a Basis for Agrichemical Development}

Building on the results with phosphite, this study was the first to test whether the plant-derived bioactives polygodial and falcarindiol would be more effective against $P$. agathidicida if they were combined with a commercial adjuvant mix. As shown in Chapter 3 (Figure 3.3), there is sufficient evidence warrant follow up experiments to determine the weather these natural products could be developed into agrichemical formulations for the treatment of kauri dieback.

The formulation of an agrichemical can take years of development ${ }^{104}$. The nonbioactive ingredients play an important role in stabilising the chemicals in solution, plant application, and uptake and retention in the plant ${ }^{30}$. Thus, the complexity of different formulations and active ingredients can play an important role in the inhibition of the target organisms. One thing to note is that Phytophthora species and higher plants have a similar chemical makeup of their cell walls $13,15,17$, meaning that there is the potential to formulate an agrichemical so that it is optimised for in planta bioavailability and increased anti-oomycete action at the same time. 
Because of time constraints, only limited concentration ranges and ratios of natural product to adjuvant were explored in Chapter 3.2.2. Nevertheless, these promising results justify further studies to determine the most effective ratios of the different components. These studies would aid the development of the scaling process, if an agrichemical was to be developed.

Interestingly, both polygodial and falcarindiol have been tested as antibiotics and anti-cancer agents in humans. In both cases, the natural products are synergistic with other treatments ${ }^{74,75,105-108}$. Another avenue of future work will be to explore whether these compounds synergise with other known anti-oomycete compounds, which in turn would be beneficial for agrichemical development.

\subsection{International Standards for Risk of Resistance}

International awareness around antimicrobial resistance has increased exponentially over the last two decades. This is not just related to multidrug resistance human pathogens and hospital-acquired infections. Pesticides, fungicides, and other agrichemicals have also been assessed for their mode of action and risk assessments are now often undertaken for the likelihood of resistance development.

Four of the most recently developed anti-oomycete and conventional fungicides have undergone resistance assessments. Larger countries, such as China and Korea, are now requiring risk assessments before an agrichemical can be commercially available. The new treatments for Phytophthora include oxathiapiprolin, zoxamide, mandipropamid, and pyrimorph. All these treatments have a known mode of action and a known path to resistance, in part, due to these new requirements.

Zoxamide is a $\beta$-tubulin inhibitor that inhibits true fungi and oomycetes. It is a competitive inhibitor of $\beta$-tubulin; it competes with colchicine binding at cystine 239 of the $\beta$-tubulin protein. Zoxamide resistance is associated with a C239S mutation ${ }^{47}$. Mandipropamid targets oomycetes by inhibiting cell wall synthesis. Mutations in the cellulose synthase-like A3 (CesA3) protein are associated with mandipropamid 
resistance. A significant concern with mandipropamid resistance is cross-resistance to other carboxylic acid amides (CAA) fungicides. Pyrimorph is also known to target the CesA3 protein ${ }^{51,52,84}$.

Oxathiapiprolin specifically inhibits Phytophthora by targeting the ORP1 proteins, and there are numerous mutations in the ORD associated with oxathiapiprolin resistance. This study looked at the first reported resistance-associated change in ORP1; a glycine to tryptophan point mutation first described in $P$. capsici ${ }^{56-59}$. P. agathidicida isolates do not have the mutation associated with resistance, and there is no genetic diversity within the P. agathidicida isolates ORP1 ORD (Chapter 5.1.2 and 5.1.3).

Typically, new treatments focus on the well-studied $P$. infestans, $P$. sojae or $P$. capsici. However, the mode of action of these agents is applicable to $P$. agathidicida. This type of pre-screening for resistant isolates led to an insight into the PaORP1 gene and sensitivity of all $P$. agathidicida isolates. The known mechanisms allow us to take a genetic approach to pre-screen a treatment and allows for an added level of knowledge for an informed decision for the treatment of kauri dieback.

\subsection{Attempted Evolution of Resistance}

This research was the first to attempt the directed evolution of $P$. agathidicida towards greater antimicrobial resistance. The methodology was based on one described elsewhere ${ }^{56}$ and attempted to force evolution by serial passaging on amended media (Chapter 4.1).

The development of phosphite tolerance in many Phytophthora species, such as $P$. infestans, P. sojae, P. capsici, is due to the extended exposure to phosphite agrichemical treatments. Phosphite has also been used to treat $P$. agathidicida in the

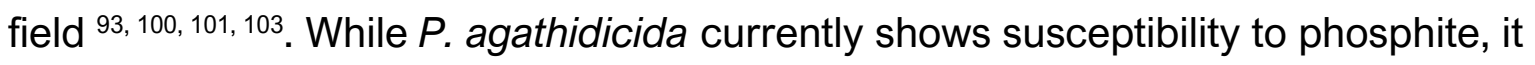
may also develop tolerance over time. 
The natural products used in this research are a new addition to the antiPhytophthora arsenal of tools. Both have unique modes of action and have been studied for treating a multitude of microbes, cancer, and other human diseases. Polygodial affects the electrochemical gradient across membranes and falcarindiol causes cell cycle arrest ${ }^{72,82}$. On the other hand, phosphite is thought to have a broad range of anti-oomycete effects, based on its incorporation into cellular processes instead of phosphate, affecting an extensive range of metabolic and structural components in Phytophthora.

Despite serial passaging for several months, I was unable to increase the resistance of $P$. agathidicida towards polygodial, falcarindiol or phosphite. I did, however, see morphological changes in the mycelia growing in the presence of the anti-oomycete compounds (e.g. Figure 4.2 and Figure 4.4). One reason could be the complex modes of action for all three chemicals. It is likely that resistance to each compound will require more than one, and perhaps many, mutational events. This is in contrast to oxathiapiprolin, where single mutations in PaORP1 (such as G771W) confer resistance.

If multiple mutations are required to give resistance to polygodial, falcarindiol or phosphite then this bodes well for using these compounds in the field. Further directed evolution with elevated mutation rates (e.g. through the addition of chemical mutagens) will be required to explore the resistance to these compounds further.

\subsection{Expression and Purification of P. Agathidicida Proteins}

Chapter 5 described the successful expression and purification of the recombinant ORD domain of PaORP1. Previous studies on oxysterol binding proteins have focused on the yeast and human proteins ${ }^{60-66,98,99,109-120}$. Human OSBP genes have been expressed successfully in $E$. coli ${ }^{66,98}$ while the yeast proteins have been functionally characterised using gene knockout and RNA knockdown experiments ${ }^{61}$, $63,65,66$. 
There are no previous reports in the literature of recombinantly expressing P. agathidicida proteins. Armstrong (2018) ${ }^{19}$ attempted to express the intracellular domain of a G-protein coupled receptor in $E$. coli but was unable to gain any soluble protein ${ }^{19}$. The results described in this thesis suggest that $E$. coli may not be the ideal host for expressing $P$. agathidicida proteins, but that this can be achieved with careful optimisation.

With an optimised purification protocol in place for PaORP1, it will now be possible to study its interaction with oxathiapiprolin. Further into the future, proteins with other resistance-associated mutations (Discussion 6.4 above) could also be expressed and purified to determine the biochemical basis of resistance and sensitivity.

\subsection{Conclusion}

The research presented in this thesis addresses some concerns for the community fighting hard to save kauri from $P$. agathidicida; such as limited treatment options and the potential for resistance to develop. Various aspects of four potential treatments (phosphite, polygodial, falcarindiol and oxathiapiprolin) have been studied. Perhaps most promisingly, I have shown the potential to formulate potent agrichemicals by adding adjuvants to the natural products polygodial and falcarindiol. While there is an urgent need for considerably more research, the results presented in this thesis suggest that new treatment options for kauri dieback are achievable. 
References 
1. King, M. Ngā iwi o te motu: 1000 years of Māori history, Edn. Rev. ed. (Reed Books, Auckland, N.Z; 2001).

2. Cassie, V.D. New Zealand Conifers. Journal of the Arnold Arboretum 35, 268-273 (1954).

3. Ecroyd, C.E. Biological flora of New Zealand 8. Agathis australis (D. Don) Lindl. (Araucariaceae) Kauri. New Zealand Journal of Botany 20, 17-36 (1982).

4. Wyse, S.V., Burns, B.R. \& Wright, S.D. Distinctive vegetation communities are associated with the long-lived conifer Agathis australis (New Zealand kauri, Araucariaceae) in New Zealand rainforests. Austral Ecology 39, 388-400 (2014).

5. Weir, B.S. et al. A taxonomic revision of Phytophthora clade 5 including two new species, Phytophthora agathidicida and P. cocois. Phytotaxa 205, 21-38 (2015).

6. Beever, R.E., Waipara, N.W., Ramsfield, T.D., Dick, M.A. \& Horner, I.J. Kauri (Agathis australis) under threat from Phytophthora. Phytophthoras in forests and natural ecosystems 74, 74-85 (2009).

7. Hill, L., Waipara, N., Stanley, R. \& Hammon, C. Kauri Dieback Report 2017: An investigation into the distribution of kauri dieback, and implications for its future management, within the Waitakere Ranges Regional Park. Kauri Dieback Report 2, 1-40 (2017).

8. Marshell, D. in Enviroment, Climate Change and Natural Heritage Committee (New Zealand Goverment; 2014).

9. Kamoun, S. Plant pathogens: Oomycetes (water mold). Protists, 689-695 (2009).

10. Kamoun, S. et al. The top 10 oomycete pathogens in molecular plant pathology. Mol Plant Patho/16, 413-434 (2015).

11. Kamoun, S. Molecular genetics of pathogenic oomycetes. Eukaryotic Ce//2, 191-199 (2003).

12. Judelson, H.S. \& Blanco, F.A. The spores of phytophthora: Weapons of the plant destroyer. Nat Rev Microbio/3, 47-58 (2005).

13. Tokunaga, J. \& Bartnicki-Garcia, S. Structure and differentiation of the cell wall of Phytophthora palmivora: cysts, hyphae and sporangia. Archiv Fur Mikrobiologie 79, 293310 (1971).

14. Gaulin, E. et al. Cellulose binding domains of a phytophthora cell wall protein are novel pathogen-associated molecular patterns. Plant Cel/ 18, 1766-1777 (2006).

15. Lippman, E., Erwin, D.C. \& Bartnicki-Garcia, S. Isolation and chemical composition of oospore-oogonium walls of Phytophthora megasperma var. sojae. Journal of General Microbiology 80, 131-141 (1974). 
16. Lawrence, S.A., Armstrong, C.B., Patrick, W.M. \& Gerth, M.L. High-throughput chemical screening identifies compounds that inhibit different stages of the Phytophthora agathidicida and Phytophthora cinnamomi life cycles. Frontiers in Microbiology 8 (2017).

17. Bartnicki-Garcia, S. Chemistry of hyphal walls of Phytophthora palmivora: sporangia and oopsore. Microbiology 42, 57-69 (1966).

18. Hardham, A.R. The cell biology behind phytophthora pathogenicity. Australasian Plant Pathology 30, 91-98 (2001).

19. Armstrong, C. in Faculty of Science, Vol. Masters of Science 122 (University of Otago, 2018).

20. Hardham, A.R. Cell biology of plant-oomycete interactions. Cell Microbio/9, 31-39 (2007).

21. Tsao, P.H. in Phytophthora diseases of citrus and other crops in the Mediterranean area, Vol. 20 11-17 (EPPO Bulletin, 1990).

22. Hermansen, A., Hannukkala, A., Nærstad, R.H. \& Brurberg, M.B. Variation in populations of Phytophthora infestans in Finland and Norway: mating type, metalaxyl resistance and virulence phenotype. Plant Pathology 49, 11-22 (2000).

23. Pasteris, R.J. et al. Discovery of oxathiapiprolin, a new oomycete fungicide that targets an oxysterol binding protein. Bioorgan Med Chem 24, 354-361 (2016).

24. Royal, T.A.C. Politics and knowledge: Kaupapa Maori and matauranga Maori. New Zealand Journal of Educational Studies 47, 30 (2012).

25. Hikuroa, D. Mātauranga Māori-the ūkaipō of knowledge in New Zealand. J Roy Soc New Zeal 47, 5-10 (2017).

26. Morton, V. \& Staub, T. A short history of fungicides. American Phytopathological Society 10, 2008-0308 (2008).

27. Achary, V.M.M. et al. Phosphite: a novel P fertilizer for weed management and pathogen control. Plant Biotechnology Journa/15, 1493-1508 (2017).

28. Dobrowolski, M.P., Shearer, B.L., Colquhoun, I.J., O'Brien, P.A. \& Hardy, G.E.S. Selection for decreased sensitivity to phosphite in Phytophthora cinnamomi with prolonged use of fungicide. Plant Pathology 57, 928-936 (2008).

29. Eshraghi, L. et al. Defence signalling pathways involved in plant resistance and phosphite-mediated control of Phytophthora cinnamomi. Plant Molecular Biology Reporter 32, 342-356 (2013).

30. Hardy, G., Barrett, S. \& Shearer, B.L. The future of phosphite as a fungicide to control the soilborne plant pathogen Phytophthora cinnamomi in natural ecosystems. Australas Plant Path 30, 133-139 (2001).

31. Gómez-Merino, F.C. \& Trejo-Téllez, L.I. Biostimulant activity of phosphite in horticulture. Sci Hortic-Amsterdam 196, 82-90 (2015). 
32. King, M. et al. Defining the phosphite-regulated transcriptome of the plant pathogen Phytophthora cinnamomi. Mol Genet Genomics 284, 425-435 (2010).

33. Smillie, R., Grant, B.R. \& Guest, D. The mode of action of phosphite - Evidence for both direct and indirect modes of action on 3 Phytophthora Spp in plants. Phytopathology 79, 921-926 (1989).

34. Adaskaveg, J.E., Förster, H., Hao, W. \& Gray, M. in Modern Fungicides and Antifungal Compounds, Vol. 8 205-210 (University of California, Department of Plant Pathology and Microbiology; 2017).

35. Nimchuk, Z., Eulgem, T., Holt, B.E. \& Dangl, J.L. Recognition and response in the plant immune system. Annu Rev Genet 37, 579-609 (2003).

36. Dangl, J. Molecular specificity in the plant immune system. Mo/ Bio/ Ce//15, 2a-2a (2004).

37. Baulcombe, D.C. VIGS, HIGS and FIGS: small RNA silencing in the interactions of viruses or filamentous organisms with their plant hosts. Current Opinion in Plant Biology 26, 141146 (2015).

38. Hou, Y. et al. A Phytophthora effector suppresses trans-kingdom RNAi to promote disease susceptibility. Cell Host Microbe 25, 153-165 e155 (2019).

39. Dunstan, R.H., Smillie, R.H. \& Grant, B.R. The effects of sub-toxic levels of phosphonates on the metabolism and potentail virulence factors of Phytophthora palmivora.

Physiological and Molecular Plant Pathology 3, 205-220 (1990).

40. Barchietto, T., Saindrenan, P. \& Bompeix, G. Characterization of phosphonate uptake in two Phytophthora spp. and its inhibition by phosphate. Archives of Microbiology 151, 5458 (1988).

41. Darakis, G.A., Bourbos, V.A. \& Skoudridakis, M.T. Phosphonate transport in Phytophthora capsici. Plant Pathology 46, 762-772 (1997).

42. Griffith, J., Coffey, I. \& R., G.B. Phosphonate inhibition as a function of phosphate concentration in isolates of Phytophthora palmivova. J Gen Microbiol, 2109-2116 (1993).

43. Niere, J.O., Deangelis, G. \& Grant, B.R. The effect of phosphonate on the acid-soluble phosphorus components in the genus Phytophthora. Microbiol-Uk140, 1661-1670 (1994).

44. Fenn, M. \& Coffey, M. Studies on the in vitro and in vivo antifungal activity of fosetyl-Al and phosphorous acid. Phytopathology 74, 606-611 (1984).

45. Martin, H., Grant, B.R. \& Stehmann, C. Inhibition of inorganic pyrophosphatase by phosphonate-A site of action in Phytophthora spp.? Pesticide Biochemistry and Physiology 61, 65-77 (1998).

46. Pastor, J.N., Buron-Moles, G., Rojo, F., Martin-Closas, L. \& Almacellas, J. In vitro and In vivo antifungal activity of phosphite against Phytophthora parasitica in tomato. Acta horticulturae, 167-172 (2011). 
47. Cai, M. et al. C239S Mutation in the beta-Tubulin of Phytophthora sojae confers resistance to zoxamide. Frontiers in Microbiology 7 (2016).

48. Cohen, Y., Rubin, A.E. \& Galperin, M. Oxathiapiprolin-based fungicides provide enhanced control of tomato late blight induced by mefenoxam-insensitive Phytophthora infestans. Plos One 13 (2018).

49. Diriwächter, G., Sozzi, D., Ney, C. \& Staub, T. Cross-resistance in Phytophthora infestans and Plasmopara viticola against different phenylamides and unrelated fungicides. Crop Protection 6, 250-255 (1987).

50. Han, X. et al. Sensitivity of Phytophthora capsici to mandipropamid and its cross resistance with other fungicides. Phytopathology 38, 173-177 (2011).

51. Liu, X., Cai, M., Miao, J. \& Zhang, C. Molecular mechanism of resistance to CAA and OSBP fungicides in Phytophthora capsiciand P. sojae. Phytopathology 108 (2018).

52. Pang, Z. et al. Resistance to the novel fungicide pyrimorph in Phytophthora capsici: risk assessment and detection of point mutations in CesA3 that confer resistance. PLOS One 8, 1 -12, (2013).

53. Ziogas, B.N., Markoglou, A.N., Theodosiou, D.I., Anagnostou, A. \& Boutopoulou, S. A high multi-drug resistance to chemically unrelated oomycete fungicides in Phytophthora infestans. Eur J Plant Patho/115, 283-292 (2006).

54. Hunter, S. in Faculty of Science, Vol. Masters of Science 152 (Univeristy of Waikato, 2018).

55. Hunter, S., Williams, N., McDougal, R., Scott, P. \& Garbelotto, M. Evidence for rapid adaptive evolution of tolerance to chemical treatments in Phytophthora species and its practical implications. PLOS One 13 (2018).

56. Miao, J. et al. Resistance assessment for oxathiapiprolin in Phytophthora capsici and the detection of a point mutation (G769W) in PcORP1 that confers resistance. Frontiers in Microbiology 7, 615 (2016).

57. Miao, J. et al. Activity of the novel fungicide oxathiapiprolin against plant-pathogenic oomycetes. Pest Management Science 72, 1572-1577 (2016).

58. Miao, J., Chi, Y., Lin, D., Tyler, B.M. \& Liu, X. Mutations in ORP1 conferring oxathiapiprolin resistance confirmed by genome editing using CRISPR/Cas9 in Phytophthora capsici and P. sojae. Phytopathology 108, 1412-1419 (2018).

59. Miao, J., Lin, D., Peng, Q., Wang, Z. \& Liu, X. N837 deletion in oxysterol binding proteinrelated protein confers oxathiapiprolin resistance in Phytophthora capsiciand $P$. sojae. Phytopathology 108, 24-24 (2018).

60. Alphey, L., Jimenez, J. \& Glover, D. A Drosophila homologue of oxysterol binding protein (OSBP) - Implications for the role of OSBP. Bba-Gene Struct Expr 1395, 159-164 (1998). 
61. Beh, C.T., Cool, L., Phillips, J. \& Rine, J. Overlapping functions of the yeast oxysterolbinding protein homologues. Genetics 157, 1117-1140 (2001).

62. Lehto, M. \& Olkkonen, V. The OSBP-related proteins: a novel protein family involved in vesicle transport, cellular lipid metabolism, and cell signalling. Bba-Mo/ Cell Biol L 1631 , 1-11 (2003).

63. Fairn, G.D. \& McMaster, C.R. Emerging roles of the oxysterol-binding protein family in metabolism, transport, and signaling. Cell Mol Life Sci65, 228-236 (2008).

64. Raychaudhuri, S. \& Prinz, W.A. The diverse functions of oxysterol-binding proteins. Annu Rev Cell Dev Bi 26, 157-177 (2010).

65. Levine, T.P. \& Munro, S. Dual targeting of Osh1p, a yeast homologue of oxysterol-binding protein, to both the golgi and the nucleus-vacuole junction. Mol Bio/ Cel/12, 1633-1644 (2001).

66. Im, Y.J., Raychaudhuri, S., Prinz, W.A. \& Hurley, J.H. Structural mechanism for sterol sensing and transport by OSBP-related proteins. Nature 437, 154-158 (2005).

67. Taniguchi, M. et al. Mode of action of polygodial, an antifungal sesquiterpene dialdehyde. Agr Biol Chem Tokyo 52, 1409-1414 (1988).

68. Brennan, N.J. et al. Fungicidal sesquiterpene dialdehyde cinnamates from Pseudowintera axillaris. J Agr Food Chem 54, 468-473 (2006).

69. Best, E. Maori medical Lore. Notes on sickness and disease amoung the Maori people of New Zealand and their treatment of the sick; Together with some accounts of various beliefs, superstitions and rites pretaining to sickness and the treatment thereof as collected from the Tuhoe tribe. Part 1.- (Continued). The Journal of the Polynesian Society 14, 1-23 (1905).

70. Calder, V.L., Cole, A.L.J. \& Walker, J.R.L. Antibiotic compounds from New-Zealand plants 3. A survey of some New-Zealand plants for antibiotic substances. J Roy Soc New Zeal 16, 169-181 (1986).

71. Bell, T.W. Medical notes on New Zealand. New Zealand Medical Journa/3, 129-145 (1890).

72. Lunde, C.S. \& Kubo, I. Effect of polygodial on the mitochondrial ATPase of Saccharomyces cerevisiae. Antimicrob Agents Ch 44, 1943-1953 (2000).

73. Castelli, M.V., Lodeyro, A.F., Malheiros, A., Zacchino, S.A. \& Roveri, O.A. Inhibition of the mitochondrial ATP synthesis by polygodial, a naturally occurring dialdehyde unsaturated sesquiterpene. Biochemical pharmacology 70, 82-89 (2005).

74. Kubo, I. \& Himejima, M. Anethole, a synergist of polygodial against filamentous microorganisms. J Agr Food Chem 39, 2290-2292 (1991). 
75. Kubo, I., Lee, S.H. \& Ha, T.J. Effect of EDTA alone and in combination with polygodial on the growth of Saccharomyces cerevisiae. J Agr Food Chem 53, 1818-1822 (2005).

76. Scher, J.M., Speakman, J., Zapp, J. \& Becker, H. Bioactivity guided isolation of antifungal compounds from the liverwort Bazzania trilobata (L.) S.F. Gray. Phytochemistry 65, 25832588 (2004).

77. Mongalo, N.I., Dikhoba, P.M., Soyingbe, S.O. \& Makhafola, T.J. Antifungal, anti-oxidant activity and cytotoxicity of South African medicinal plants against mycotoxigenic fungi. Heliyon 4 (2018).

78. Rawson, A. et al. Stability of falcarinol type polyacetylenes during processing of Apiaceae vegetables. Trends in food science \& technology 30, 133-141 (2013).

79. Nam, N. et al. Furanocoumarins and Falcarindiol from Angelica Dahurica. Journal of Sciecne and Technology 87 (2012).

80. Prior, R.M. et al. The polyacetylene falcarindiol with COX-1 activity isolated from Aegopodium podagraria L. J Ethnopharmaco/113, 176-178 (2007).

81. Wang, C. et al. Identification of potential anticancer compounds from Oplopanax horridus. Phytomedicine 20, 999-1006 (2013).

82. Miyazawa, M., Shimamura, H., Bhuva, R.C., Nakamura, S. \& Kameoka, H. Antimutagenic activity of falcarindiol from Peucedanum praeruptorum. J Agr Food Chem 44, 3444-3448 (1996).

83. Christensen, L.P. \& Brandt, K. Bioactive polyacetylenes in food plants of the apiaceae family: occurrence, bioactivity and analysis. J Pharmaceut Biomed 41, 683-693 (2006).

84. Blum, M. et al. Mandipropamid targets the cellulose synthase-like PiCesA3 to inhibit cell wall biosynthesis in the oomycete plant pathogen, Phytophthora infestans. Molecular Plant Pathology 11, 227-243 (2010).

85. Gisi, U. \& Sierotzki, H. Fungicide modes of action and resistance in downy mildews. Eur J Plant Patho/122, 157-167 (2008).

86. Studholme, D.J. et al. Genome sequences of six Phytophthora species associated with forests in New Zealand. Genomics Data 7, 54-56 (2016).

87. Erwin, D.C.R., O. K; Phytophthora diseases worldwide. (American Phytopathological Society (APS press), Minnesota, USA; 1996).

88. Jeffers, S.N. \& Martin, S.B. Comparison of two media selective for Phytophthora and Pythium species. Plant Dis 10, 1038-1043 (1986).

89. Rueden, C.T.J., S.; Hiner M. C.; DeZonia B. E,; Walter, A. E;; Arena, E. T; Eliceiri, K. W.; ImageJ2: ImageJ for the next generation of scientific image data. BMC BioinformaticsBMC series 18 (2017). 
90. Andreassi, J., Gutteridge, S., Pember, S., Sweigard, J. \& Rehberg, E. in World Interllectual Property Organisation. (ed. D. Pont) 1- 54 (US; 2013).

91. Waterhouse, A. et al. SWISS-MODEL: homology modelling of protein structures and complexes. Nucleic Acids Res 46, W296-W303 (2018).

92. Lo, M. et al. Evaluation of fluorescence-based thermal shift assays for hit identification in drug discovery. Anal Biochem 332, 153-159 (2004).

93. Horner, I.J. \& Hough, E.G. Phosphorous acid for controlling Phytophthorataxon Agathis in kauri: glasshouse trials. Plant Pathology, 242-248 (2013).

94. Mulqueen, P. Recent advances in agrochemical formulation. Advances in Colloid and Interface Science 106, 83-107 (2003).

95. Hunter, S., McDougal, R., Clearwater, M.J., Williams, N. \& Scott, P. Development of a high throughput optical density assay to determine fungicide sensitivity of oomycetes. J Microbiol Meth 154, 33-39 (2018).

96. Parra, G. \& Ristaino, J.B. Resistance to mefenoxam and metalaxyl among field isolates of Phytophthora capsicicausing Phytophthora blight of bell pepper. Plant Dis 85, 1069-1075 (2001).

97. Geer, L.Y., Domrachev, M., Lipman, D.J. \& Bryant, S.H. CDART: protein homology by domain architecture. Genome Res 12, 1619-1623 (2002).

98. Ngo, M. \& Ridgway, N.D. Oxysterol binding protein-related protein 9 (ORP9) Is a cholesterol transfer protein that regulates golgi structure and function. $\mathrm{Mol} \mathrm{Bio} / \mathrm{Ce} / / \mathbf{2 0}$, 1388-1399 (2009).

99. Ridgway, N.D., Dawson, P.A., Ho, Y.K., Brown, M.S. \& Goldstein, J.L. Translocation of oxysterol binding protein to Golgi apparatus triggered by ligand binding. J Cel/ Bio/116, 307-319 (1992).

100. Horner, I.J., Hough, E.G. \& B., H.M. Forest efficacy trials on phosphite for control of kauri dieback. New Zealand Plant Protection 7-12 (2015).

101. Horner, I.J., Hough, E.G. \& Horner, M. in Trunk sprays and lower phosphite injection rates for kauri dieback control. (ed. I.J. Horner) 8 (Plant and Food Research, 2017).

102. Horner, I.J. in Trunk sprays and lower phosphite injection rates for kauri dieback control. (ed. I.J. Horner) 4 (Plant and Food Research, 2017).

103. Horner, I.J. in Trunk sprays and lower phosphite injection rates for kauri dieback control. (ed. I.J. Horner) 4 (Plant and Food Research, 2018).

104. O'Riordan, T. UN Sustainable development goals: How can sustainable/green chemistry contribute? The view from the agrochemical industry. Current Opinion in Green and Sustainable Chemistry 13, 158-163 (2018). 
105. Jin, H.R. et al. The antitumor natural compound falcarindiol promotes cancer cell death by inducing endoplasmic reticulum stress. Cell Death Dis 3 (2012).

106. Notabi, M.K., Olle, E., Walke, P., Andersen, M.O. \& Arnspang, E.C. Lipid nanoparticles as drug delivery systems for cancer therapy: Uptake and response of falcarindiol and synthesis and effect of antibody conjugated nanoparticles. Mol Biol Ce//28 (2017).

107. Wang, J., Shao, L., Rao, T., Zhang, W. \& Huang, W.H. Chemo-preventive potential of falcarindiol-enriched fraction from Oplopanax elatus on colorectal cancer Interfered by human gut microbiota. Am J Chinese Med 47, 1381-1404 (2019).

108. Taniguchi, M. et al. Polygodial-induced sensitivity to rifampicin and actinomycin-D of Saccharomyces cerevisiae. Agr Biol Chem Tokyo 52, 1881-1883 (1988).

109. Broccoli, V. \& Caiazzo, M. NUCLEAR RECEPTORS: Oxysterols detour to neurodevelopment. Nat Chem Bio/9, 70-71 (2013).

110. Kanaki, M., Tiniakou, I., Thymiakou, E. \& Kardassis, D. Physical and functional interactions between nuclear receptor LXR alpha and the forkhead box transcription factor FOXA2 regulate the response of the human lipoprotein lipase gene to oxysterols in hepatic cells. Bba-Gene Regul Mech 1860, 848-860 (2017).

111. Lala, D.S. et al. Activation of the orphan nuclear receptor steroidogenic factor 1 by oxysterols. P Natl Acad Sci USA 94, 4895-4900 (1997).

112. Lee, M. \& Fairn, G.D. Both the PH domain and N-terminal region of oxysterol-binding protein related protein $8 \mathrm{~S}$ are required for localization to PM-ER contact sites. Biochem Bioph Res Co 496, 1088-1094 (2018).

113. Lessmann, E. et al. Oxysterol-binding protein-related protein (ORP) 9 is a PDK-2 substrate and regulates Akt phosphorylation. Cell Signal19, 384-392 (2007).

114. Ma, L.Q. \& Nelson, E.R. Oxysterols and nuclear receptors. Mol Cel/ Endocrino/ 484, 42-51 (2019).

115. Marceau, G. et al. Placental expression of the nuclear receptors for oxysterols LXR alpha and LXR beta during mouse and human development. Anat Rec Part A 283a, 175-181 (2005).

116. Mouzat, K. et al. Absence of Nuclear Receptors for Oxysterols Liver X Receptor Induces Ovarian Hyperstimulation Syndrome in Mice. Endocrinology 150, 3369-3375 (2009).

117. Volle, D.H. et al. Multiple roles of the nuclear receptors for oxysterols liver $\mathrm{X}$ receptor to maintain male fertility. Mol Endocrino/21, 1014-1027 (2007).

118. Wang, Y.J., Kumar, N., Crumbley, C., Griffin, P.R. \& Burris, T.P. A second class of nuclear receptors for oxysterols: Regulation of ROR alpha and ROR gamma activity by 24Shydroxycholesterol (cerebrosterol). Bba-Mol Cell Biol L 1801, 917-923 (2010). 
119. Xu, L.Y. et al. Nuclear Oxysterols, $25 \mathrm{HC}$ and 25HC3S, Regulate Nuclear Orphan Receptor Activities and Attenuate Intracellular Lipid Levels. Faseb J 23 (2009).

120. Yan, D. \& Olkkonen, V.M. Characteristics of Oxysterol Binding Proteins, in A Survey of Cell Biology 253-285 (2008). 